COO-4711-20

BAW-1553

September 1979 UC-78

\title{
NONDESTRUCTIVE EXAMINATION OF OCONEE 1 . FUEL ASSEMRLIES AFTER THREE CYCLES OF IRRADIATION
}

by

T. D. Pyecha

H. H. Davis

J. T. Mayer

B. A. Guthrie, III

J. G. Larson

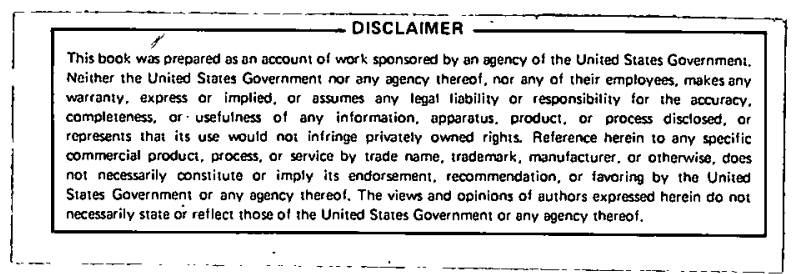

DOE Contract No. ET-78-02-4711

$\mathrm{B} \& \mathrm{~W}$ Contract No. CRD-1018

Prepared for

The U.S. Department of Energy

by

Babcock \& Wilcox

Power Generation Group

DISTRIBUTIOA OF THIS DOCURENT IS URLLIPTTE

Nuclear Power Generation Division

Duke Power Company

P. 0. Box 1260

Lynchburg, Virginia 24505

P. 0. Box 33189

Charlotte, North Carolina 28482 


\section{DISCLAIMER}

This report was prepared as an account of work sponsored by an agency of the United States Government. Neither the United States Government nor any agency Thereof, nor any of their employees, makes any warranty, express or implied, or assumes any legal liability or responsibility for the accuracy, completeness, or usefulness of any information, apparatus, product, or process disclosed, or represents that its use would not infringe privately owned rights. Reference herein to any specific commercial product, process, or service by trade name, trademark, manufacturer, or otherwise does not necessarily constitute or imply its endorsement, recommendation, or favoring by the United States Government or any agency thereof. The views and opinions of authors expressed herein do not necessarily state or reflect those of the United States Government or any agency thereof. 


\section{DISCLAIMER}

Portions of this document may be illegible in electronic image products. Images are produced from the best available original document. 


\section{ACKNOWLEDGMENT}

As with any task of this magnitude, the results reported herein are the product of the efforts of many individuals from the Lynchburg Research Center and the Nuclear Power Generation Division (Fuel Engineering) who contributed in the areas of planning, operations, data reduction, and analyses. While space does not permit acknowledging all of the people involved, their assistance and efforts are greatly appreciated. The efforts of the following individuals who participated directly in the poolside examination are greatfully acknowledged: D. K. Thome, W. H. Machin, W. A. Shield, B. C. Dudley, B. L. Adkins, E. A. Barringer, J. T. Dick, D. E. Kimmel, and R. E. Lide.

The cooperation of Duke Power Company personnel from the Oconee Nuclear Station and from the Charlotte offices is also greatfully acknowledged. 


\author{
Babcock \& Wilcox \\ Power Generation Group \\ Nuclear Power Generation Division \\ Lynchburg, Virginia \\ Report. BAW-1553 \\ September 1979
}

Nondestructive Examination of Oconee 1 Fuel

Assemblies After Three Cycles of Irradiation

T. D. Pyecha, H. H. Davis, J. T. Mayer, B. A. Guthrie, III, J. G. Larson

Key Words: $\mathrm{UO}_{2}$ Fuel, Zircaloy-4, Irradiation Testing, Fuel Performance, Fuel Cladding Performance

\begin{abstract}
Standard B\&W Mark B $(15 \times 15)$ pressurized water reactor fuel assemblies were nondestructively examined after three cycles of irradiation prior to re-insertion in the Oconee 1 reactor for a fourth cycle of operation. Burnups of the five assemblies examined averaged 30,600 $\mathrm{MWd} / \mathrm{mtU}$ and are expected to average approximately $40,000 \mathrm{MWd} / \mathrm{mtU}$ on completion of the fourth (extended) cycle of operation. This effort was part of a Department of Energy sponsored program to improve uranium utilization by extending the burnup of light water reactor fuel.

The examinations were conducted in the Oconee 1 and 2 spent fuel storage pool using the installed underwater post-irradiation examination equipment. Data obtained included fuel assembly and fuel rod dimensions, water channel spacings, holddown spring forces, and fuel column axial gap and stack lengths. The results reported here indicate that the assemblies performed wel.1 through three cycles of operation. All of the data were within design limits and agreed well with values of predicted performance.
\end{abstract}


1. INTRODUCTION . . . . . . . . . . . . . . . . . . 1-1

2. SUMMARY . . . . . . . . . . . . . . . . . . . . 2-1

2.1. Examinations Conducted . . . . . . . . . . . . . . 2-1

2.2. Examination Results . . . . . . . . . . . . . . . 2-1

3. MARK B FUEL ASSEMBLY DESIGN AND OPERATING HISTORY . . . . . . . . . 3-1

3.1. Fuel Assembly Design . . . . . . . . . . . . . . . . 3-1

3.2. Operating History . . . . . . . . . . . . . . . . 3-2

3.2.1. Operating History . . . . . . . . . . . . . 3-2

3.2.2. Assembly Axial Power and Burnup Distributions . . . 3-2

4. POST-IRRADIATION EXAMINATION MEASUREMENT TECHNIQUES (POOLSIDE) . . . 4-1

4.1. Poolside Equipment Arrangement . . . . . . . . . . . . . 4-1

4.2. Visual Inspection Techniques . . . . . . . . . . . . . . . . . . 4-1

4.3. Fuel Assembly and Rod Length Measurements . . . . . . . . . . 4-2

4.4. Fuel Rod Diameter Profilometry Measurements . . . . . . . . 4-2

4.5. Water Channel Spacing Measurements............ . 4-3

4.6. Holddown Spring Test . . . . . . . . . . . . . . . . 4-4

4.7. Gamma Scan System . . . . . . . . . . . . . . . . 4-4

5. RESULTS AND DISCUSSION . . . . . . . . . . . . . . . . 5-1

5.1. Fuel Assembly Leak Tests . . . . . . . . . . . . . 5-1

5.1.1. Results . . . . . . . . . . . . . . 5-1

5.1.2. Discussion ................... . 5-1

5.2. Visual Examinations . . . . . . . . . . . . . . . 5-2

5.2.1. Results .................... 5-2

5.2.2. Discussion ...................... . . . . . . $5-2$

5.3. Fuel Assembly and Rod Length Measurements . . . . . . . . . 5-3

5.3.1. Fuel Assembly Growth Results ............. . 5-4

5.3.2. Fuel Rod Growth Results .............. . 5-4

5.3.3. Discussion .. . . . . . . . . . . . . . 5-4

5.4. Fuel Rod Diameter Profilometry . . . . . . ......... . . 5-5

5.4.1. Cladding Creepdown Results ............ . 5-5

5.4.2. Cladding Ovality Results ............. 5-6

5.4.3. Discussion .. . . . . . . . . . . . . . 5-6

5.5. Water Channel Spacings .. . . . . . . . . . . . . 5-7

5.5.1. Results ................... 5-8

5.5.2. Discussion . . . . . . . . . . . . . 5-8 
Page

5.6. Holddown Spring Force . . . . . . . . . . . . . 5-9

5.6.1. Results.................... 5 5-9

5.6.2. Discussion ..................... . . . . . $5-9$

5.7. Gamma Scans . . . . . . . . . . . . . . . . . 5-9

5.7.1. Results................... . 5-10

5.7.2. Discussion ................ 5-10

6. CONCLUSIONS ......................... 6-1

7. REFERENCES . . . . . . . . . . . . . . . . . . . . . . 7-1

APPENDIX . . . . . . . . . . . . . . . . . . . . . . . . . A-1

\section{List of Tables}

Table

1-1. Summary of Poolside Examinations Conducted at Oconee 1, EOC 4 . . 1-3

3-1. Oconee 1 Nominal Fuel Design Parameters . . . . . . . . . . . 3-4

3-2. Summary of Operating Histories - Oconee 1, Cycles 2, 3, and 4. . 3-4

3-3. Calculated Power Peaking Factors - Oconee 1, Cycle 2.... . 3-5

3-4. Calculated Power Peaking Factors - Oconee 1, Cycle 3 . . . . 3-6

3-5. Calculated Power Peaking Factors - Oconee 1, Cycle 4 . . . . . 3-7

3-6. Assembly Average Burnups - Oconee 1, End-of-Cycles 2, 3,

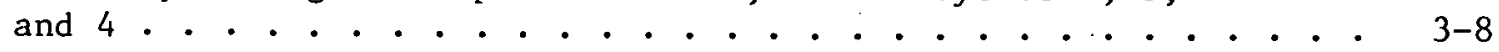

5-1. Summary of Fuel Assembly Growth Results . . . . . . . . . . . 5-11

5-2. Summary of Fuel Rod Growth Results . . . . .. . . . . . . . . . 5-11

5-3. Average Mean Diameter and Creepdown by Grid-Span Location. . . 5-12

5-4. Average Maximum Ovality by Grid-Span Location . . . . . . . . . . 5-13

5-5. Summary of Fuel Assembly Water Channel Spacing Measurements . . . 5-14

5-6. Summary of Holddown Spring Force Measurements. . . . . . . . . 5-15

5-7. Fuel Column Axial Gap Data From Gamma Scans . . . . . . . . . . . 5-16

5-8. Fuel Column Stack Length Data From Gamma Scans . . . . . . . 5-17 
List of Figures

Figure

Page

3-1. Mark B Fuel Assembly

3-2. Fuel Assembly Cross Section Displaying Numbering Conventions

3-3. Power History - Oconee 1 , Cycle 2 . Power History - Oconee 1, Cycle 3

$3-5$. Power History - Oconee 1, Cycle 4 . $\cdot \cdot \cdot \cdot \cdot \cdot \cdot \cdot \cdot \cdot \cdot \cdot$. $3-12$

$3-6$. Extended Burnup Assembly Locations Axial Power Shape - Oconee 1, Cycle 2: Assemblies 1D13,

3-8. Axial Power Shape - Oconee 1 , Cycle 3: Assemblies 1Di3,

3-9. Axial Power Shape - Oconee $\dot{1}$, Cycle $4:$ Assembilies 1 idi3,

3-10. 1D26, 1D45, 1D55

$3-11$

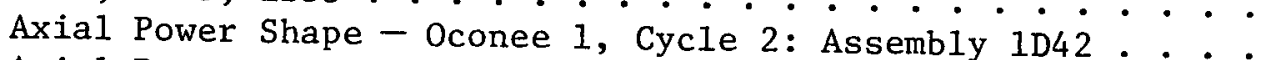

Axial Power Shape - Oconee 1, Cycle 3: Assembly 1D42... . Water Water Channel Spacing Measurement Water Channel Midspan Levels

$4-7$.

4-8.

$5-1$. Holddown Spring Tester in Operation

5-9. Typical Full-Size Diameter Trace Segments (Orthogonal Scans) - Fuel Assembly 1D55

5-10. Axial Distribution of Fuel Rod Average Maximum Ovality $\cdot \cdot$

5-11. Worst-Span Water Channel Closure as Function of Assembly Average Burnup

5-12. Axial Distribution of Water Channel Closure $\cdot \cdot \cdot \cdot \cdot \cdot \cdot \cdot$

$5-13$ Axial Distribution of Water Channel Closure . . . . . . . . .

5-14. Portion of Gamma Scan Trace - Assembly iDi3, CD-Corner Fuel Rod 


\section{INTRODUCTION}

The Babcock \& Wilcox Company $(B \& W)$ in conjunction with Duke Power Company is participating in a Department of Energy sponsored research and development program to qualify current design pressurized water reactor (PWR) fuel assemblies for extended burnup (>40,000 $\mathrm{MWd} / \mathrm{mtU}$ ). The information obtained from this program will provide a basis for future design improvements in PWR fuel assemblies culminating in an extended burnup assembly having a nominal operating limit of approximately 50,000 MWd/mtU. An extension of the current assembly design to higher burnups will result in the following benefits: (1) lower uranium ore requirements, (2) greater fuel cycle efficiency, (3) reduction in spent fuel storage requirements, and (4) increased flexibility in tailoring fuel batch sizes to better accommodate the varying energy requirements of the utilities.

In order to obtain experimental information on the extended performance characteristics of $B \& W$ Mark $B(15 \times 15)$ assemblies, five fuel assemblies were selected to receive a fourth cycle of irradiation in Oconee Nuclear Station Unit 1 , cycle 5. Burnups of the five selected assemblies, four of which were from symmetric core locations, averaged $30,600 \mathrm{MWd} / \mathrm{mtU}$ after three cycles of irradiation and are expected to average approximately 40,000 $\mathrm{MWd} / \mathrm{mtU}$ after four cycles. A nondestructive (poolside) examination was conducted during the Oconee 1, endof-cycle (EOC) 4 refueling outage to characterize these extended burnup assemblies. The data obtained from this examination will serve as baseline data to evaluate the fuel assembly performance during the fourth (extended) cycle of irradiation. A poolside examination of these assemblies will be conducted at the end of their fourth cycle. One of the assemblies will then be selected and returned to $\mathrm{B} \& \mathrm{~W}^{\prime}$ 's hot cell laboratory at the Lynchburg Research Center for detailed destructive examination.

The EOC 4 poolside examination consisted of two basic operations: (1) measurement of individual fuel assembly performance parameters, and (2) fuel assembly leak testing (sipping) to verify fuel rod integrity. The individual performance 
parameters were measured using $B \& W^{\prime} s$ post-irradiation examination (PIE) equipment and included: (1) visual examinations, (2) length measurements, (3) diameter profilometry, (4) water channel spacing measurements, (5) holddown spring force measurements, and (6) gamma scans of corner fuel rods. Visual inspections and length measurements were also conducted on five alternate candidate fuel assemblies that had operated in core locations symmetric to the locations of the five primary candidate assemblies initially designated for extended burnup. Sipping was performed on each of the 57 three-cycle (batch 4) fuel assemblies using a two-can sipping system installed in the Oconee 1 and 2 spent fuel pool facility. The scope of the poolside examination is summarized in Table 1-1. The results, along with the relevant fuel assembly design parameters and operating histories, are summarized and discussed in this report. 
Table 1-1. Summary of Poolside Examinations Conducted at Oconee 1 , EOC 4

Type of examination

Fuel assembly leak test (sipping)

Visual examination

Assembly length and grid location measurements

Fuel rod diameter profilometry

Water channel spacing measurements

Holddown spring force measurements

Gamma scans
Scope of examination

Each of the 57 batch 4 fuel assemblies.

Underwater television scans (videotaped) of all four faces of each of five primary (1D13, 1D21, 1D42, 1D45, and 1D54) and five alternate candidate assemblies (1D06, 1D20, 1D26, 1D43, and 1D55), periscope examination and selected photography of areas of interest.

All four faces of each of the five primary and five alternate candidate assemblies.

Orthogonal continuous line scans on each corner rod and single-orientation continuous line. scans of selected peripheral rods of the five selected extended burnup assemblies (1D13, 1D26, 1D42, 1D45, and 1D55).

All channels at seven midplane levels from two orthogonal directions on four extended burnup assemblies and at one midplane level (12) on the fifth assembly (1D26).

Each of the five selected extended burnup assemblies.

All four corner rods of each of the five selected extended burnup assemblies. 


\section{SUMMARY}

This report describes and summarizes the resuits of the Oconee 1 EOC 4 nondestructive (poolside) post-irradiation examination of five fuel assemblies (designated as batch 4D) which were selected for extended burnup. The poolside examination was conducted for the purpose of final selection and characterization of the five fuel assemblies prior to their re-insertion into the Oconee 1 core (cycle 5) for a fourth (extended) cycle of irradiation. The batch $4 \mathrm{D}$ assembly burnup averaged $30,600 \mathrm{MWd} / \mathrm{mt}$ after three cycles of irradiation. These assemblies are expected to achieve an average burnup of approximately 40,000 MWd/mtU on completion of their fourth cycle of irradiation.

\subsection{Examinations Conducted}

Final selection of the batch $4 \mathrm{D}$ assemblies was made after sipping tests and visual examinations were completed. The five selected assemblies were then characterized with respect to the following:

1. Fuel assembly and fuel rod growth (fuel assembly length measurements).

2. Cladding creepdown and ovality (fuel rod diameter profilometry).

3. Fuel rod bow (water channel spacing measurements).

4. Holddown spring force (holddown spring load-deflection measurements).

5. Fuel column axial gap and stack lengths (gamma scans).

\subsection{Examination Results}

The results of the poolside examinations indicate that the assemblies performed well through three cycles of irradiation. Of the 57 batch 4 assemblies sipped, four were classified as leakers on the basis of the ${ }^{137} \mathrm{Cs}$ activity in their water samples. Visual examination of 560 peripheral fuel rods revealed no serious defects, although a surface indentation was observed on one fuel rod of an assembly that had passed the sipping test. Fuel assembly and fuel rod growth averaged 0.36 and $0.51 \%$, respectively. Fuel rod creepdown averaged 0.0038 in.; the maximum creepdown observed between spacer grids was 0.0045 in. The mean value of the statistically determined average maximum ovality was 0.0023 in.; the peak ovality observed was approximately 0.005 in. Minor 
indications of fuel pellet-cladding contact were noted at fuel pellet interfaces in several corner rods of three of the five batch 4D assemblies. Fuel rod bow, expressed as percent of water channel closure, averaged $23.7 \%$. Holddown spring preload forces averaged a 35\% decrease from the beginning-of-1ife (BOL) values. This decrease in spring preload force is adequately compensated for by fuel assembly growth during operation, resulting in a relatively constant net holddown force during the operating lifetime of the assemblies. In the 20 fuel rods subjected to gamma scans only eight fuel column axial gaps were found - each of these gaps was $0.1 \mathrm{in.}$ or less in length. The average fuel column stack length exhibited no net change after three cycles of irradiation and was in good agreement with predicted results. 


\section{MARK B FUEL ASSEMBLY DESIGN AND OPERATING HISTORY}

\subsection{Fuel Assembly Design}

Duke Power Company's Oconee 1 Unit is a B\&W designed pressurized water reactor (PWR) with a core composed of 177 Mark B $(15 \times 15)$ fuel assemblies. A cutaway version of a typical Mark $B$ fuel assembly is shown in Figure 3-1. The structural cage of the assembly consists of 16 control rod guide tubes (CRGTs) (cold-worked, stress-relieved, Zircaloy-4) permanently attached to the upper and lower end fittings. The spacer grids (Inconel 718) form the structural link between the guide tubes and the fuel rods' (cold-worked, stress-relieved, Zircaloy-4 clad), but are free to move with the fuel rods as the rods grow. During fuel rod insertion, the grids are keyed open to prevent mechanical damage to the surface of the rods or to the grids. After positioning, the grids are unkeyed, holding the fuel rods securely in their lattice position. Fuel assembly lift resulting from coolant flow is prevented by the helical holddown spring contained within the upper end fitting of the assembly.

Each fuel assembly consists of a $15 \times 15$ lattice arrangement with 16 positions occupied by guide tubes and one position, the center lattice site, occupied by an incore instrumentation tube (CW, SR Zircaloy-4). The remaining 208 lattice positions contain fuel rods. A schematic cross section of a typical fuel assembly displaying the fuel rod numbering convention is presented in Figure 3-2. The fuel contained within the rods is low-enriched $\mathrm{UO}_{2}$ in the form of dishedend, chamfered cylindrical pellets (sintered). The nominal design parameters and operating conditions of Oconee 1 fuel are summarized in Table 3-1. Additional details are contained in Section 3 of the Final Safety Analysis Report ${ }^{1}$ for the Oconee Nuclear Station Unit 1.

The five assemblies selected for extended burnup were 1D13, 1D26, 1D42, ID45, and 1D55. These were initially loaded into the Oconee 1 reactor after its first cycle of operation as members of the batch $4 \mathrm{~B}$ group of assemblies; they were redesignated as batch 4D assemblies for their fourth cycle of irradiation in Oconee 1 , cycle 5 . The fuel contained within the batch $4 \mathrm{D}$ assemblies had 
an initial average enrichment of $3.20 \%{ }^{235} \mathrm{U}$. The pre-irradiation fuel column length (mean of the as-built fuel rod lot averages) of these five assemblies was $141.20 \mathrm{in.}$

\subsection{Operating History}

The operating histories for cycles 2,3 , and 4 of Oconee 1 are summarized in Table 3-2. The power history of each cycle is shown graphically in Figures 3-3 through 3-5; control rod interchanges and control rod group. 7 withdrawals are also noted in these figures.

\subsubsection{Control Rod Configurations}

The eighth-core symmetry locations of the extended burnup fuel and control rod assemblies, along with the control rod group designations for the various control rod configurations of Oconee 1 cyles 2, 3, and 4, are given in Figure 3-6. Within the first 100 effective full power days (EFPDs) of each of cycles 2 and 3 , a control rod interchange was made in which several of the control rods used for transient xenon control were reprogrammed as safety rods and a group of safety rods were redesignated for transient xenon control (as noted in Figure 3-6). For approximately the first 240 EFPDs of each of cycles 2 and 3 control rod group 6 was about 85 to 95\% withdrawn and group 7 was about 15 to $25 \%$ withdrawn. For the remainder of these two cycles group 6 was entirely withdrawn while group 7 was about 82 to $88 \%$ withdrawn. During cycle 4, control rod group 6 remained 100\% withdrawn while group 7 withdrawal varied between 80 and 90\%; no control rod interchanges were made. For each of these three cycles the part-length axial power shaping rods comprising control rod group 8 ranged from 5 to $25 \%$ withdrawn.

\subsubsection{Assembly Axial Power and Burnup Distributions}

As shown in Figure 3-6, four of the batch 4D assemblies (1D13, 1D26, 1D45, and 1D55) were from the same group of symmetric core locations (e.g., L-14 during cycle 2 operation). During cycle 2, these four assemblies were in a control rod group 6 location and thus contained partially inserted control rods for the first 237 EFPDs of the cycle. The effect of this rod insertion is clearly seen in Figure 3-7 which presents several axial power distributions that are considered representative of the 1D13 group of assemblies during cycle 2 operation. Figures 3-8 and 3-9 display representative axial power shapes for these assemblies during cycles 3 and 4, respectively. The fifth extended burnup 
assembly (1D42) did not contain a control assembly in cycles 2, 3, or 4 but was adjacent to group 7 and 8 control rods during cycle 3 . Representative axial power shapes for this assembly during cycles 2,3 , and 4 are given in Figures 3-10, 3-11, and 3-12, respectively. Since cycle 4 of Oconee 1 operated with the full-length control rods essentially withdrawn from the core, the axial power shape of the batch $4 \mathrm{D}$ assemblies did not change significantly over cycle 4 .

All of the axial power distributions were calculated using the three-dimensional nodal code FLAME $^{2}$ with one node per assembly in the radial direction and 32 nodes per assembly in the axial direction. The actual reactor operations during each cycle were modeled as closely as practicable using this code. Calculated power peaking factors for each of the three cycles are given in Tables 3-3 through 3-5. FLAME-calculated axial burnup profiles for the batch 4D assemblies at the end of each cycle are shown in Figures 3-13 and 3-14, and endof-cycle (EOC) assembly average burnups are presented in Table 3-6. 
Table 3-1. Oconee 1 Nominal Fuel Design Parameters

\section{$\underline{\text { Reactor Core }}$}

Core power rating, MWt 2568

Core average linear heat rate, $\mathrm{kW} / \mathrm{ft} \quad 5.66$

Core inlet coolant temperature, $F \quad 555$

Core outlet coolant temperature, F 606

Core operating pressure, psia " 2200

Fuel Assemblies and Fue1 Rods

Number of fuel assemblies in core $\quad 177$

Number of fuel rods per fuel assembly 208

Number of CRGTs per assembly 16

Fuel rod outside diameter, in. $\quad 0.430$

Fuel tubing (cladding) thickness, in. 0.0265

Fuel rod pitch, in. 0.568

Fuel assembly pitch, in. 8.587

Fue1

Material

Fuel pellet length, in.

$\mathrm{UO}_{2}$ (sintered)

Fuel pellet diameter, in.

0.70

Active fuel length, in.

0.3670

Fuel density, \% theoretical

141.0

95.5

Table 3-2. Summary of Operating Histories Oconee 1, Cycles 2, 3, and 4

\begin{tabular}{|c|c|c|c|c|c|}
\hline Cycle & BOC & EOC & $\begin{array}{c}\text { Cycle } \\
\text { length, } \\
\text { EFPD } \\
\end{array}$ & $\begin{array}{c}\text { Exposure at } \\
\text { control rod } \\
\text { interchange, } \\
\text { EFPD } \\
\end{array}$ & $\begin{array}{c}\text { Exposure at } \\
\text { group } 7 \\
\text { withdrawal, } \\
\text { EFPD } \\
\end{array}$ \\
\hline 2 & $02 / 11 / 75$ & $02 / 07 / 76$ & 292.2 & 53 & 237 \\
\hline 3 & $03 / 31 / 76$ & $08 / 05 / 77$ & 308.3 & 100 & 238 \\
\hline 4 & $10 / 14 / 77$ & $09 / 02 / 78$ & 245.9 & - & -- \\
\hline
\end{tabular}


Table 3-3. Calculated Power Peaking Factors - Oconee 1, Cycle 2

\begin{tabular}{|c|c|c|c|c|c|c|}
\hline $\begin{array}{c}\text { Exposure, } \\
\text { EFPD }\end{array}$ & $\begin{array}{c}\text { Core } \\
\text { burnup, } \\
\text { MWd/mtU }\end{array}$ & $\begin{array}{l}\text { Assembly } \\
\text { burnup, } \\
\text { MWd/mtU }\end{array}$ & $\begin{array}{l}\text { Assembly } \\
\text { relative } \\
\text { power (a) }\end{array}$ & $\begin{array}{l}\text { Node } \\
\text { maximum } \\
\text { relative } \\
\text { power (b) }\end{array}$ & $\begin{array}{l}\text { Maximum } \\
\text { node } \\
\text { axial } \\
\text { location (c) }\end{array}$ & $\begin{array}{l}\text { Peak } \\
\text { pin } \\
\text { relative } \\
\text { power (d) }\end{array}$ \\
\hline
\end{tabular}

Assembly $1 \mathrm{D} 42$ in Core Location K-15

\begin{tabular}{|c|c|c|c|c|c|c|}
\hline 22.5 & 6,268 & 745 & 1.006 & 1.390 & 29 & 1.247 \\
\hline 65.0 & 7,589 & 2,104 & 1.092 & 1.407 & 52 & 1.238 \\
\hline 103.5 & 8,785 & 3,411 & 1.067 & 1.334 & 47 & 1.233 \\
\hline 131.0 & 9,639 & 4,323 & 1.046 & 1.316 & 38 & 1.229 \\
\hline 156.0 & 10,416 & 5,135 & 1.037 & 1.270 & 38 & 1.226 \\
\hline 184.0 & 11,286 & 6,038 & 1.026 & 1.247 & 34 & 1.224 \\
\hline 217.0 & 12,312 & 7,090 & 1.007 & 1.254 & 34 & 1.223 \\
\hline 235.0 & 12,871 & 7,653 & 0.984 & 1.180 & 106 & 1.270 \\
\hline $252.9(\mathrm{f})$ & 13,427 & 8,200 & 0.975 & 1.106 & 34 & 1.269 \\
\hline $273.5^{(t)}$ & 14,068 & 8,826 & 0.968 & 1.154 & 25 & 1.259 \\
\hline
\end{tabular}

Assembly $1 \mathrm{D} 13^{(\mathrm{e})}$ in Core Location L-14

$\begin{array}{rrrrrrr}22.5 & 6,268 & 963 & 1.293 & 1.793 & 25 & 1.108 \\ 65.0 & 7,589 & 2,700 & 1.381 & 1.810 & 56 & 1.103 \\ 103.5 & 8,785 & 4,352 & 1.339 & 1.711 & 52 & 1.101 \\ 131.0 & 9,639 & 5,496 & 1.295 & 1.671 & 47 & 1.099 \\ 156.0 & 10,416 & 6,502 & 1.276 & 1.602 & 47 & 1.098 \\ 184.0 & 11,286 & 7,613 & 1.257 & 1.560 & 34 & 1.097 \\ 217.0 & 12,312 & 8,902 & 1.216 & 1.575 & 25 & 1.096 \\ 235.0 & 12,871 & 9,582 & 1.226 & 1.465 & 110 & 1.135 \\ 252.9 \text { (f) } & 13,427 & 10,264 & 1.222 & 1.354 & 34 & 1.134 \\ 273.5 & 14,068 & 11,047 & 1.218 & 1.457 & 25 & 1.127\end{array}$

(a) Assembly relative power $=$ assembly power $\times 177 /$ core power (FLAME

calculated).

(b) Node maximum relative power $=$ maximum nodal power $\times 177 \times 32 /$ core power (FLAME calculated).

(c) Inches from bottom of fuel column to center of node of maximum relative power.

(d) Peak pin relative power $=$ maximum pin power $\times 208 /$ assembly power (twodimensional $\mathrm{PDQ}^{3}$ calculated).

(e) Assemb1ies 1D13, 1D26, 1D45, and 1D55 were irradiated in symmetrically equivalent core locations during this cycle. Thus, $1 D 13$ is representative of the four assemblies.

(f) The total exposure for this cycle was 292.2 EFPDs. 
Table 3-4. Calculated Power Peaking Factors - Oconee 1, Cycle 3

\begin{tabular}{|c|c|c|c|c|c|}
\hline $\begin{array}{c}\text { Exposure, } \\
\text { EFPD }\end{array}$ & $\begin{array}{c}\text { Core } \\
\text { burnup, } \\
\text { MWd/mtU }\end{array}$ & $\begin{array}{l}\text { Assembly } \\
\text { burnup, } \\
\text { MWd/mtU }\end{array}$ & $\begin{array}{l}\text { Assemb1y } \\
\text { relative } \\
\text { power (a) }\end{array}$ & $\begin{array}{l}\text { Node } \\
\text { maximum } \\
\text { relative } \\
\text { power (b) }\end{array}$ & $\begin{array}{cc}\text { Maximum } & \text { Peak } \\
\text { node } & \text { pin } \\
\text { axial } & \text { relative } \\
\text { location } & \text { power (d) }\end{array}$ \\
\hline
\end{tabular}

Assembly $1 D 42$ in Core Location $\mathrm{K}-12$

$\begin{array}{rrrrrrr}32.0 & 9,174 & 10,576 & 1.226 & 1.629 & 20 & 1.121 \\ 59.0 & 10,023 & 11,613 & 1.206 & 1.592 & 20 & 1.117 \\ 97.5 & 11,229 & 13,056 & 1.185 & 1.518 & 20 & 1.117 \\ 121.9 & 11,992 & 13,999 & 1.235 & 1.571 & 25 & 1.330 \\ 165.2 & 13,346 & 15,661 & 1.212 & 1.543 & 25 & 1.121 \\ 189.3 & 14,099 & 16,571 & 1.204 & 1.522 & 25 & 1.117 \\ 203.3 & 14,539 & 17,100 & 1.193 & 1.474 & 25 & 1.116 \\ 245.8 & 15,868 & 18,690 & 1.220 & 1.468 & 83 & 1.106 \\ 273.0 & 16,721 & 19,733 & 1.218 & 1.410 & 92 & 1.102 \\ 308.3 & 17,841 & 21,044 & 1.210 & 1.476 & 43 & 1.099\end{array}$

Assembly $1 \mathrm{D} 13^{(\mathrm{e})}$ in Core Location K-11

$\begin{array}{rrrrrrr}32.0 & 9,174 & 13,076 & 1.362 & 1.615 & 119 & 1.065 \\ 59.0 & 10,023 & 14,225 & 1.327 & 1.538 & 119 & 1.065 \\ 97.5 & 11,229 & 15,811 & 1.291 & 1.472 & 20 & 1.065 \\ 121.9 & 11,992 & 16,758 & 1.231 & 1.467 & 25 & 1.077 \\ 165.2 & 13,346 & 18,412 & 1.210 & 1.446 & .25 & 1.071 \\ 189.3 & 14,099 & 19,324 & 1.211 & 1.436 & 25 & 1.069 \\ 203.3 & 14,539 & 19,857 & 1.198 & 1.392 & 25 & 1.068 \\ 245.8 & 15,868 & 21,448 & 1.177 & 1.257 & 79 & 1.093 \\ 273.0 & 16,721 & 22,454 & 1.172 & 1.307 & 97 & 1.087 \\ 308.3 & 17,841 & 23,733 & 1.173 & 1.370 & 38 & 1.083\end{array}$

(a) Assembly relative power = assembly power $\times 177 /$ core power (FLAME calculated).

(b) Node maximum relative power $=$ maximum nodal power $\times 177 \times 32 /$ core power ( (TLAME calculated).

(d) power.

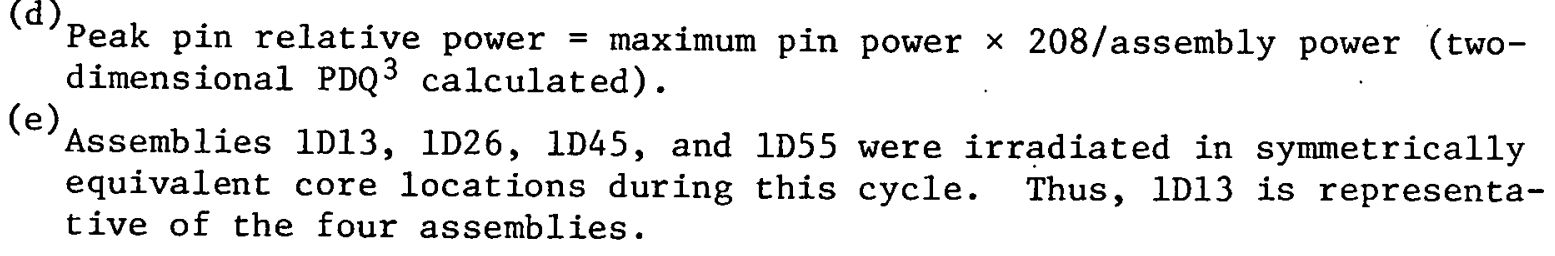


Table 3-5. Calculated Power Peaking Factors - Oconee 1, Cycle 4

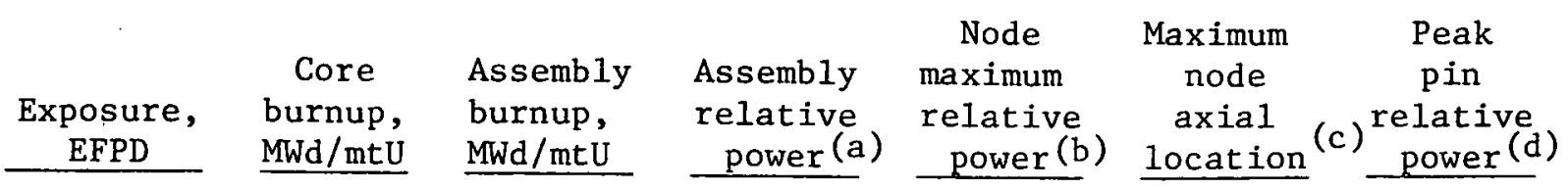

Assembly $1 \mathrm{D} 42$ in Core Location $\mathrm{K}-14$

$\begin{array}{rrrrrrr}23.4 & 10,717 & 21,731 & 0.892 & 1.064 & 101 & 1.174 \\ 46.2 & 11,430 & 22,367 & 0.900 & 1.065 & 52 & 1.163 \\ 76.5 & 12,380 & 23,230 & 0.920 & 1.082 & 97 & 1.153 \\ 103.4 & 13,220 & 24,007 & 0.929 & 1.069 & 92 & 1.142 \\ 125.2 & 13,902 & 24,641 & 0.933 & 1.090 & 83 & 1.134 \\ 150.7 & 14,702 & 25,390 & 0.940 & 1.057 & 92 & 1.126 \\ 174.8 & 15,457 & 26,099 & 0.946 & 1.070 & 43 & 1.120 \\ 208.6 & 16,514 & 27,100 & 0.952 & 1.044 & 106 & 1.113 \\ 234.7(f) & 17,331 & 27,877 & 0.955 & 1.060 & 38 & 1.106\end{array}$

Assembly $1 \mathrm{D} 13^{(\mathrm{e})}$ in Core Location $M-13$

$\begin{array}{rrrrrrr}23.4 & 10,717 & 24,462 & 0.946 & 1.134 & 106 & 1.076 \\ 46.2 & 11,430 & 25,136 & 0.954 & 1.092 & 43 & 1.072 \\ 76.5 & 12,380 & 26,044 & 0.959 & 1.127 & 101 & 1.068 \\ 103.4 & 13,220 & 26,849 & 0.963 & 1.101 & 101 & 1.063 \\ 125.2 & 13,902 & 27,505 & 0.969 & 1.114 & 92 & 1.058 \\ 150.7 & 14,702 & 28,279 & 0.965 & 1.079 & 101 & 1.053 \\ 174.8 & 15,457 & 29,009 & 0.962 & 1.085 & 34 & 1.049 \\ 208.6 \text { (f) } & 16,514 & 30,030 & 0.965 & 1.060 & 110 & 1.044 \\ 234.7 & 17,331 & 30,819 & 0.966 & 1.070 & 29 & 1.041\end{array}$

\footnotetext{
(a) Assembly relative power $=$ assembly power $\times 177 /$ core power (FLAME calculated).

(b) Node maximum relative power $=$ maximum nodal power $\times 177 \times 32 /$ core power (FLAME calculated).

(c) Inches from bottom of fuel column to center of node of maximum relative power.

(d) Peak pin relative power $=$ maximum pin power $\times 208 /$ assembly power (twodimensional $\mathrm{PDQ}^{3}$ calculated).

(e) Assemb1ies 1D13, 1D26, 1D45, and $1 \mathrm{D} 55$ were irradiated in symmetrically equivalent core locations during this cycle. Thus, 1013 is representative of the four assemblies.

(f) The total exposure of this cycle was 245.9 EFPDs.
} 
Table 3-6. Assembly Average Burnups - Oconee 1, End-of-Cycles 2, 3, and 4

\begin{tabular}{ccc} 
& \multicolumn{2}{c}{ Assembly 1D42 } \\
\cline { 2 - 3 } Cycle & $\begin{array}{c}\text { Eighth-core } \\
\text { location }\end{array}$ & $\begin{array}{c}\text { Assembly average } \\
\text { EOC burnup, } \\
\text { MWd/mtU }\end{array}$ \\
\cline { 2 - 3 } 2 & $\mathrm{~K}-15$ & 9,350 \\
3 & $\mathrm{~K}-12$ & 21,040 \\
4 & $\mathrm{~K}-14$ & 28,210
\end{tabular}

\begin{tabular}{cc}
$\begin{array}{c}\text { Assemb1ies 1D13, 1D26, } \\
\text { 1D45, and 1D55 }\end{array}$ \\
\hline $\begin{array}{c}\text { Eighth-core } \\
\text { location }\end{array}$ & $\begin{array}{c}\text { Assembly average } \\
\text { EOC burnup, } \\
\text { MWd/mtU }\end{array}$ \\
\cline { 2 - 2 } L-14 & 11,710 \\
K-11 & 23,770 \\
M-13 & 31,160
\end{tabular}


Figure 3-1. Mark B Fuel Assembly

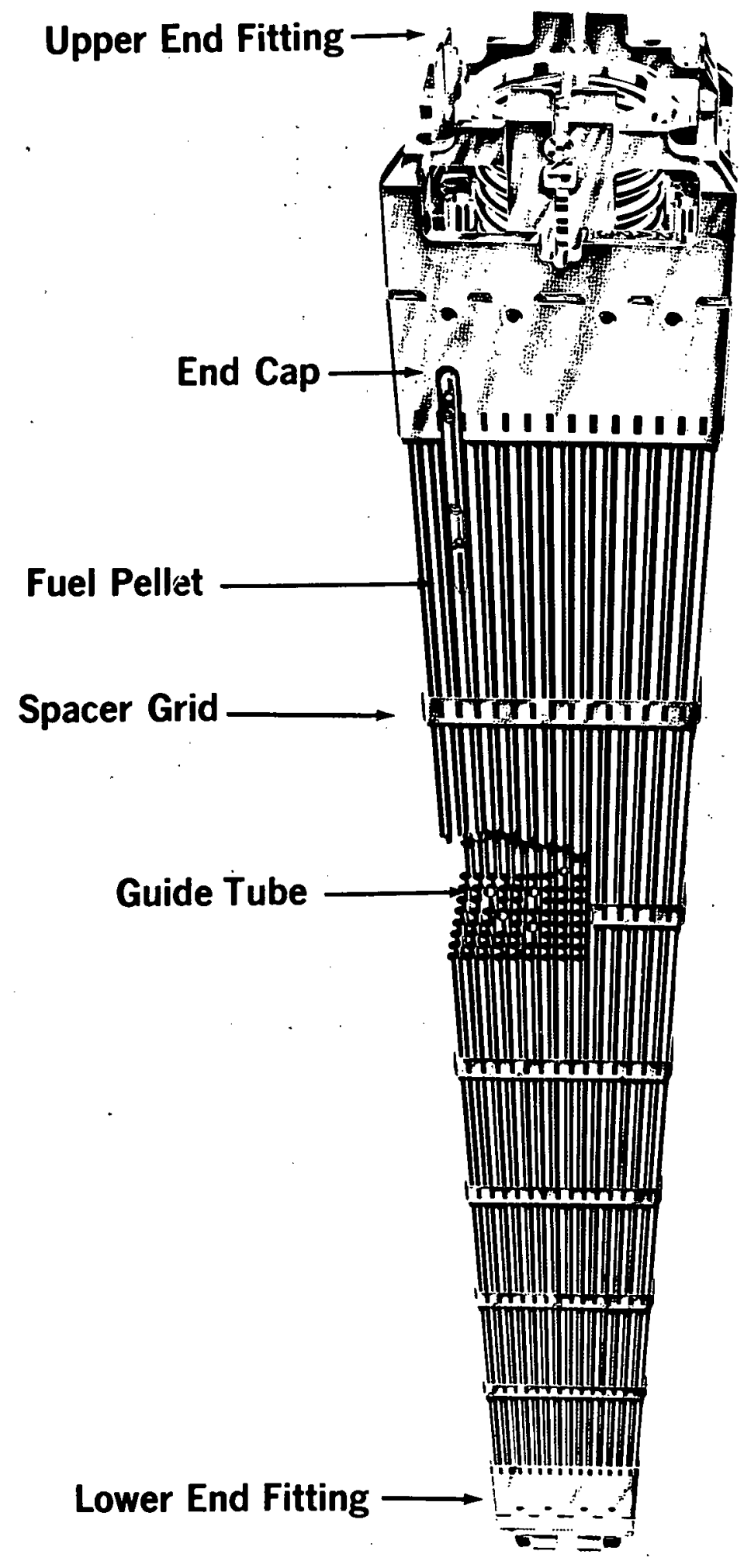


Figure 3-2. Fuel Assembly Cross Section Displaying Numbering Conventions

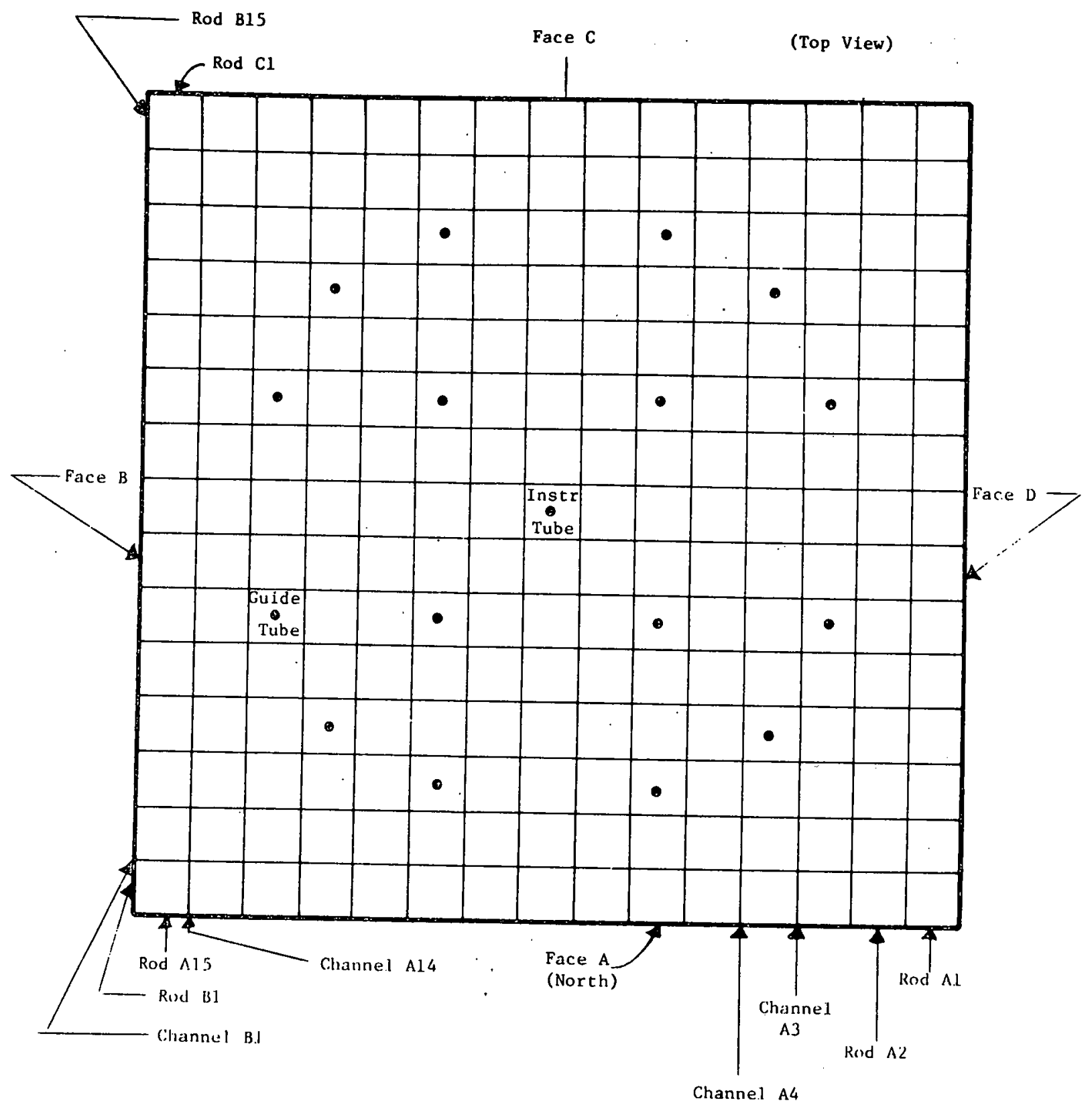


Figure 3-3. Power History - Oconee 1, Cycle 2

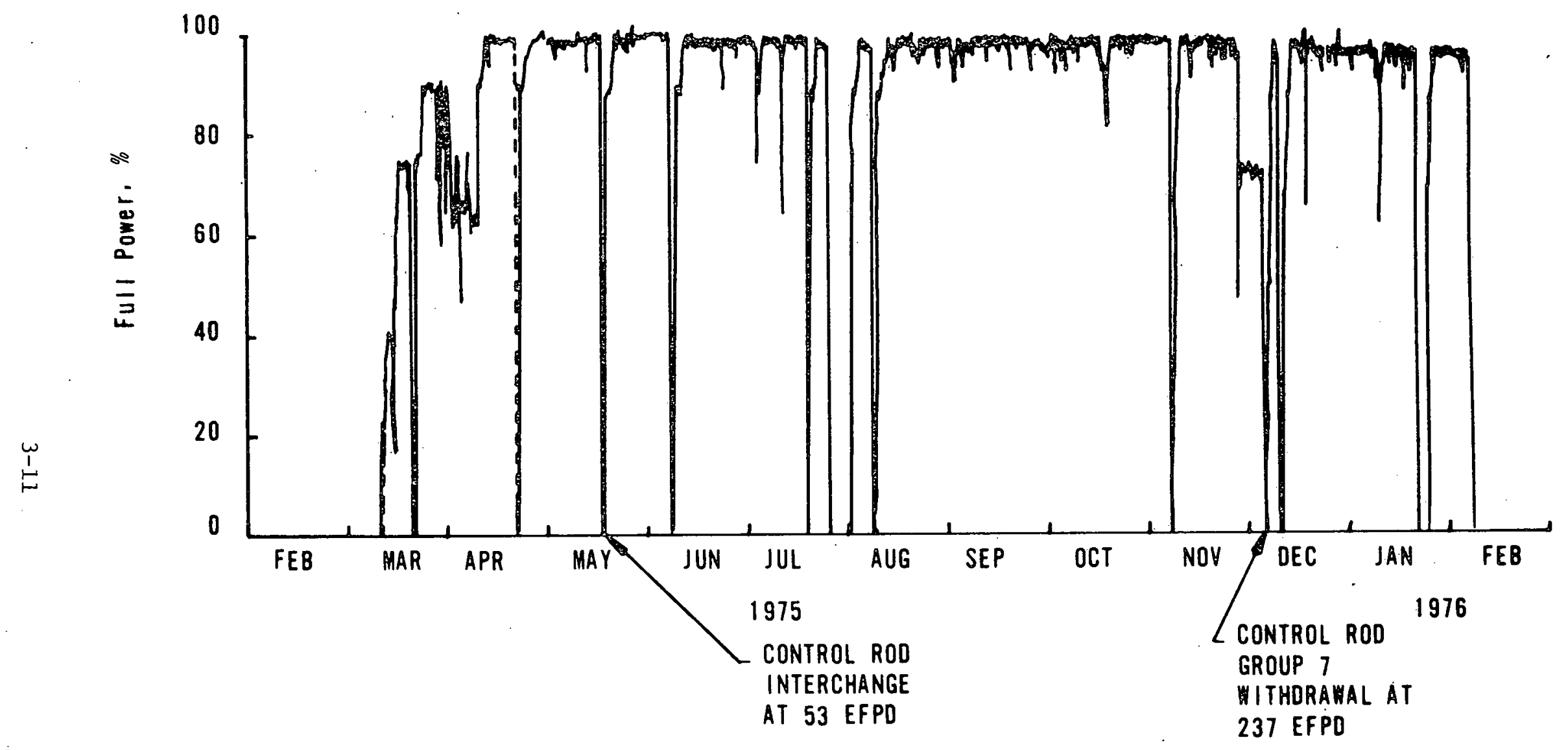

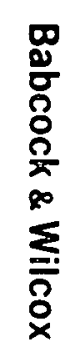


Figure 3-4. Power History - Oconee 1, Cycle 3
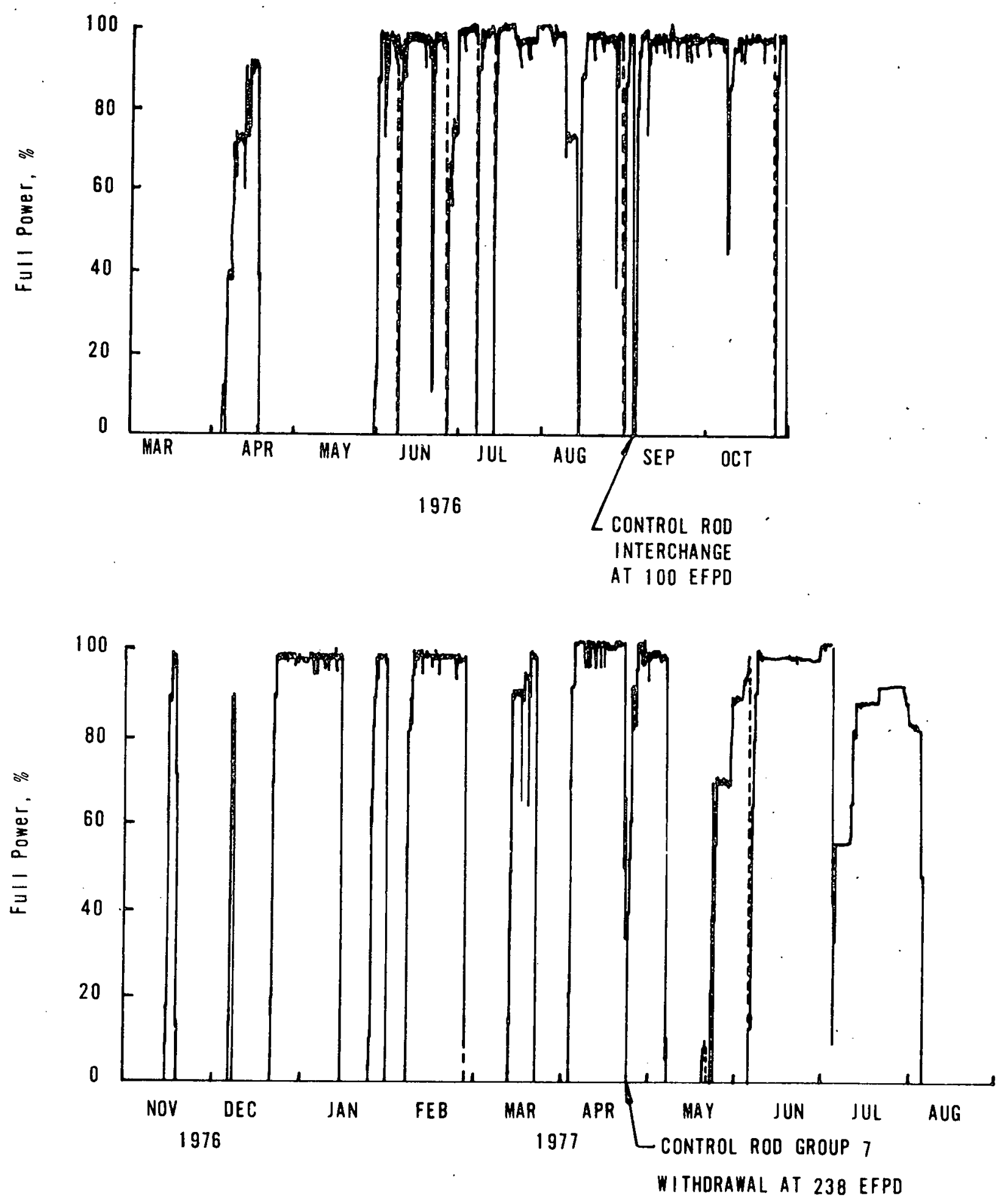
Figure 3-5. Power History - Oconee 1, Cycle 4

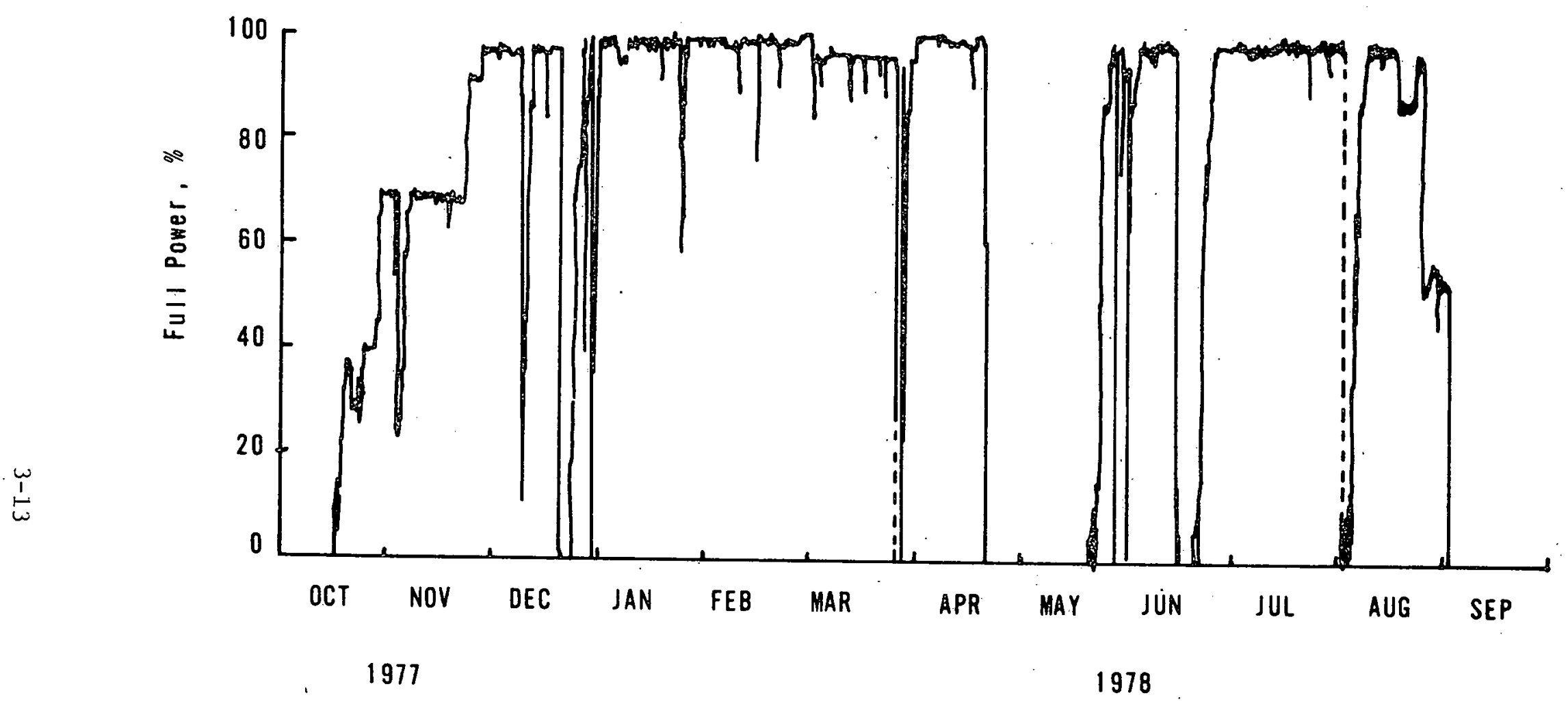

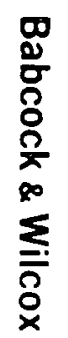


Figure 3-6. Extended Burnup Assembly Locations

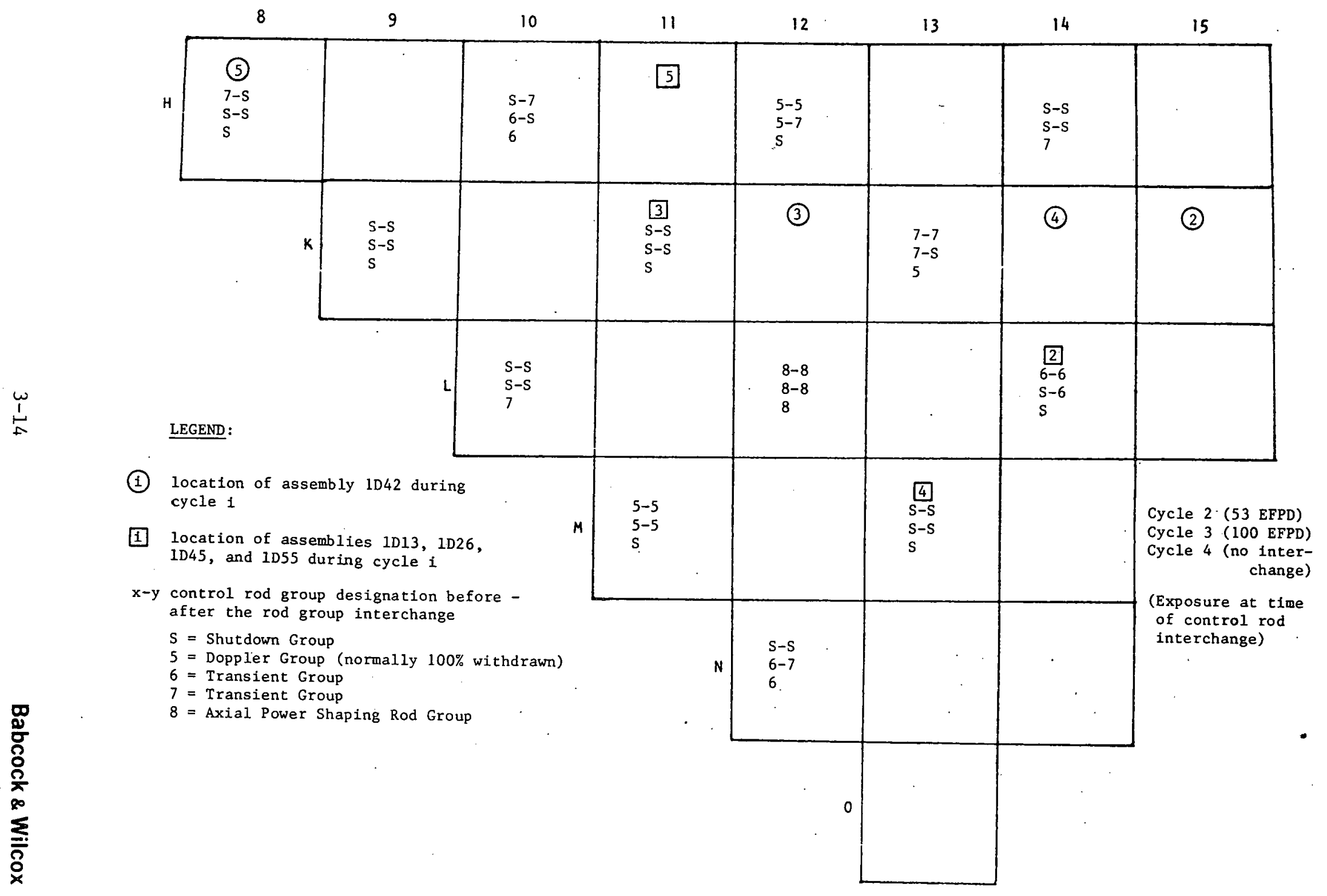


Figure 3-7. Axial Power Shape - Oconee 1, Cycle 2:

Assemblies 1D13, 1D26, 1D45, 1D55

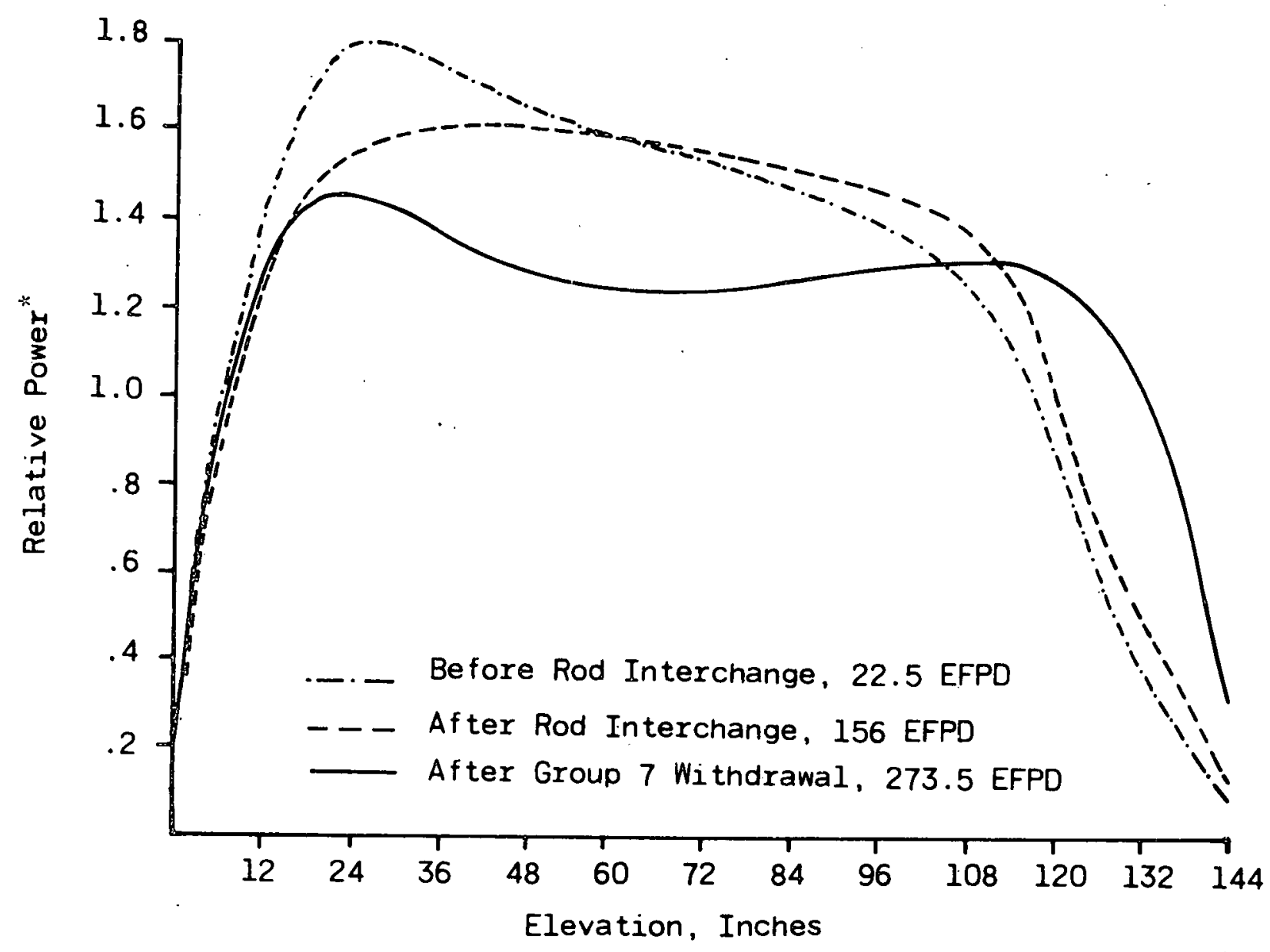

*Relative to core averago power. 
Figure 3-8. Axial Power Shape - Oconee 1, Cycle 3:

Assemb1ies 1D13, 1D26, 1D45, ID55

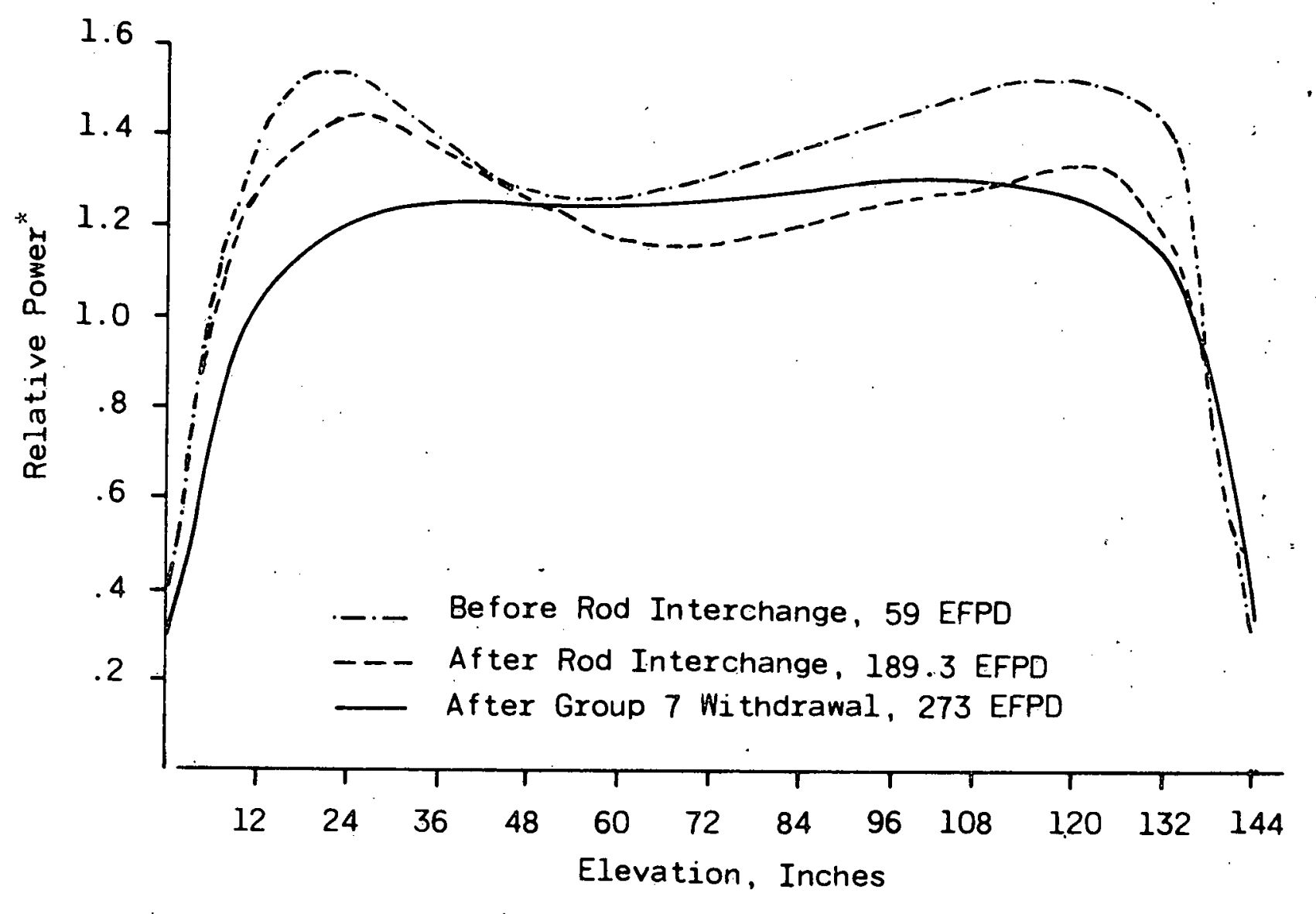

iRelative to core average power. 
Figure 3-9. Axial Power Shape - Oconee 1, Cycle 4: Assemb1ies 1D13, 1D26, 1D45, 1D55

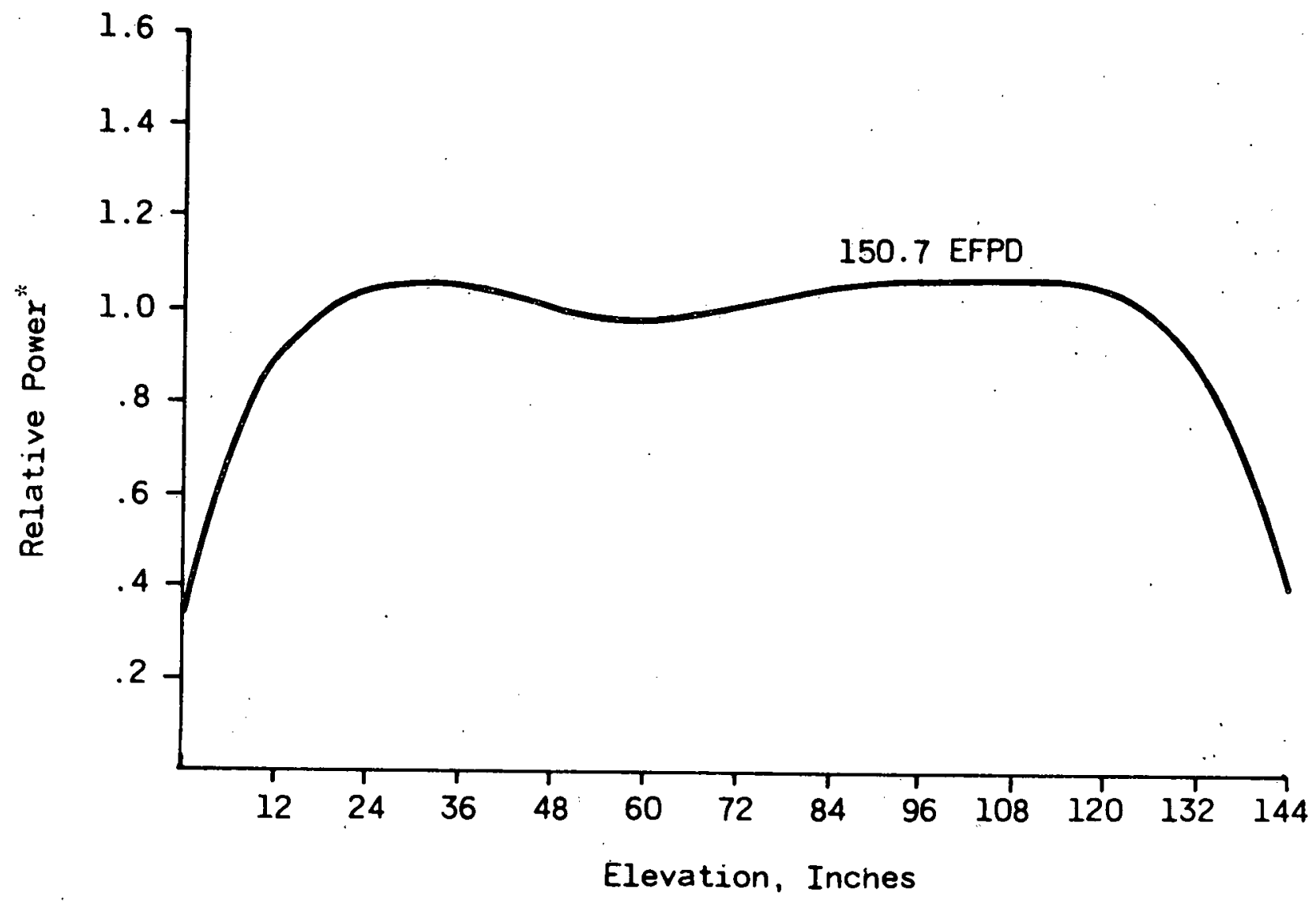

* Relative to core average power. 
Figure 3-10. Axial Power Shape - Oconee 1, Cycle 2: Assembly $1 D 42$

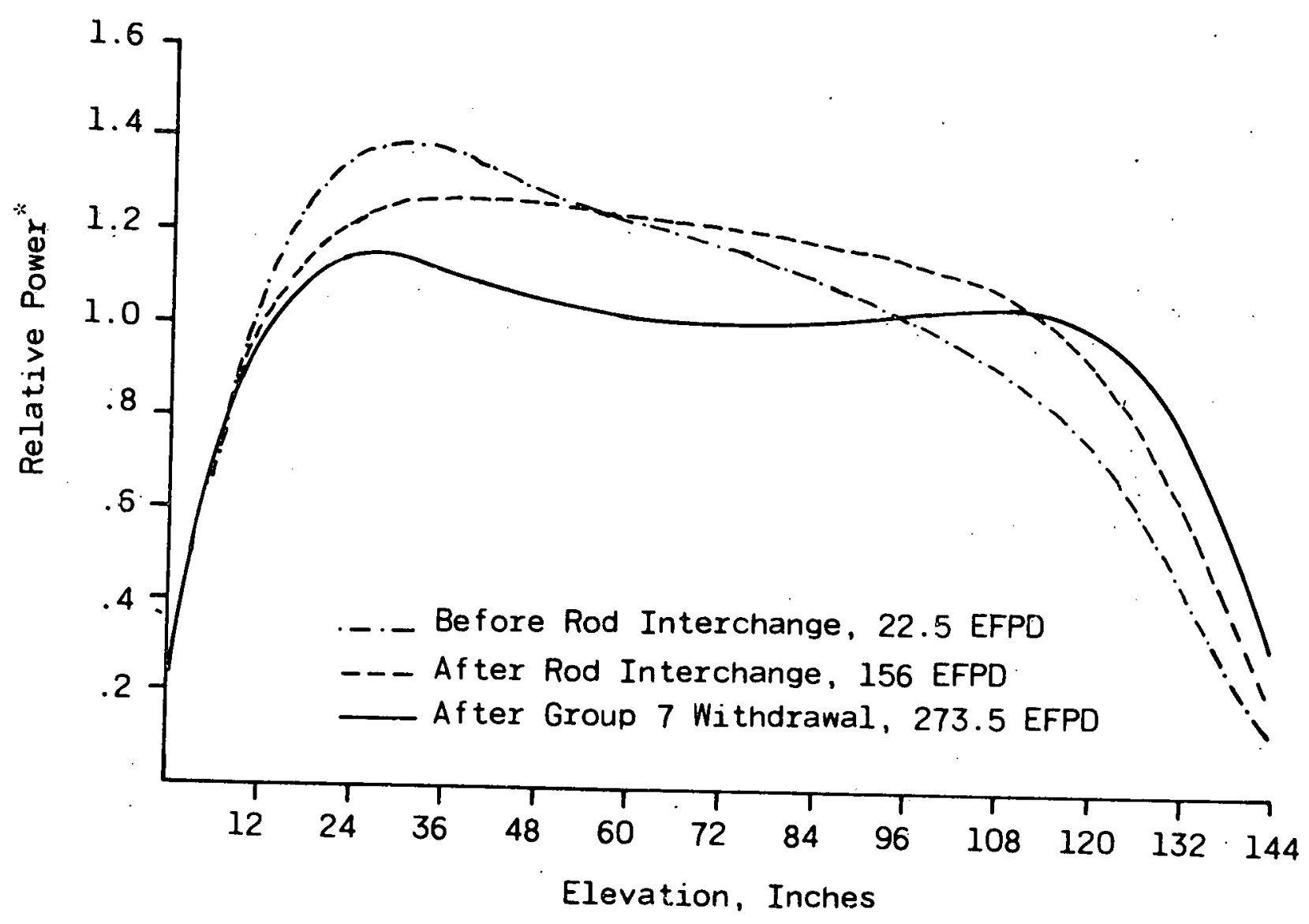

* Rellat ive to core average power. 

Figure 3-11. Axia1 Power Shape - Oconee 1, Cycle 3:
Assembly 1D42

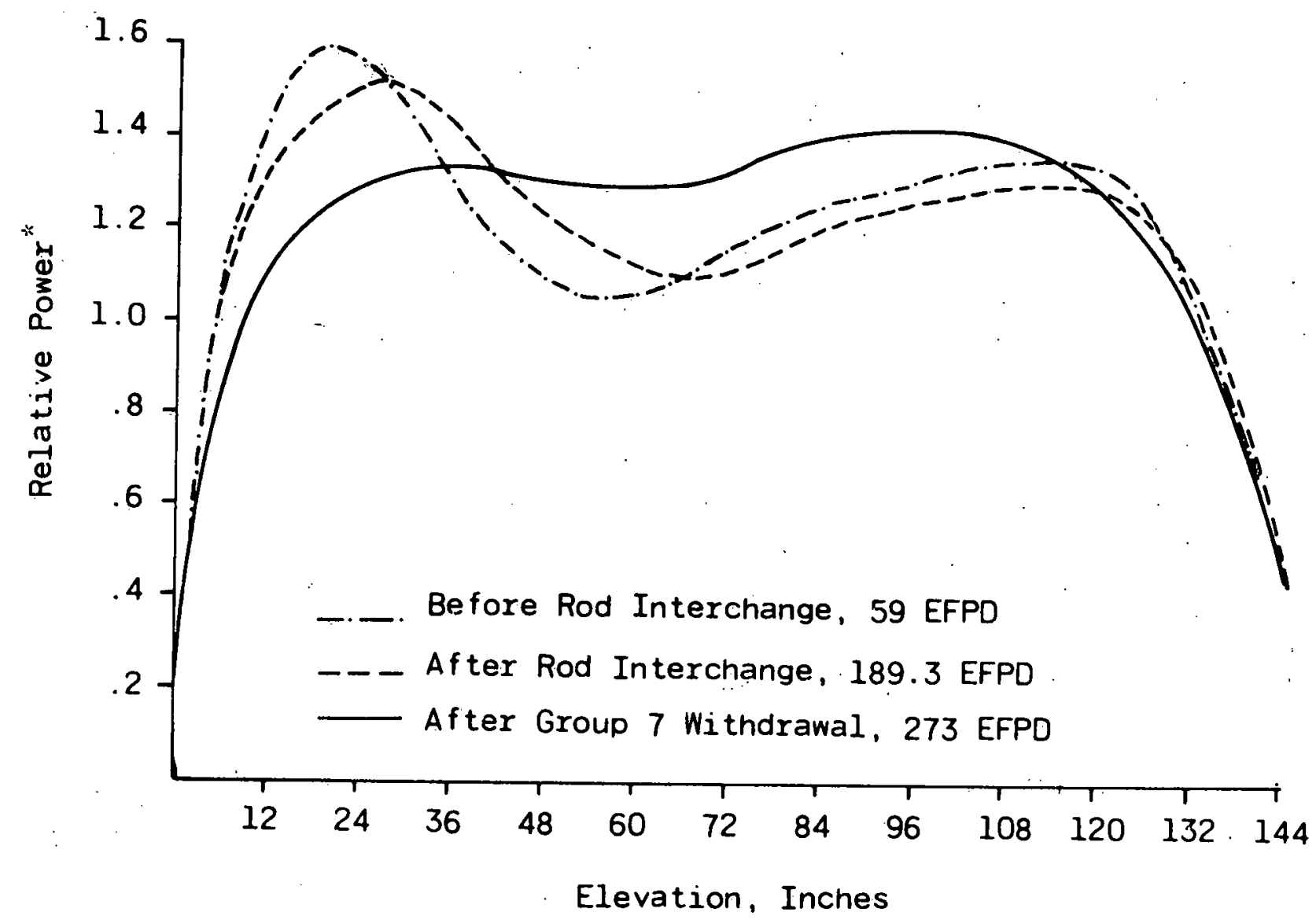

* Relative to core average power. 
Figure 3-12. Axial Power Shape - Oconee 1, Cycle 4: Assembly 1D42

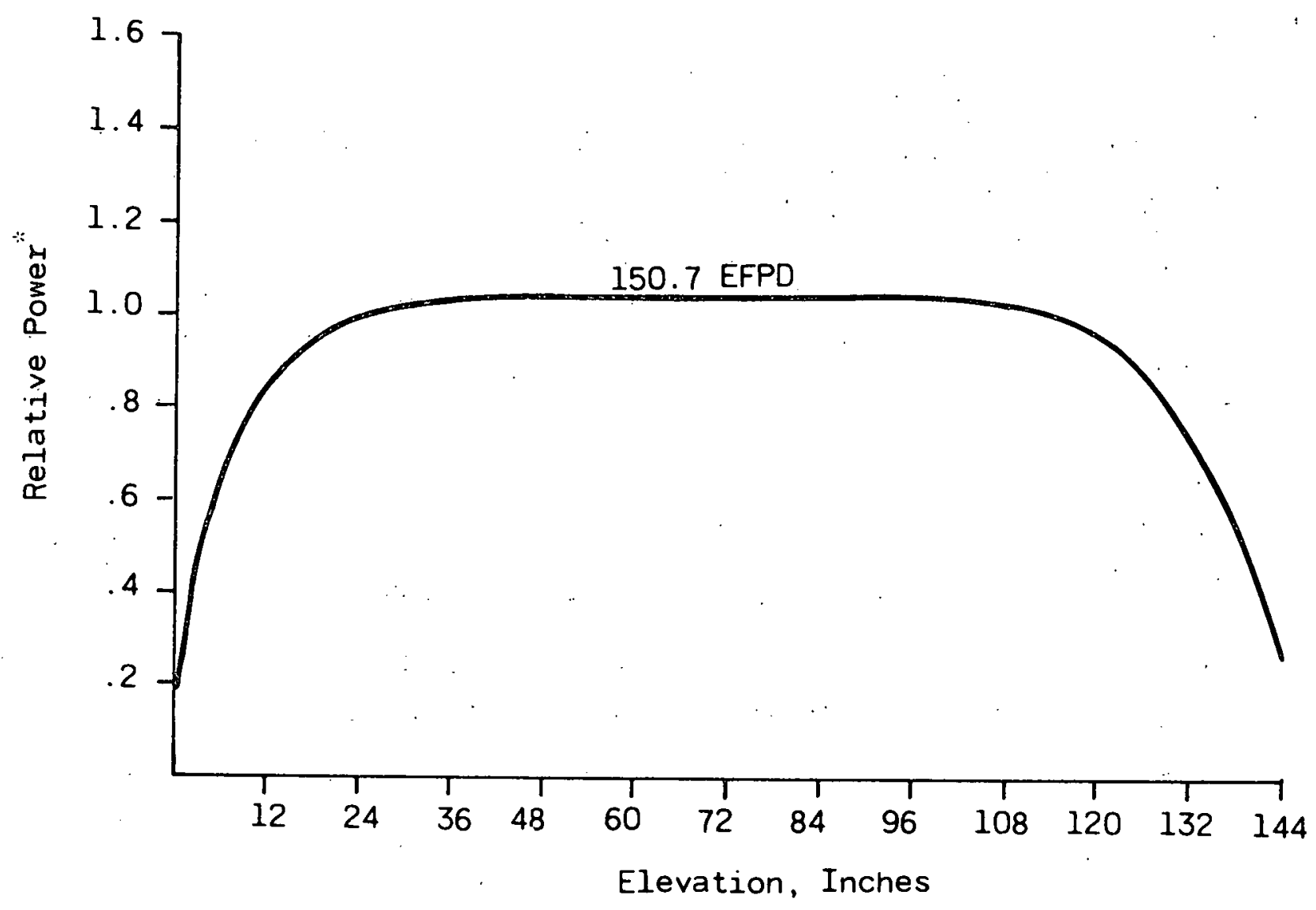

*Relative to core average power. 
Figure 3-13. Assembly 1D13 Axial Burnup Profiles

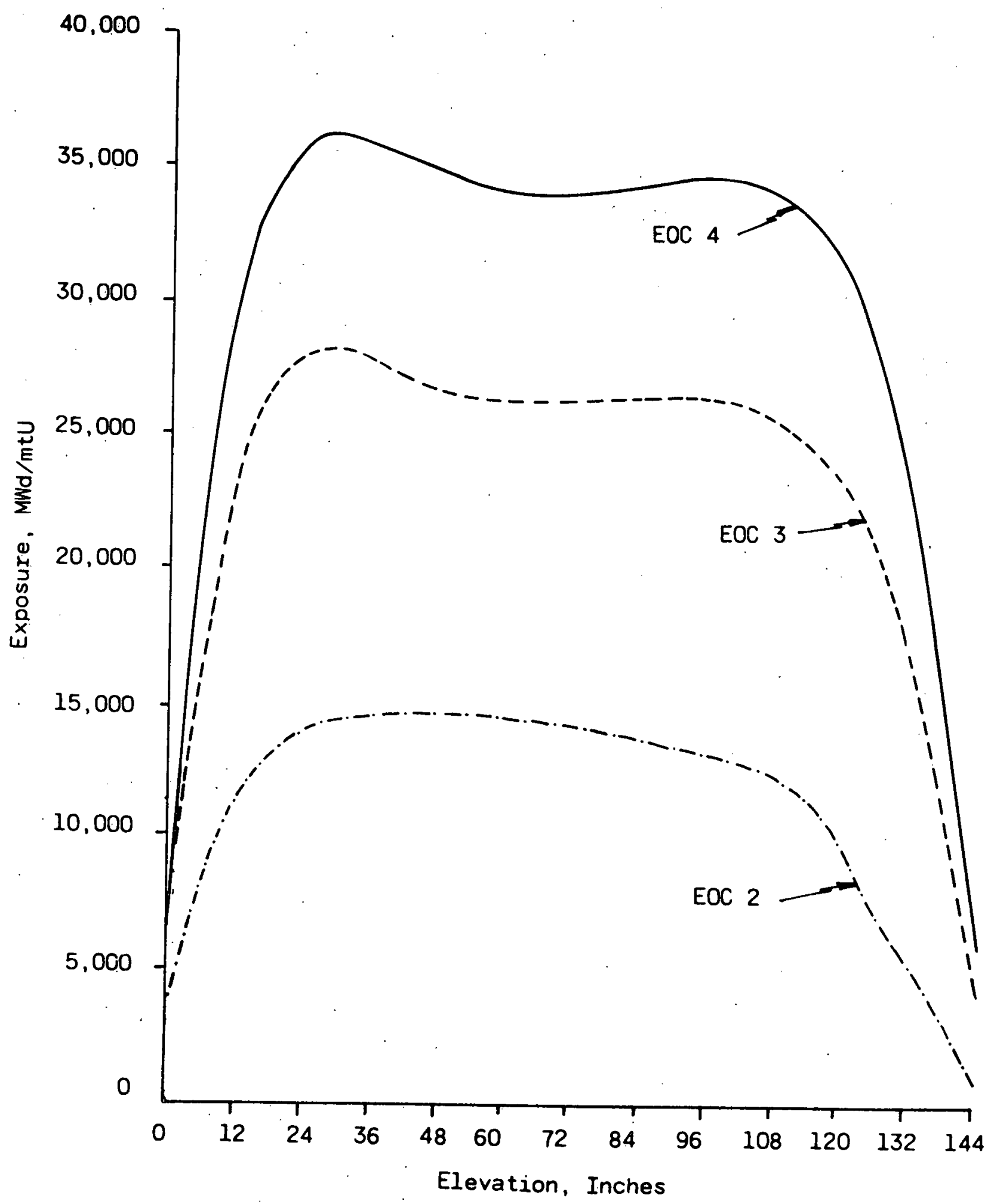


Figure 3-14. Assembly 1 42 Axial Burnup Profiles

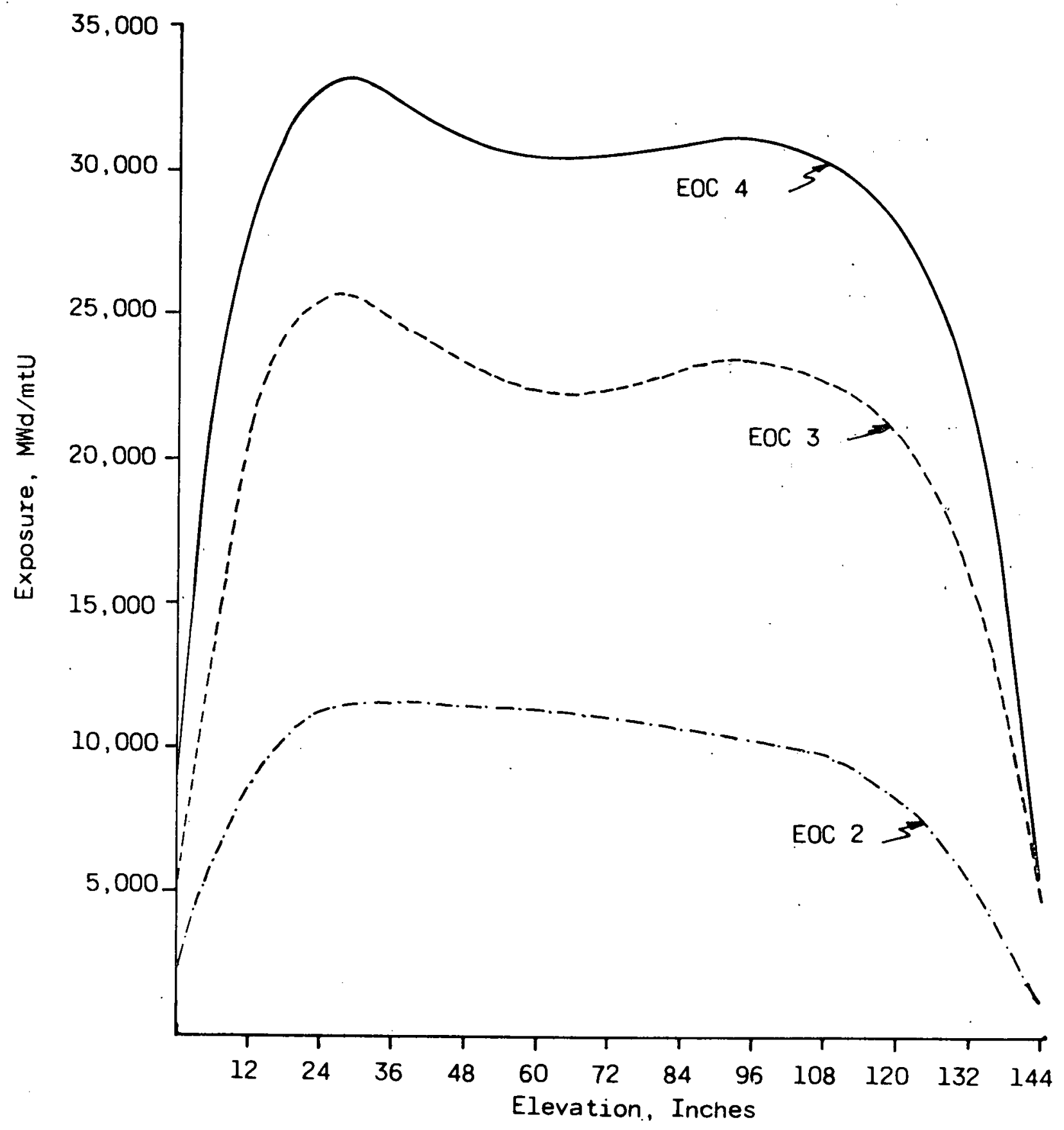




\section{POST-IRRADIATION EXAMINATION MEASUREMENT \\ TECHNIQUES (POOLSIDE)}

\subsection{Poolside Equipment Arrangement}

The arrangement of the post-irradiation examination (PIE) test equipment in the spent fuel pool during fuel assembly examination is shown in Figure 4-1. The heart of the PIE equipment system is the line scan tester (LST) which consists of a strong back frame and various test heads for conducting diameter profilometry, assembly bow, and water channel spacing measurements. An assembly is positioned in the LST with its lower end fitting resting in a support socket at the bottom of the LST and its upper end fitting restrained within the confines of a cylinder at the top. The bottom of the LST is about $26 \mathrm{ft}$ below the surface of the water. The bottom support socket is a turntable permitting fuel assembly rotation in the LST so that any face of the assembly is accessible to the measuring heads. The measuring heads are mounted on a cart which travels vertically along a reference track in order to scan the axial profile of the assembly. In addition, the reference track itself has a horizontal translation capability parallel to the face of the fuel assembly, thus allowing the measuring equipment to be aligned on any peripheral rod. All of the measuring heads are remotely removable from the LST to permit periodic maintenance, inspection, and repair of the system. Controls for the measuring heads and the data acquisition packages are located topside at the spent fuel pool. Figure 4-2 is a photograph of the area while work is in progress.

Detailed descriptions of each measurement technique are given in the following sections.

\subsection{Visual Inspection Techniques}

Visual examinations of fuel assemblies are conducted with the assembly suspended from the hoist. Two methods are used for visual inspections. First, an underwater television camera which is mounted on a pan/tilt mechanism at the bottom end of a telescoping shaft is used to scan an entire assembly face. The assembly is rotated and another face is then scanned. This procedure is 
followed to complete the examination of the entire assembly. Videotape recordings are made during the full length scans of each face. At any time during the axial scanning, the TV camera movement can be stopped and closeup views taken of any area of interest.

The second method of visual examination utilizes an underwater periscope. The assembly is lowered past the periscope and $35 \mathrm{~mm}$ color photographs are taken of selected areas along the assembly length.

Both the TV camera and the periscope are shown in the underwater equipment view in Figure 4-1.

4.3. Fuel Assemb1y and Rod Length Measurements

Length measurements are also obtained with the fuel assembly suspended from the hoist. A steel tape, which is mounted on a bracket above the fuel grapple, is attached to the bottom of the fuel assembly and tensioned along its length with a constant force. Reference locations on the assembly are then observed visually using the television camera. These locations include the reference edges on the upper and lower end fittings and the top edge of each spacer grid. Each reading is recorded in a logbook and on videotape. The readings are estimated to be accurate to within \pm 0.024 in. The reliability. of the data is increased by performing these measurements on all four faces of the assembly.

Measurements of fuel rod length cannot be made directly on the batch 4D assemblies because of the end grid design. A grid skirt extends from the end grid to the assembly end fitting, thus obstructing the view of the rod ends. In these cases, an extrapolated value of rod length is obtained from the spacer grid locations.

\subsection{Fuel Rod Diameter Profilometry Measurements}

Measurements of fuel rod diameter are performed with the fuel assembly resting in the LST. The diameter measurement head (shown in Figure 4-3) is one of the test heads located on the LST cart. The fuel rod diameter measuring equipment is composed of a pair of sapphire rod fingers which are inserted to contact across the diameter of a peripheral rod. The separation distance between the two fingers is monitored with a linear variable differential transformer (LVDT). When the fingers are inserted to contact a rod, the measuring head carriage is translated from bottom to top (or vice versa) of a fuel assembly 
to obtain a diameter profile trace along the length of the rod. A protective guide around the fingers permits them to ride over the intermediate spacer grids on the assembly so that a continuous motion is used to trace a rod from one end to the other.

However, diameter data on the rod are obtained only on the segments between the grids. The extent of travel of the diameter head along the length of a rod is 132 inches. Except for the corner rods all poolside profilometer traces are single-orientation scans which measure the diameter of the rod in the plane of the fuel assembly face. Since corner rods on the assembly can be measured from two faces, orthogonal traces on the corner rods are obtained. Initial calibration of the diameter head was carried out using a 13-step diameter standard with NBS traceability to produce a calibration curve for the system. Routine checks of the calibration were performed at the beginning of measurements on each face of each assembly. This was accomplished by inserting a calibration standard between the measuring fingers which positioned them sequentially in two characterized spacings. The signal processing equipment was then adjusted to produce the required chart scale factors.

When the diameter head was initially installed, one fuel rod was scanned five successive times to provide data for analysis of variance to determine the system precision. The probable error $(1 \sigma)$ of a data point (based on 335 sets of data) has been shown to be within \pm 0.000104 inch.

\subsection{Water Channel Spacing Measurements}

The water channel spacings are measured with the fuel assembly resting in the LST. A probe is inserted into the channels between rows of fuel rods, and the spacings (transverse to the direction of insertion) are measured. Figure 4-4 shows a schematic illustration of the measurement technique. The probe itself is a waterproofed version of a Sulo probe, in which two strain-gaged leaf springs are attached to the sides of a thin wand. The relaxed dimension of the springs is about 0.190 inch, while the fully compressed dimension is 0.045 inch.

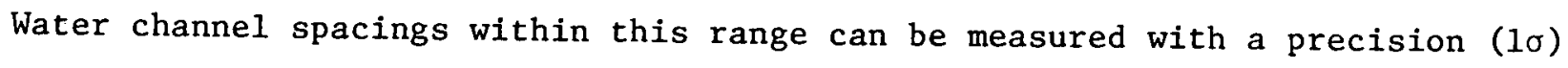
of \pm 0.00007 in.

The probe is positioned sequentially for full insertion into each of the 14 channels from one direction, as shown in Figure 4-4. Each insertion extends fully through the assembly to record 15 spacings. This sequence is then 
repeated on the adjacent face to obtain a complete mapping for one location along the assembly length. Seven different axial locations on the assembly are characterized, each corresponding to a midspan level between spacer grids. Thus, a total of 2940 spacings are measured on a fuel assembly. of these, 2464 are rod-to-rod spacings and 476 are rod-to-guide tube spacings (including instrumentation tube). The midspan level and spacer grid locations are shown schematically in Figure 4-5. For reference; the six intermediate spacer grids are numbered sequentially from 1 to 6 from top to bottom, and the water channel midspan levels are evenly numbered from 2 to 14 .

The water channel measurement system contains an internal calibration standard. Each time the probe is inserted into the fuel assembly, it passes through two pairs of calibration pins made of tungsten carbide. The separation dimensions of these pins were measured immediately after fabrication using NBS traceable standards.

\subsection{Holddown Spring Test}

Holddown spring measurements are performed while the assembly is resting in the LST. The holddown spring tester is pole-mounted and is attached to the top of the assembly and operated from poolside. Figure 4-6 shows a photograph of the holddown spring tester in operation, while Figure 4-7 is a schematic illustration of the tester. It is seen that the tester consists of a grapplelike fixture which locks onto the fuel assembly upper end fitting. A hydraulic cylinder, mounted inside the fixture, is used to apply force to the holddown spring. The cylinder is operated with a hand pump; its pressure is increased gradually to provide a maximum force of about $600 \mathrm{lb}$ on the holddown assembly and is then slowly released. The displacement of the spring is transmitted to a dial micrometer via a connecting rod attached to the end of the cylinder and extending through the support tube to the operator platform at poolside.

\subsection{Gamma Scan System}

Gamma scans are obtained using the system seen in the lower right part of Figure 4-1. A fuel assembly is shown suspended from the fuel handing hoist as it is being lowered past the gamma radiation detector to obtain a gamma scan of a corner rod of the assembly. Duplicate scans on each rod are obtained as the assembly is first lowered and then raised past the detector. After the assembly is raised out of the alignment bracket, it is rotated approximately $90^{\circ}$ and another corner rod is scanned in the same manner. Figure $4-8$ is a 
schematic illustration showing the alignment of the gamma scan system to detect the gamma radiation from only the corner rod of the assembly. Spring loaded guide rollers maintain this alignment during the lowering and lifting motions. The gamma radiation $\left(\mathrm{E}_{\gamma}>0.2 \mathrm{MeV}\right)$ is measured with a NaI detector. The detector, along with a preamplifier, is housed in a hermetically sealed cask which is positioned just above the fuel storage rack. The front portion of the cask is a shielded adjustable collimator. For this program, the slit opening of the collimator was set at a vertical opening of 0.033 -inch. This vertical opening essentially determines the system resolution for fuel stack gap measurements. The fuel assembly's rate of travel during a scan, which also affects the resolution, is established by controlling the speed of the variable speed hoist. Downscans were measured at $16 \mathrm{in./min.} \mathrm{while} \mathrm{upscans} \mathrm{were} \mathrm{taken}$ at $6 \mathrm{in./min.} \mathrm{Of} \mathrm{these} \mathrm{two} \mathrm{scans,} \mathrm{the} \mathrm{upscan} \mathrm{is} \mathrm{the} \mathrm{more} \mathrm{accurate} \mathrm{since} \mathrm{it} \mathrm{is}$ taken at the slower speed and since the hoist motion is more reproducible in the up direction. Therefore, the upscans are generally used for analysis while the downscans are primarily used to establish the signal processing parameters. Gap size measurement precision at the slower scanning speed of $6 \mathrm{in./min}$. is approximately $0.05 \mathrm{in.,}$ and stack length precision is approximately 0.15 in. (based on 0.033-in. collimator slit opening). 
Figure 4-1. Underwater PIE Equipment in Oconee

1 and 2 Spent Fuel Pool

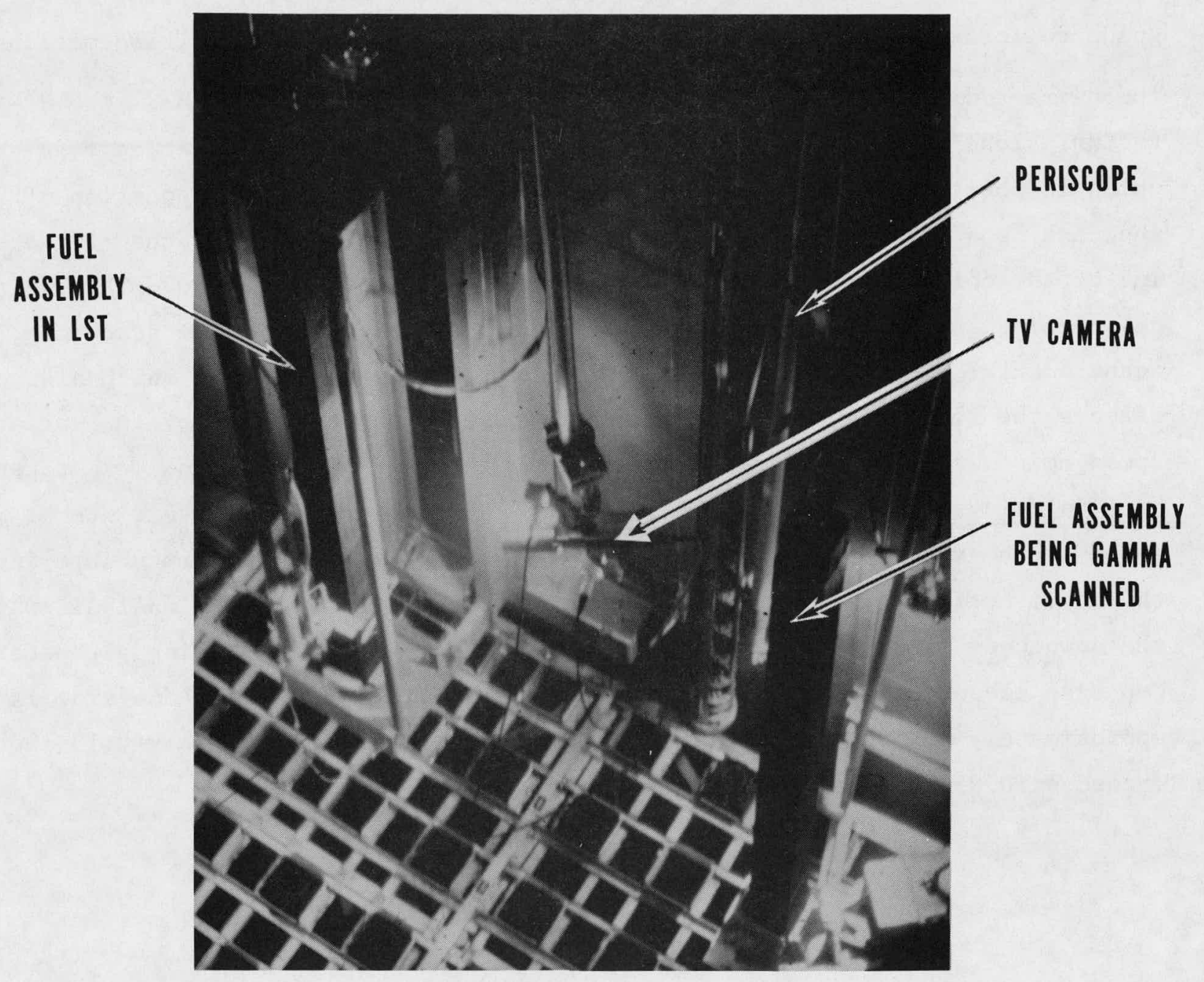


Figure 4-2. PIE Peripheral Equipment at Oconee 1 Poolside With PIE Work in Progress

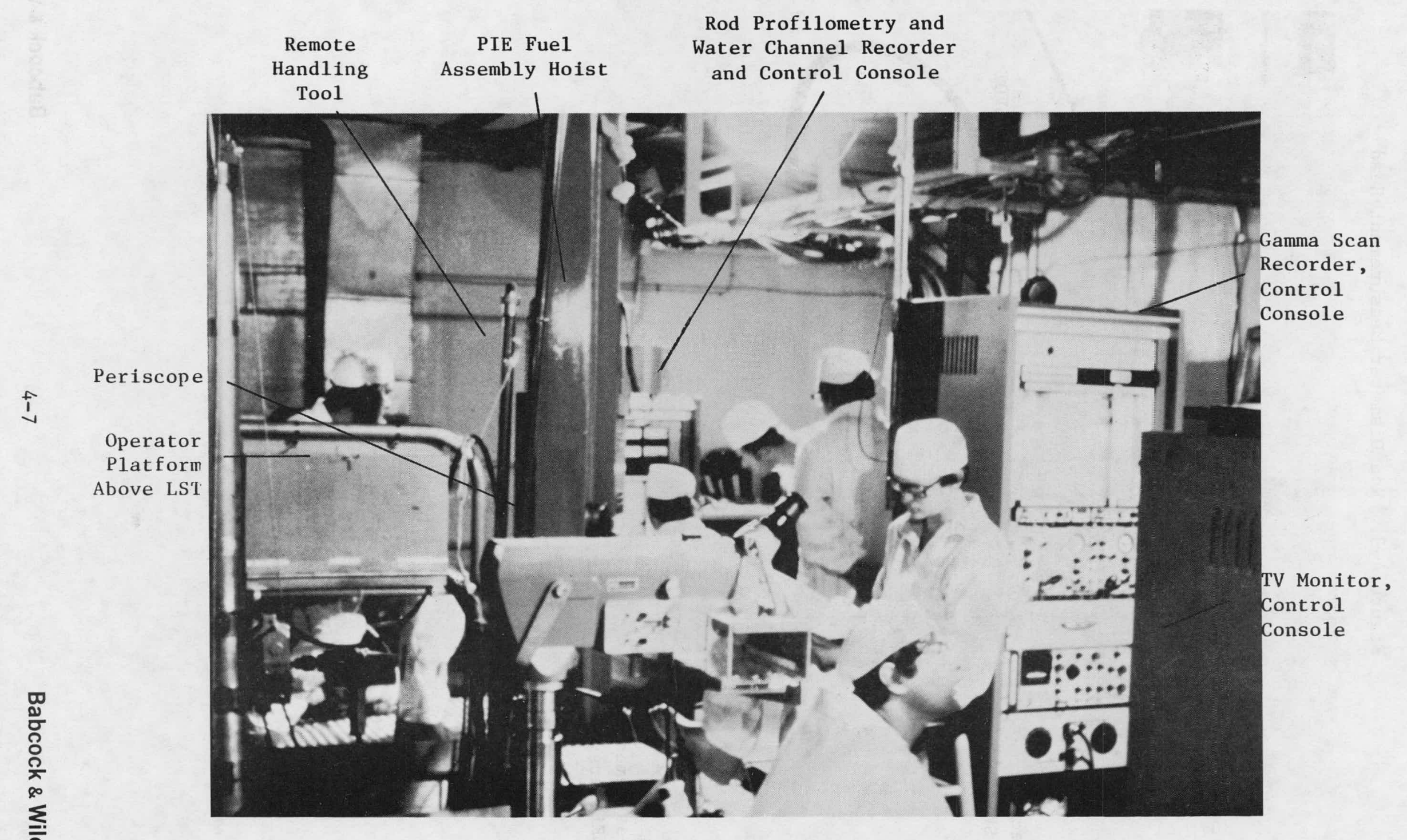


Figure 4-3. Rod Diameter Measurement Head

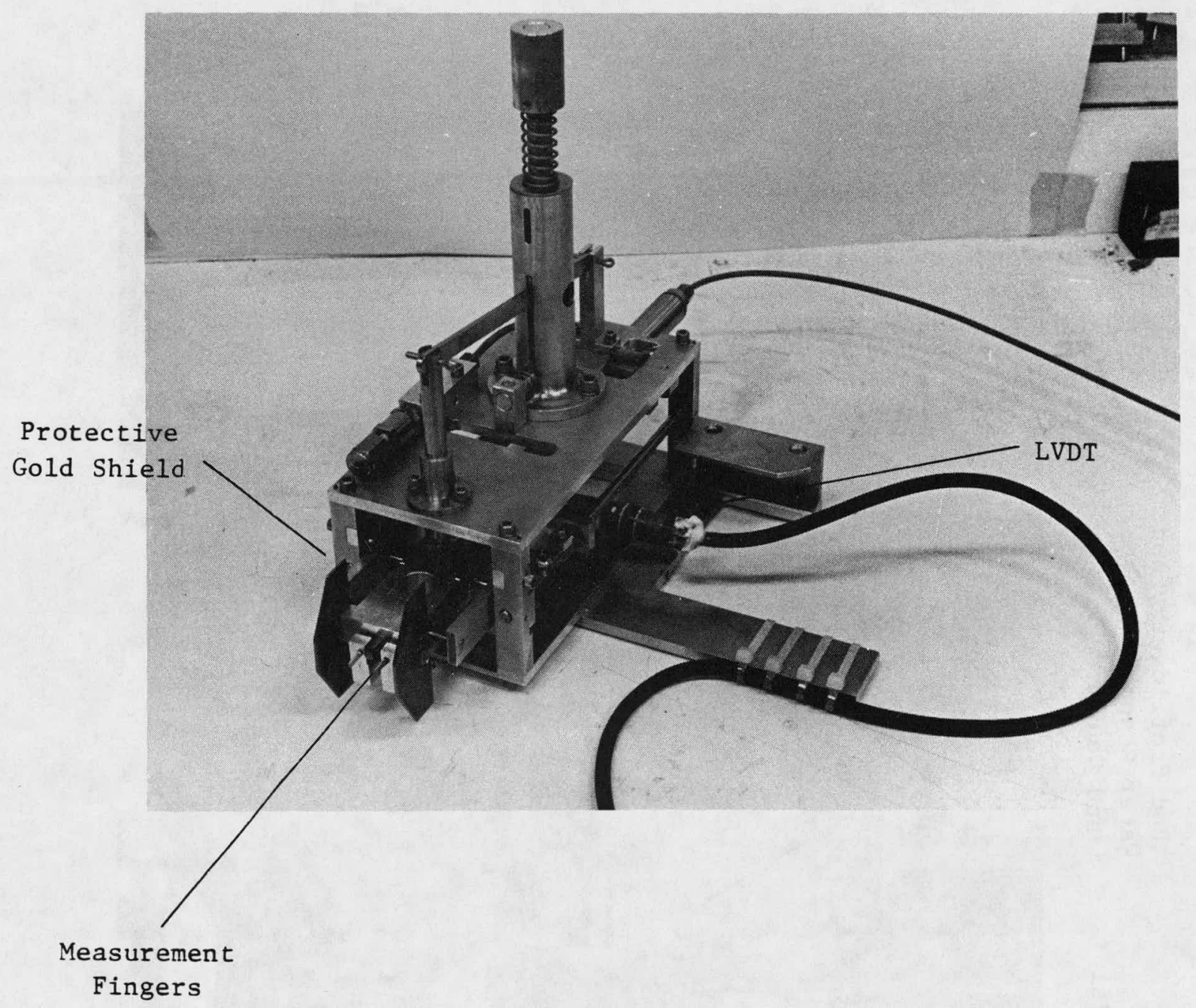


Figure 4-4. Fuel Assembly Cross Section With Sulo Probe Aligned for Water Channel Spacing Measurement

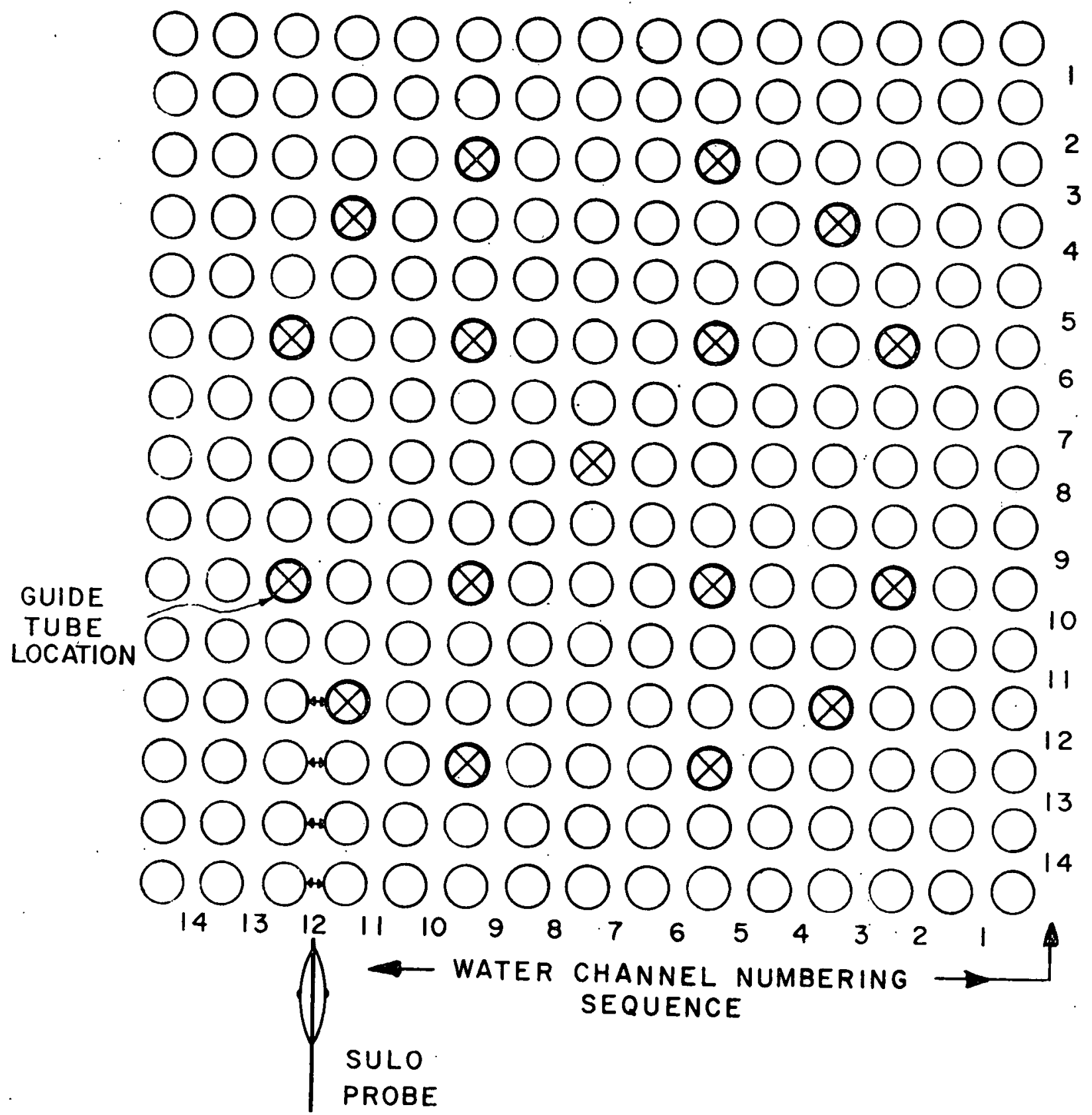

Note: Cross-section (from top) showing sulo probe aligned for insertion into channel 12. The probe passes through the assembly to measure 15 spacings and then retracts. The first four spacings ( 3 rod-to-rod and 1 rod-to-guide tube) are indicated with arrows. 
Figure 4-5. Mark B Fuel Assembly Showing Numbering Convention of Water Channel Midspan Levels

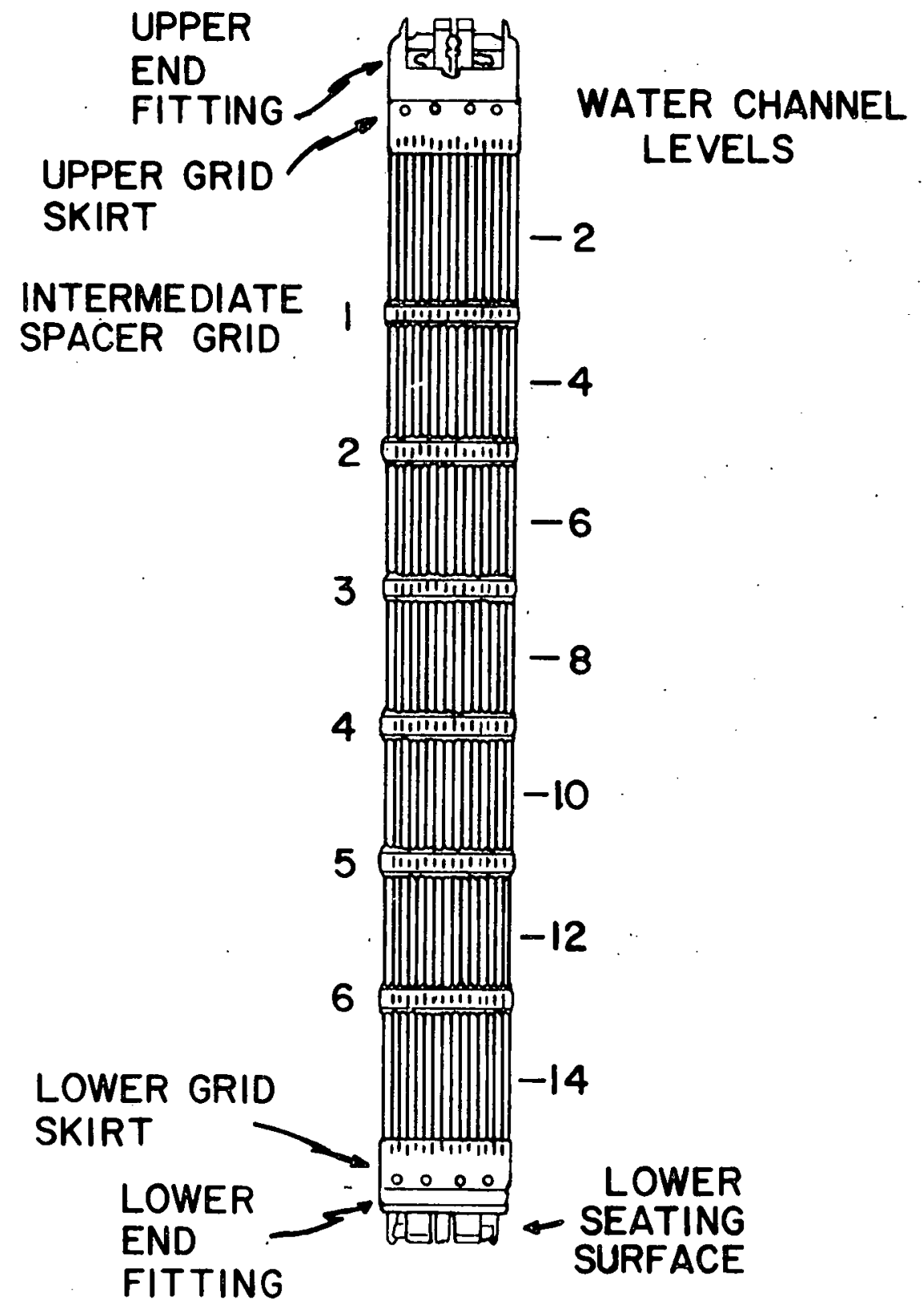

FITTING 
Figure 4-6. Holddown Spring Tester in Operation

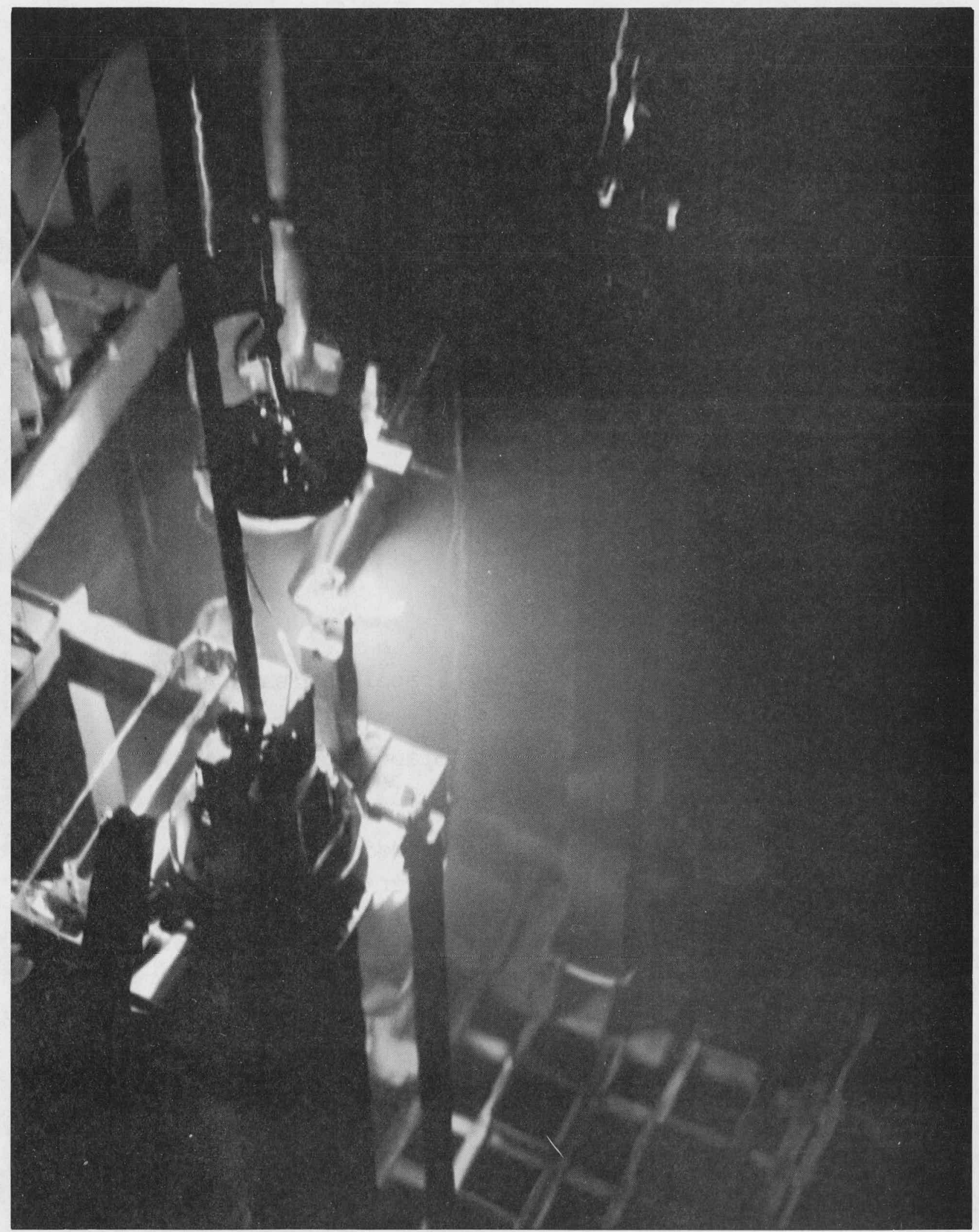


Figure 4-7. Holddown Spring Tester

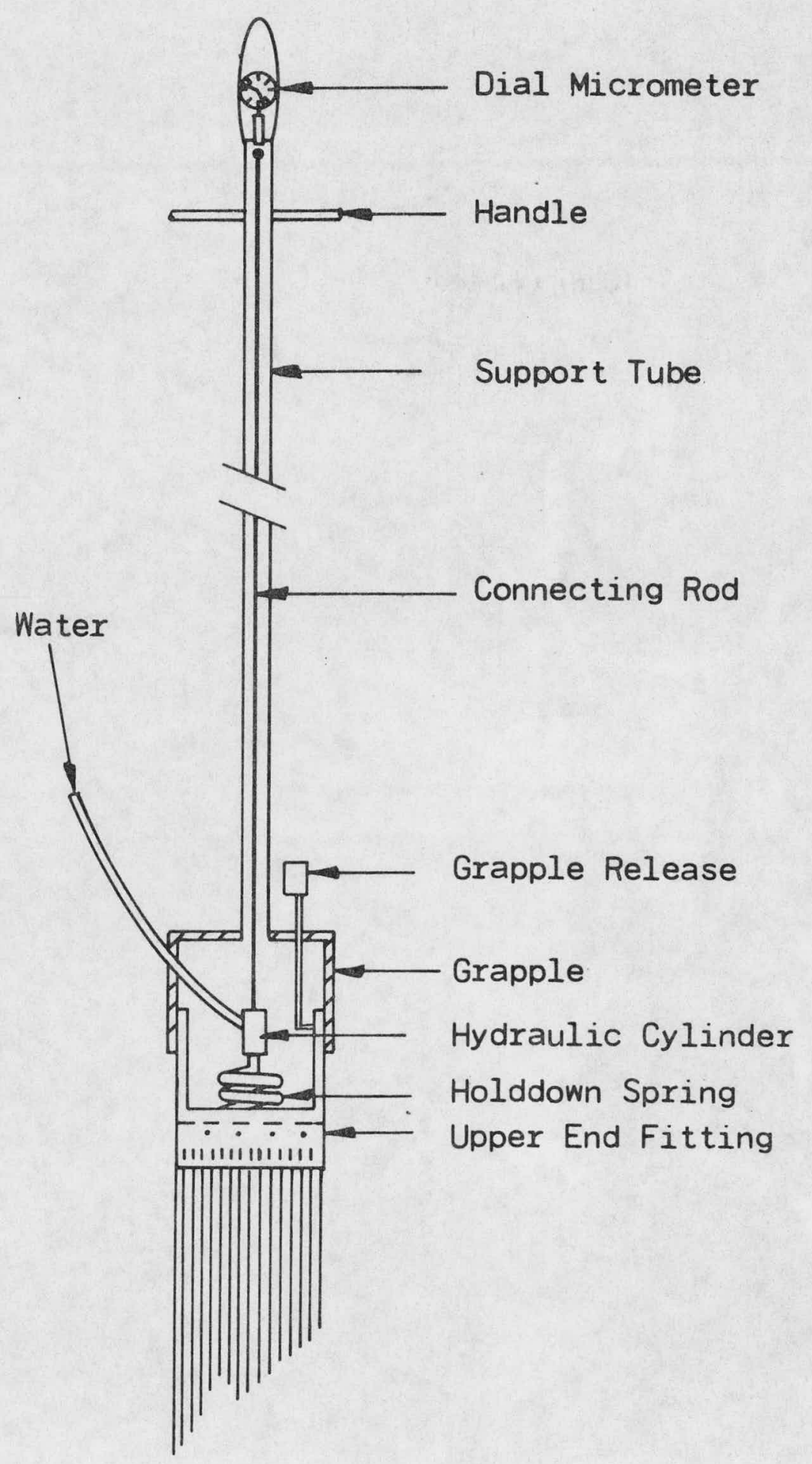


Figure 4-8. Gamma Scan Alignment

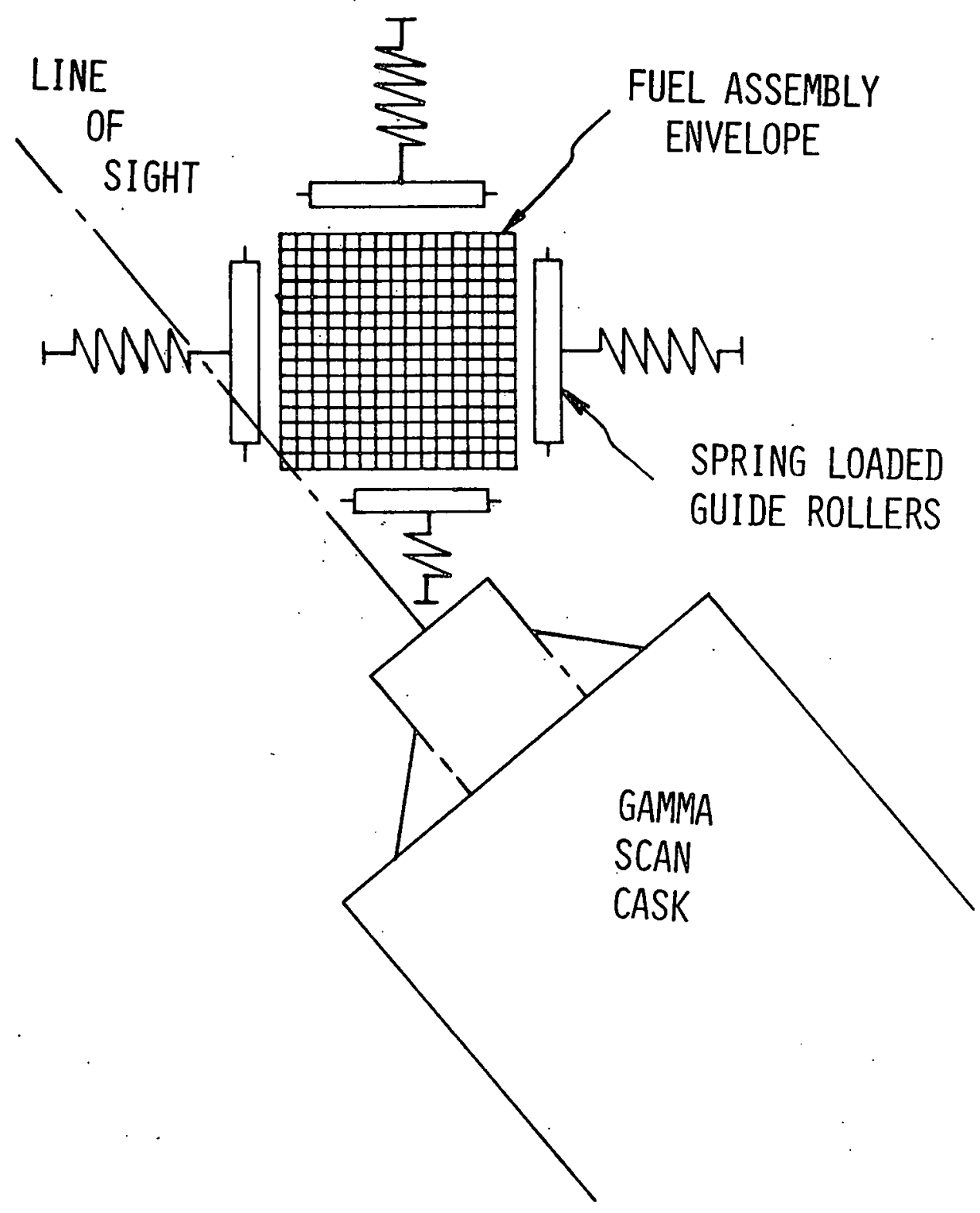




\section{RESULTS AND DISCUSSION}

\subsection{Fuel Assembly Leak Tests}

A fuel assembly leak-check (sipping) test was conducted by the Nuclear Assurance Corporation on each of the 57 batch 4 assemblies in order to obtain a large data base and to establish a confident baseline level of activity. Sixteen of these assemblies, representing two symmetrically equivalent core locations, had been previously designated as candidates for a fourth cycle of irradiation.

\subsubsection{Results}

The results of the sipping tests of the 57 batch 4 assemblies are summarized in Figure 5-1. Of the 16 candidate assemblies, three were determined to be leakers based on the level of ${ }^{137} \mathrm{Cs}$ activity in their water samples. The three identified as leakers were 1D20, 1D31, and 1D54. The latter was one of the original five assemblies selected for a fourth cycle, so it was replaced in the program by 1D55. Among the remaining 41 assemblies of batch 4, one additional leaker (1D49) was found.

\subsubsection{Discussion}

A visual examination of leaking assemblies 1D20 and 1D54 was conducted. No inuications of a defect on any of the visible portions of the peripheral rods were evident.

The present examination program has recently been expanded to include a more thorough examination of the leaking assemblies to determine the cause of the failures. This expanded program includes both a more thorough visual inspection of the four leakers and a detailed destructive examination of a selected assembly. The results of this examination will also enlarge the fuel performance data base at burnups of approximately $30,000 \mathrm{MWd} / \mathrm{mtU}$. 


\subsection{Visual Examinations}

Ten fuel assemblies (five primary and five alternate candidates as identified in Table 1-1) were visually examined on all four sides using underwater television as discussed in section 4.2. All such examinations were videotaped. In addition, an optical periscope examination was conducted on assemblies 1D26 and 1D55, along with portions of 1D13, 1D21, and 1D42. Selected areas were photographed during the periscope examination.

\subsubsection{Results}

All the assemblies were generally similar in appearance, exhibiting the typical. crud patterns seen in previous $B \& W$ fuel examinations. ${ }^{4}$ A common surface feature of the crud was a series of narrow circumferential bands 20.1 in. wide (see Figure 5-2). These bands were seen on all assemblies and were generally confined to the higher burnup region of the assemblies between grids 3 and 6 , although some were seen as far down as the center of the bottom grid span. The bands were evenly spaced axially at approximately pellet-length intervals and were apparently located at fuel pellet interfaces. Another crud pattern commonly seen was a wide (at least 2 in.) horizontal band or bands near the top of the fuel column and extending across the assembly face.

Minor physical damage was observed on fuel assemblies 1D21 and 1D42, both of which had passed the sipping test. Assembly 1D21 had minor grid tear on the corner of grid 1 and an indentation on peripheral rod Al3 immediately below grid 3 (Figure 5-3). Since the depth of the indentation could not be determined accurately at poolside, the assembly was not reinserted for a fourth cycle of irradiation; assembly $1 \mathrm{D} 26$ was selected as a substitute. Assembly $1 D 42$ had a small dent in the edge of the upper grid skirt near corner rod D15 as shown in Figure 5-4. Close examination revealed that the edge of the skirt was not touching the cladding surface. Thus, assembly $1 D 42$ was reinserted for a fourth cycle of operation.

\subsubsection{Discussion}

The surface crud patterns seen on the fuel rods are not uncommon. They are considered to be variations in crud coloration or composition possibly resulting from variations in coolant flow and heat flux. Flow distribution around. spacer grids is known to cause local crud pattern variations. ${ }^{4}$ The possible effect of heat flux on crud formation is illustrated by the patterns seen at 
the top of the fuel column where the heat flux varies considerably even though the cladding temperature and coolant flow are fairly constant. Since the interface region between two fuel pellets can be expected to have slight heat flux variations due to the small fuel void created by the pellet end-dish and chamfer and late-in-life pellet-clad contact, these variations may result in the formation of the narrow circumferential crud bands observed at the pellet interfaces.

\subsection{Fuel Assembly and Rod Length Measurements}

Fuel assembly length and intermediate spacer grid locations were measured on all four faces of each of the five extended burnup assemblies, as discussed in section 4.3. Similar measurements were also performed on the five sister assemblies (as identified in Table 1-1) and the results included in the data base. A11 measurements were corrected for the effects of tape stretch and thermal expansion. Since the measuring tape was read to an accuracy of within \pm 0.024 in. at the reference edges, the maximum expected error in the corrected measurements was less than \pm 0.048 in.

Two types of growth data were obtained from these measurements: (1) fuel assembly (guide tube) growth, and (2) assembly average fuel rod growth (total axial strain). The assembly growth results were obtained directly from tine locations of reference positions at each end of the fuel assembly. Rod growth results, however, were obtained indirectly from measurements of the fuel assembly spacer grid locations as described below.

Differential growth between the fuel assembly (guide tubes) and its fuel rods is accommodated by the spacer grids moving with the fuel rods and sliding along the guide tubes. Since the fuel rods rest on the grillage of the lower end fitting, thermal expansion and irradiation-induced differential growth of the fuel rods is accumulated upward from the rod bottoms into the designed gap between the top of the fuel rods and the grillage of the upper end fitting. Thus, each successive spacer grid from the bottom of the fuel assembly is displaced upward from its original position (relative to the bottom of the assembly) by an increasing amount as the rod growth accumulates, thereby providing a measure of the assembly average fuel rod growth. 


\subsubsection{Fuel Assemb1y Growth Results}

The results of the fuel assembly length measurements of the five extended burnup assemblies are summarized in Table 5-1. The average observed length change was $0.36 \% \Delta \mathrm{L} / \mathrm{L}$ at an assembly average fast neutron fluence $\left(\mathrm{E}_{\mathrm{n}}>1 \mathrm{MeV}\right)$ of $5.11 \times 10^{21}$ nvt. These results and those obtained from previous poolside measurements ${ }^{4}$ taken at Oconee 1 on other Mark B fuel assemblies are shown in Figure 5-5. The growth curve shown on this figure is the result of a linear regression analysis which incorporated all of the Oconee 1 poolside results obtained to date.

\subsubsection{Fuel Rod Growth Results}

The assembly average fuel rod growth results for the five extended burnup assemblies are summarized in Table 5-2. The average of the tabulated fuel rod growth was $0.51 \% \Delta \mathrm{L} / \mathrm{L}$ at an assembly average fast neutron fluence $\left(\mathrm{E}_{\mathrm{n}}>1 \mathrm{MeV}\right)$ of $5.11 \times 10^{21}$ nvt after three cycles of irradiation. These results and all of the fuel rod growth results obtained to date from Oconee poolside (nondestructive) and hot-cell (destructive) examinations ${ }^{4}, 5$ are shown in Figure 5-6. Linear regression analyses were performed for two cases: (1) using all of the results shown, and (2) using only the results from the hot-cell examinations in which the fuel rod lengths were measured directly and more accurately. The regression analysis for the second case yielded the curve shown in Figure 5-6 which is judged to more accurately describe fuel rod growth. The regression analysis for the first case yielded a curve of approximately the same slope but a slightly greater growth for a given fluence.

\subsubsection{Discussion}

A comparison of the fuel assembly and fuel rod growth curves (Figures 5-5 and 5-6) indicates that an adequate allowance exists in the fuel assembly design to accommodate the differential growth between the fuel assembly and its fuel rods. Thus, fuel rod growth is not considered to be a limiting condition for extending fuel assembly operation. However, the fuel assembly growth results indicate that assembly growth, which closes the gap between the assembly upper end fitting and the reactor internals, will likely impose an exposure limit on fuel assembly operation. The nondestructive and destructive examinations to be conducted after the fourth cycle of irradiation will quantify this limitation on extending the fuel assembly lifetime. 


\subsection{Fuel Rod Diameter Profilometry}

Fuel rod diameters of a number of peripheral rods were determined between the intermediate spacer grids of each of the five extended burnup assemblies using single-orientation line-scan profilometry as described in section 4.4 .

Orthogonal line-scans were obtained only on the four corner rods of each assembly. All of the profilometry data were digitized at 0.05-in. chart intervals (corresponding to $0.20 \mathrm{in}$. actual fuel rod distances) using a minicomputer with an interactive plotter. From the digitized data, fuel rod mean diameter, creepdown, and average maximum ovality (as defined in the appendix of this report) were determined as a function of axial position along each rod. Reduced profilometry traces were redrawn by the minicomputer, overlaying the orthogonal scans on the same axes for comparison. As an example, reduced traces of the corner fuel rods of assemb1y 1D26 are shown on Figure 5-7.

Note that the average maximum ovality obtained in the poolside examinations is defined as the $4 \sigma$ range (from $-2 \sigma$ to $+2 \sigma$ ) of the mean diameter (i.e., a $95 \%$ confidence interval about the mean diameter), rather than the conventionally defined peak ovality $\left(O D_{\max }-O D_{\min }\right)$ at a given transverse plane. A comparison of single-orientation line-scan profilometry and rotating step-scan profilometry measurements obtained during previous post-irradiation hot-cell (destruc-tive) examinations ${ }^{5}$ indicates that the statistically determined average maximum ovality is a reasonable approximation of the conventionally defined peak ovality, the estimated relative error being within $25 \%$.

\subsubsection{Cladding Creepdown Results}

A summary of the average mean diameter and the average diametric creepdown values for the peripheral rods of each fuel assembly is given in Table 5-3. The quantities, listed by grid-span location, are the mean values of all rods measured in their respective assemblies. The creepdown values are based on an as-built cladding lot average diameter of 0.4299 in. The average measured creepdown of the fuel rods in assembly 1 D42 was $3.2 \mathrm{mils}$ (assembly average burnup of $28,210 \mathrm{MWd} / \mathrm{mtU})$; the average of the other batch $4 \mathrm{D}$ assemblies was $3.8 \mathrm{mils}(31,160 \mathrm{MWd} / \mathrm{mtU})$. The maximum average creepdown observed between spacer grids was 4.5 mils.

A distinct axial variation in creepdown was noted on the fuel rods and is shown in Figure 5-8. Minimum observed creepdown occurred at the top of the fuel column, while the maximum occurred below the midpoint of the assembly 
between spacer grids 4 and 6 . This trend in the creepdown is similar to that observed on other fuel assemblies during previous post-irradiation examinations ${ }^{6}$.

The original strip chart traces were also examined closely for indications of contact between the fuel pellets and cladding. This pellet-cladding contact was inferred from small ripples in the profilometry traces which correlated with fuel pellet lengths (see Figure 5-9), particularly in regions where orthogonal traces exhibited little or no difference in diameter (low ovality). Numerous indications were observed on the four corner rods of assembly 1D55 extending over the region from grid 2 to grid 6 . Similar indications were noted on three of the four corner rods of assembly 1D26. Assembly 1D45 exhibited fewer indications, with these being concentrated near the peak creepdown region between grids 5 and 6 . No indications were evident on the fuel rods of assembly $1 \mathrm{D} 13$.

5.4.2. Cladding Ovality Results

The average maximum ovalities measured for the peripheral rods of each assembly are presented in Table 5-4. The values, 1isted by grid-span location, are the averages of all rods measured in their respective assemblies. The average maximum ovalities ranged from 0.0015 to 0.0029 in. with an overall mean of $0.0023 \mathrm{in.}$ The largest peak ovality determined from the orthogonal line-scans of the corner rods was approximately $0.005 \mathrm{in}$. The nominal ovality of the batch 4 as-built cladding lots was $0.0002 \pm 0.0002$ (20) in.

The average maximum ovality of the rods of each fuel assembly as a function of grid-span position is shown in Figure 5-10. No distinct axial variation in average maximum ovality is evident.

\subsubsection{Discussion}

The axial distribution of fuel rod creepdown (shown in Figure 5-8) peaked below the midpoint of the fuel column in the region of maximum burnup, rather than near the top of the fuel column in the region of higher temperature. This implies a greater dependence of creepdown on burnup than on temperature. It should be noted, however, that the interaction of ovalization and creepdown could cause the maximum creepdown to occur at a location removed from the area of maximum creep rate. This effect could result from two-point contact of the cladding with the fuel stack during more rapid ovalization, thereby changing 
the local stress state in the cladding and retarding further ovalization and creepdown. Since ovalization is expected to occur more rapidly at higher cladding temperatures, this effect would be more pronounced in the upper region of the fuel rod. Thus, the observed creepdown would be less in this region than in the lower portions of the rod. Indications of this effect were seen in previous hot-cell examinations. This area will be examined in greater detail in the forthcoming destructive examination.

Several design changes, relative to the original full design, were made in the batch 4 fuel to further improve fuel performance. These changes resulted in the reductions of fuel rod cladding creepdown and ovality which were observed in the batch 4D assemblies. The design changes consisted of: (1) increasing the density of the fuel pellets to $95.5 \% \mathrm{TD}$, and (2) increasing the internal helium prepressure of the fuel rods. By increasing the fuel pellet density, the densification behavior of the fuel is improved and the ultimate density (reached early in life) is reduced. Thus, a reduced void volume is maintained within the fuel rods. Increasing the fuel rod prepressure while maintaining the reduced void volume reduces the potential for cladding creepdown and ovalization. In comparison to the results recorded for the Oconee 1 batch 3 fuel rods, the rods of the batch 4D assemblies exhibited a slightly lower value of average creepdown ( 0.0038 Vs 0.0042 in.) and a significantly lower value of average ovality ( 0.0023 vs $0.0044 \mathrm{in.})$. The batch 3 fuel assemblies operated in the first three cycles of Oconee 1 and achieved an assembly average burnup of $25,100 \mathrm{MWd} / \mathrm{mtU}$ (compared to the batch 4D assembly average burnup of 30,600 MWd/mtU).

\subsection{Water Channel Spacings}

Measurements of the water channel spacings between fuel rods were performed on each of the five extended burnup assemblies as described in section 4.5 . This included full characteriaztion of four of the assemblies (1D13, 1D42, 1D45, and 1D55). Measurements on the fifth assembly (1D26) were conducted only at midspan level 12 (between spacer grids 5 and 6 , as shown in Figure 4-5) where maximum rod bow has historically been observed. All water channel spacing measurements were taken at the axial midspans between spacer grids except for those taken at level 2. Because of equipment 1imitations, measurements for this level were taken approximately 3 in. below the midspan. 
The reported data were corrected for the effect of the measurement probe which spreads the fuel rods slightly as it measures the spacings. Fuel rod bow, expressed as the standard deviation ( $\sigma$ ) of the corrected water channel spacing measurements, was converted to percent of water channel (gap) closure using a statistical method which assumes that the magnitude of the fuel rod bow is described by a normal distribution having a mean of zero and that the pre-irradiation water channel spacings had the nominal value of $0.138 \mathrm{in}$. The relation used is

$$
\% \text { closure }=(1.645 / 0.138) \times 100 \%
$$

where the factor 1.645 is a statistical factor of the nominal distribution, which is introduced to ensure that the calculated value of \% closure is more than $95 \%$ of the water channel spacings. Thus, the gap closure values represent a conservative estimate of fuel rod bow.

\subsubsection{Results}

The results of the water channel spacing measurements are summarized in Table 5-5. Statistically, $95 \%$ of the water channels had a gap closure (\%) less than the values tabulated. Of the fuel assemblies examined, assembly 1D42 exhibited the greatest average gap closure of $26.2 \%$. The average of the four fully characterized assemblies was $23.6 \%$.

The worst-span water channel closure observed on all of the assemblies examined to date in $B \& W$ post-irradiation examinations is shown in Figure 5-11 as a function of fuel assembly average burnup. While the closure increased in an approximately linear manner with burnup through three cycles of irradiation, an increase in scatter in the data beyond $23,000 \mathrm{MWd} / \mathrm{mtU}$ is apparent. Worst-span closure for the batch $4 \mathrm{D}$ assemblies averaged $30.3 \%$ (95\% UTL) at the batch average burnup of $30,600 \mathrm{MWd} / \mathrm{mtU}$.

The axial distribution of fuel rod bow, expressed as $\%$ of water channel closure, is shown in Figure 5-12 for the four fully characterized assemblies. This axial distribution is reasonably consistent with that of other fuel assemblies examined after three cycles of irradiation and generally follows the axial fluence profiles with closure increasing in the lower portion of the assemblies. 


\subsubsection{Discussion}

The axial distribution of water channel closure has historically been closely related to the respective assembly fluence profiles with maximum closure occurring between spacer grids 5 and 6 (midspan level 12). The closure behavior exhibited by the extended burnup assemblies (shown in Figure 5-12) differs slightly from that observed in the past. Although the maximum closure is still skewed toward the bottom of the assemblies, it has shifted slightly towards the middle for assemblies 1D42 and 1D45. For assemblies $1 D 13$ and 1D55, a slight tendency towards a bimodal axial distribution has started to appear with closure exhibiting maxima at midspan levels 6 and 12 and decreasing slightly at levels 8 and 10. This change in axial distribution and the increasing scatter in the worst-span closure data may indicate that a secondary mechanism is beginning to predominate late in life. Examination of the extended burnup assemblies after four cycles of irradiation will provide additional information to assist in determining the manner in which water channel closure is occurring and its driving mechanism.

\subsection{Holddown Spring Force}

Holddown spring load-deflection curves were obtained, as discussed in section 4.6, for each of the five extended burnup assemblies to aid in determining the holddown spring relaxation. The measured holddown spring preload force and spring rate were used in conjunction with the measured length of each fuel assembly to calculate the holddown spring net force at normal operating temperature (operating force).

\subsubsection{Results}

The results of the spring force measurements and net operating force calculations are summarized in Table 5-6. Spring preload force decreased an average of $35.3 \%$ Erom the as-built preload value of $575 \mathrm{lb}$. However, the net operating force remained essentially unchanged from its beginning-of-life value of $595.1 \mathrm{~b}$, having decreased less than $2 \%$ after three cycles of irradiation. Holddown spring net operating force as a function of fuel assembly burnup is shown in Figure 5-13.

\subsubsection{Discussion}

Analyses indicate that the decrease in spring preload force is neither creep dependent nor is it dependent on fluence. Rather, it is apparently caused by 
plastic set within the spring which occurs at cold shutdown. The resulting decrease in spring preload force, however, is countered by fuel assembly growth which further compresses the spring. Thus, during operation, the net holddown force remains relatively constant with increasing fluence throughout the operating lifetime of the fuel assembly, as shown in Figure 5-13.

\subsection{Gamma Scans}

Fuel column axial gap and fuel stack length measurements were obtained on the four corner rods of each of the batch 4D assemblies utilizing the gamma scan system described in section 4.7. The system output of gamma count rate $\left(E_{\gamma}>0.2 \mathrm{MeV}\right)$ as a function of axial location (hoist readout) was plotted on a strip chart recorder. Recorder traces from each scan were used to determine the axial length and location of fuel column gaps as well as the overall length of the fuel column. Gap size measurement precision at the slower scanning speed of $6 \mathrm{in./min.} \mathrm{was} \mathrm{approximately} 0.05$ inch and stack length precision 0.1 to 0.2 inch.

A portion of the gamma scan trace of the CD-corner fuel rod of assembly 1D13 is shown in Figure 5-14 as an example of the sensitivity and resolution of the system. The low amplitude negative peaks occurring at consistent intervals along the trace indicate the normal interfaces between individual pellets. These interface peaks result from the dished voids at the ends of each pellet which are only 0.018 in. deep and which combine to form a volume-equivalent cylindrical gap of about 0.012 in. The negative peak of greater amplitude indicates an axial gap between pellets of 0.1 in. in length. This gap is located approximately 1 in. below the top of the fuel column.

\subsubsection{Results :}

Gap size and location data for the 20 rods scanned in the five extended burnup assemblies are given in Table 5-7. A total of only eight gaps were seen, all less than about $0.1 \mathrm{in.}$ long. The locations of the gaps along the length of the fuel columns were variable, displaying no distinct axial pattern.

Values for the fuel column stack lengths (with total gap lengths subtracted) are given in Table 5-8. The overall average stack length of 141.2 in. indicates no net change after three cycles of irradiation. 


\subsubsection{Discussion}

The small number and sizes of the axial gaps observed and their near-random distribution indicate that the fuel performed as designed through three cycles of irradiation. The zero net change in fuel column average stack length from the fuel rod lot average pre-irradiation value of $141.2 \mathrm{in}$. is in good agreement with predicted results.

The locations and sizes of these axial gaps will be compared with corresponding values to be obtained at the end of the fourth cycle of irradiation exposure. The individual stack length values will also be compared to obtain a fourth cycle fuel swelling component.

Table 5-1. Summary of Fuel Assembly Growth Results

\begin{tabular}{ccc}
$\begin{array}{c}\text { Fuel } \\
\text { assembly }\end{array}$ & $\begin{array}{c}\text { Assemb1y average } \\
\text { fluence }(>1 \mathrm{MeV}) \\
\dot{\times} 10^{-21} \mathrm{nvt}\end{array}$ & $\begin{array}{c}\text { Assembly } \\
\text { growth, } \\
\% \Delta \mathrm{L} / \mathrm{L}\end{array}$ \\
\cline { 2 - 2 } 1D13 & 5.20 & 0.40 \\
ID26 & 5.20 & 0.35 \\
1D42 & 4.71 & 0.35 \\
1D45 & 5.20 & 0.30 \\
1D55 & 5.20 & 0.38 \\
Average & 5.11 & 0.36
\end{tabular}

Table 5-2. Summary of Fuel Rod Growth Results

\begin{tabular}{ccc}
$\begin{array}{c}\text { Fuel } \\
\text { assemb1y }\end{array}$ & $\begin{array}{c}\text { Assembly average } \\
\text { fluence }(>1 \mathrm{MeV}), \\
\times 10^{-21} \mathrm{nvt}\end{array}$ & $\begin{array}{c}\text { Average fuel } \\
\text { rod growth, } \\
\% \Delta \mathrm{L} / \mathrm{L}\end{array}$ \\
\cline { 2 - 2 } 1D13 & 5.20 & 0.52 \\
$1 \mathrm{D} 26$ & 5.20 & 0.50 \\
$1 \mathrm{D} 42$ & 4.71 & 0.48 \\
$1 \mathrm{D} 45$ & 5.20 & 0.56 \\
1D55 & 5.20 & 0.51 \\
Average & 5.11 & 0.51
\end{tabular}


Table 5-3. Average Mean Diameter and Creepdown by Grid-Span Location

\begin{tabular}{|c|c|c|c|c|c|}
\hline \multirow{2}{*}{$\begin{array}{c}\text { Grid-span } \\
\text { location } \\
\end{array}$} & \multicolumn{5}{|c|}{ Fue1 assembly } \\
\hline & $1 \mathrm{D} 13$ & $1 \mathrm{D} 26$ & 1042 & 1045 & 1055 \\
\hline \multicolumn{6}{|l|}{ Top-grid 1} \\
\hline $\begin{array}{l}\text { Diameter, in. } \\
\sigma \\
\text { Creepdown }^{(a)} \text {, mils }\end{array}$ & $\begin{array}{l}0.4273 \\
0.0006 \\
2.6\end{array}$ & $\begin{array}{l}0.4273 \\
0.0005 \\
2.6\end{array}$ & $\begin{array}{l}0.4280 \\
0.0003 \\
1.9\end{array}$ & $\begin{array}{l}0.4276 \\
0.0006 \\
2.3\end{array}$ & $\begin{array}{l}0.4276 \\
0.0007 \\
2.3\end{array}$ \\
\hline \multicolumn{6}{|l|}{ Grid 1-2 } \\
\hline $\begin{array}{l}\text { Diameter, in. } \\
\sigma \\
\text { Creepdown, mils }\end{array}$ & $\begin{array}{l}0.4261 \\
0.0004 \\
3.8\end{array}$ & $\begin{array}{l}0.4261 \\
0.0005 \\
3.8\end{array}$ & $\begin{array}{l}0.4272 \\
0.0002 \\
2.7\end{array}$ & $\begin{array}{l}0.4266 \\
0.0005 \\
3.3\end{array}$ & $\begin{array}{l}0.4265 \\
0.0006 \\
3.4\end{array}$ \\
\hline \multicolumn{6}{|l|}{ Grid 2-3 } \\
\hline $\begin{array}{l}\text { Diameter, in. } \\
\sigma \\
\text { Creepdown, mils } \\
\text { Grid 3-4 }\end{array}$ & $\begin{array}{l}0.4258 \\
0.0004 \\
4.1\end{array}$ & $\begin{array}{l}0.4257 \\
0.0003 \\
4.2\end{array}$ & $\begin{array}{l}0.4266 \\
0.0002 \\
3.3\end{array}$ & $\begin{array}{l}0.4262 \\
0.0004 \\
3.7\end{array}$ & $\begin{array}{l}0.4260 \\
0.0005 \\
3.9\end{array}$ \\
\hline $\begin{array}{l}\text { Diameter, in. } \\
\sigma \\
\text { Creepdown, mils } \\
\text { Grid 4-5 }\end{array}$ & $\begin{array}{l}0.4256 \\
0.0003 \\
4.3\end{array}$ & $\begin{array}{l}0.4255 \\
0.0003 \\
4.4\end{array}$ & $\begin{array}{l}0.4264 \\
0.0002 \\
3.5\end{array}$ & $\begin{array}{l}0.4259 \\
0.0004 \\
4.0\end{array}$ & $\begin{array}{l}0.4259 \\
0.0004 \\
4.0\end{array}$ \\
\hline $\begin{array}{l}\text { Diameter, in. } \\
\sigma \\
\text { Creepdown, mils }\end{array}$ & $\begin{array}{l}0.4255 \\
0.0003 \\
4.4\end{array}$ & $\begin{array}{l}0.4254 \\
0.0003 \\
4.3\end{array}$ & $\begin{array}{l}0.4262 \\
0.0004 \\
3.7\end{array}$ & $\begin{array}{l}0.4257 \\
0.0003 \\
4.2\end{array}$ & $\begin{array}{l}0.4258 \\
0.0005 \\
4.1\end{array}$ \\
\hline \multicolumn{6}{|l|}{ Grid 5-6 } \\
\hline $\begin{array}{l}\text { Diameter, in. } \\
\sigma \\
\text { Creepdown, mils }\end{array}$ & $\begin{array}{l}0.4254 \\
0.0003 \\
4.5\end{array}$ & $\begin{array}{l}0.4255 \\
0.0003 \\
4.4\end{array}$ & $\begin{array}{l}0.4263 \\
0.0003 \\
3.6\end{array}$ & $\begin{array}{l}0.4257 \\
0.0003 \\
4.2\end{array}$ & $\begin{array}{l}0.4257 \\
0.0004 \\
4.2\end{array}$ \\
\hline \multicolumn{6}{|l|}{ Grid 6-bottom } \\
\hline $\begin{array}{l}\text { Diameter, in. } \\
\sigma \\
\text { Creepdown, mils }\end{array}$ & $\begin{array}{l}0.4259 \\
0.0005 \\
4.0\end{array}$ & $\begin{array}{l}0.4257 \\
0.0004 \\
4.2\end{array}$ & $\begin{array}{l}0.4265 \\
0.0004 \\
3.4\end{array}$ & $\begin{array}{l}0.4258 \\
0.0006 \\
4.1\end{array}$ & $\begin{array}{l}0.4259 \\
0.0005 \\
4.0\end{array}$ \\
\hline Assembly avg & & & & & \\
\hline $\begin{array}{l}\text { Diameter, in. } \\
\sigma \\
\text { Creepdown, mils }\end{array}$ & $\begin{array}{l}0.4259 \\
0.0012 \\
4.0\end{array}$ & $\begin{array}{l}0.4259 \\
0.0010 \\
4.0\end{array}$ & $\begin{array}{l}0.4267 \\
0.0008 \\
3.2\end{array}$ & $\begin{array}{l}0.4262 \\
0.0012 \\
3.7\end{array}$ & $\begin{array}{l}0.4262 \\
0.0014 \\
3.7\end{array}$ \\
\hline$n^{(b)}$ & 21 & 32 & 12 & 17 & 32 \\
\hline
\end{tabular}

(a) All of the listed creepdown values are based on an as-built cladding average diameter of 0.4299 in.

(b) Number of fuel rods measured in each assembly. 
Table 5-4. Average Maximum Ovality by Grid-Span Location

\begin{tabular}{|c|c|c|c|c|c|}
\hline \multirow{2}{*}{$\begin{array}{c}\text { Grid-span } \\
\text { location }\end{array}$} & \multicolumn{5}{|c|}{ Fuel assembly } \\
\hline & $1 \mathrm{D} 13$ & $1 \mathrm{D} 26$ & $1 D 42$ & 1045 & 1055 \\
\hline Top-grid 1 & $0.0015^{(a)}$ & 0.0022 & 0.0015 & 0.0020 & 0.0019 \\
\hline Grid $1-2$ & 0.0024 & 0.0023 & 0.0022 & 0.0026 & 0.0023 \\
\hline Grid 2-3 & 0.0026 & 0.0021 & 0.0022 & 0.0023 & 0.0021 \\
\hline Grid $3-4$ & 0.0026 & 0.0022 & 0.0024 & 0.0024 & 0.0021 \\
\hline Grid 4-5 & 0.0027 & 0.0024 & 0.0026 & 0.0026 & 0.0021 \\
\hline Grid 5-6 & 0.0024 & 0.0021 & 0.0024 & 0.0024 & 0.0021 \\
\hline Grid 6-bottom & 0.0026 & 0.0020 & 0.0025 & 0.0029 & 0.0019 \\
\hline Assembly avg & 0.0024 & 0.0022 & 0.0023 & 0.0024 & 0.0021 \\
\hline$n^{(b)}$ & 21 & 32 & 12 & 17 & 32 \\
\hline
\end{tabular}

(a) Average maximum ovality is defined as the $4 \sigma$ range of the mean diameter (i.e., a 95\% confidence interval about the mean diameter). The units of the values given are inches.

(b) Number of fuel rods measured in each fuel assembly. 
Table 5-5. Summary of Fuel Assembly Water Channel Spacing Measurements

\begin{tabular}{|c|c|c|c|}
\hline $\begin{array}{l}\text { Midspan (a) } \\
\text { leve1 }\end{array}$ & $\begin{array}{c}\text { Mean } \\
\text { spacing, } \\
\text { mils } \\
\end{array}$ & $\begin{array}{c}\text { Rod } \\
\text { bow (o.), } \\
\text { mils } \\
\end{array}$ & $\begin{array}{c}\begin{array}{c}\text { Gap } \\
\text { closure } \\
\% \\
\%\end{array} \\
\end{array}$ \\
\hline \multicolumn{4}{|c|}{ Assemb1y $1 \mathrm{D} 13$} \\
\hline 2 & 137.4 & 6.8 & 8.1 \\
\hline 4 & 139.9 & 12.9 & 15.4 \\
\hline 6 & 141.8 & 22.6 & 26.9 \\
\hline 8 & 141.1 & 20.5 & 24.6 \\
\hline 10 & 141.6 & 20.0 & 23.8 \\
\hline 12 & 141.1 & 21.1 & 25.2 \\
\hline 14 & 140.3 & 11.6 & 13.9 \\
\hline Avg & 140.4 & 17.5 & 20.8 \\
\hline
\end{tabular}

Assembly 1045

$\begin{array}{rrrr}2 & 137.0 & 5.7 & 6.8 \\ 4 & 139.4 & 12.3 & 14.6 \\ 6 & 140.7 & 25.0 & 29.8 \\ 8 & 139.4 & 28.7 & 34.2 \\ 10 & 141.5 & 28.6 & 34.1 \\ 12 & 141.3 & 26.4 & 31.4 \\ 14 & 139.0 & 15.4 & 18.4 \\ \text { Avg } & 139.8 & 21.9 & 26.2\end{array}$

Assemb1y 1D42

$\begin{array}{rrrr}2 & 137.6 & 5.8 & 6.9 \\ 4 & 139.1 & 9.6 & 11.5 \\ 6 & 141.7 & 22.0 & 26.2 \\ 8 & 140.4 & 28.8 & 34.3 \\ 10 & 138.7 & 31.6 & 37.7 \\ 12 & 142.8 & 27.1 & 32.3 \\ 14 & 139.5 & 15.2 & 18.1 \\ \text { Avg } & 140.0 & 22.0 & 26.2\end{array}$

Assemb1y 1D55

$\begin{array}{rrrr}2 & 137.2 & 5.8 & 6.9 \\ 4 & 139.1 & 10.3 & 12.3 \\ 6 & 140.2 & 21.5 & 25.7 \\ 8 & 141.8 & 21.6 & 25.7 \\ 10 & 141.6 & 20.4 & 24.3 \\ 12 & 142.7 & 21.0 & 25.0 \\ 14 & 140.2 & 12.2 & 14.5 \\ \text { Avg } & 140.4 & 17.3 & 20.6\end{array}$

Assemb1y 1D26

$\begin{array}{llll}12 & 142.4 & 22.5 & 26.8\end{array}$

(a) Refer to Figure 4-5.

(b) Statistically, 95\% of the water channels have a gap closure less than the. value tabulated. 
Table 5-6. Summary of Holddown Spring. Force Measurements

\begin{tabular}{cccccc}
$\begin{array}{c}\text { Fue1 } \\
\text { assembly }\end{array}$ & $\begin{array}{c}\text { Spring } \\
\text { rate, } \\
\text { lb/in. }\end{array}$ & $\begin{array}{c}\text { Measured } \\
\text { preload, } \\
\text { lb }\end{array}$ & $\begin{array}{c}\text { Change in } \\
\text { preload, } \\
\% \Delta F / F\end{array}$ & $\begin{array}{c}\text { Net operating } \\
\text { force, lb }\end{array}$ \\
\cline { 1 - 2 } $1 \mathrm{D} 13$ & 282 & 348 & & -39.5 & 562 \\
$1 \mathrm{D} 26$ & 308 & 385 & -33.0 & 600 \\
$1 D 42$ & 298 & 374 & -35.0 & 583 \\
$1 D 45$ & 285 & 393 & -31.6 & 574 \\
$1 D 55$ & 320 & 361 & -37.2 & 611 \\
Average & 299 & 372 & -35.3 & 586
\end{tabular}
(a) The nominal as-built spring rate is $277 \mathrm{lb} / \mathrm{in}$.
(b) Using a mean as-built preload force (F) of $575 \mathrm{lb}$.
(c) The nominal BOL value is $5951 \mathrm{~b}$. 
Table 5-7. Fuel Column Axial Gap Data From Gamma Scans

\begin{tabular}{|c|c|c|c|}
\hline $\begin{array}{c}\text { Fuel } \\
\text { assembly }\end{array}$ & Rod, & $\begin{array}{c}\text { Gap size, } \\
\text { in. }\end{array}$ & Gap location \\
\hline \multirow[t]{4}{*}{$1 \mathrm{D} 13$} & $\mathrm{AB}$ & None & \\
\hline & $\mathrm{BC}$ & None & \\
\hline & $\mathrm{CD}$ & 0.1 & 1 inch from top of fuel column \\
\hline & $\mathrm{AD}$ & 0.1 & 54 inches from bottom \\
\hline \multirow[t]{4}{*}{$1 D 26$} & $\mathrm{AB}$ & None & \\
\hline & $\mathrm{BC}$ & None & \\
\hline & $\mathrm{CD}$ & None & \\
\hline & $\mathrm{AD}$ & None & \\
\hline \multirow[t]{4}{*}{$1 D 42$} & $A B$ & None & \\
\hline & $\mathrm{BC}$ & None & \\
\hline & $\mathrm{CD}$ & None & \\
\hline & $\mathrm{AD}$ & None & \\
\hline \multirow[t]{5}{*}{ 1D45 } & $A B$ & None & \\
\hline & $\mathrm{BC}$ & None & \\
\hline & $C D$ & None & \\
\hline & $\mathrm{AD}$ & 0.1 & 14 inches from top \\
\hline & & 0.1 & 19 inches from top \\
\hline \multirow[t]{4}{*}{$1 D 55$} & $\mathrm{AB}$ & 0.08 & 66 inches from bottom \\
\hline & $\mathrm{BC}$ & 0.08 & $5-1 / 2$ inches from top (a) \\
\hline & $\mathrm{CD}$ & 0.1 & 33 inches from bottom (a) \\
\hline & $\mathrm{AD}$ & 0.05 & 78 inches from top \\
\hline
\end{tabular}


Table 5-8. Fuel Column Stack Length Data From Gamma Scans

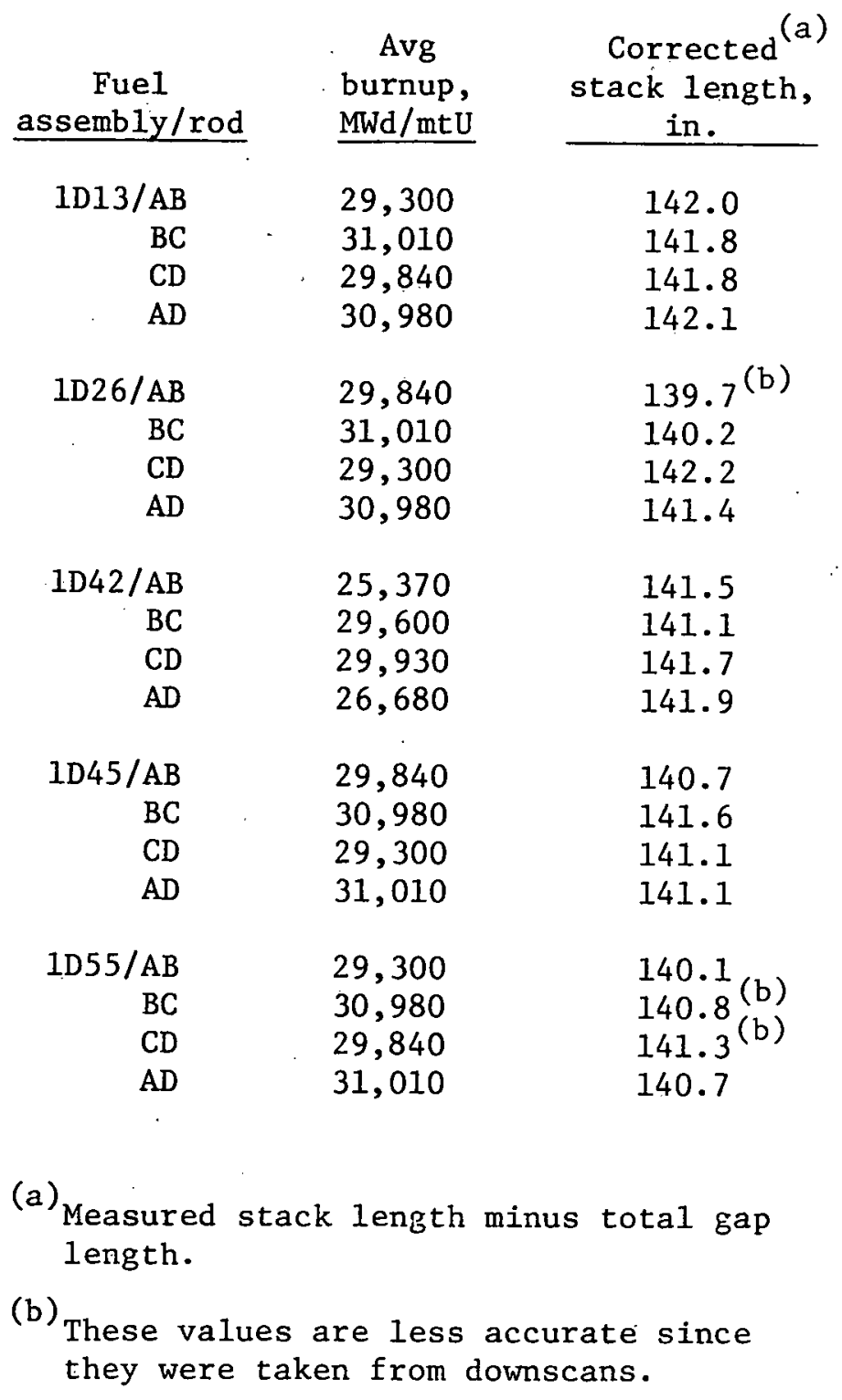


Figure 5-1. Histogram of Sipping Results for Oconee 1 Batch 4 Fuel Assemblies

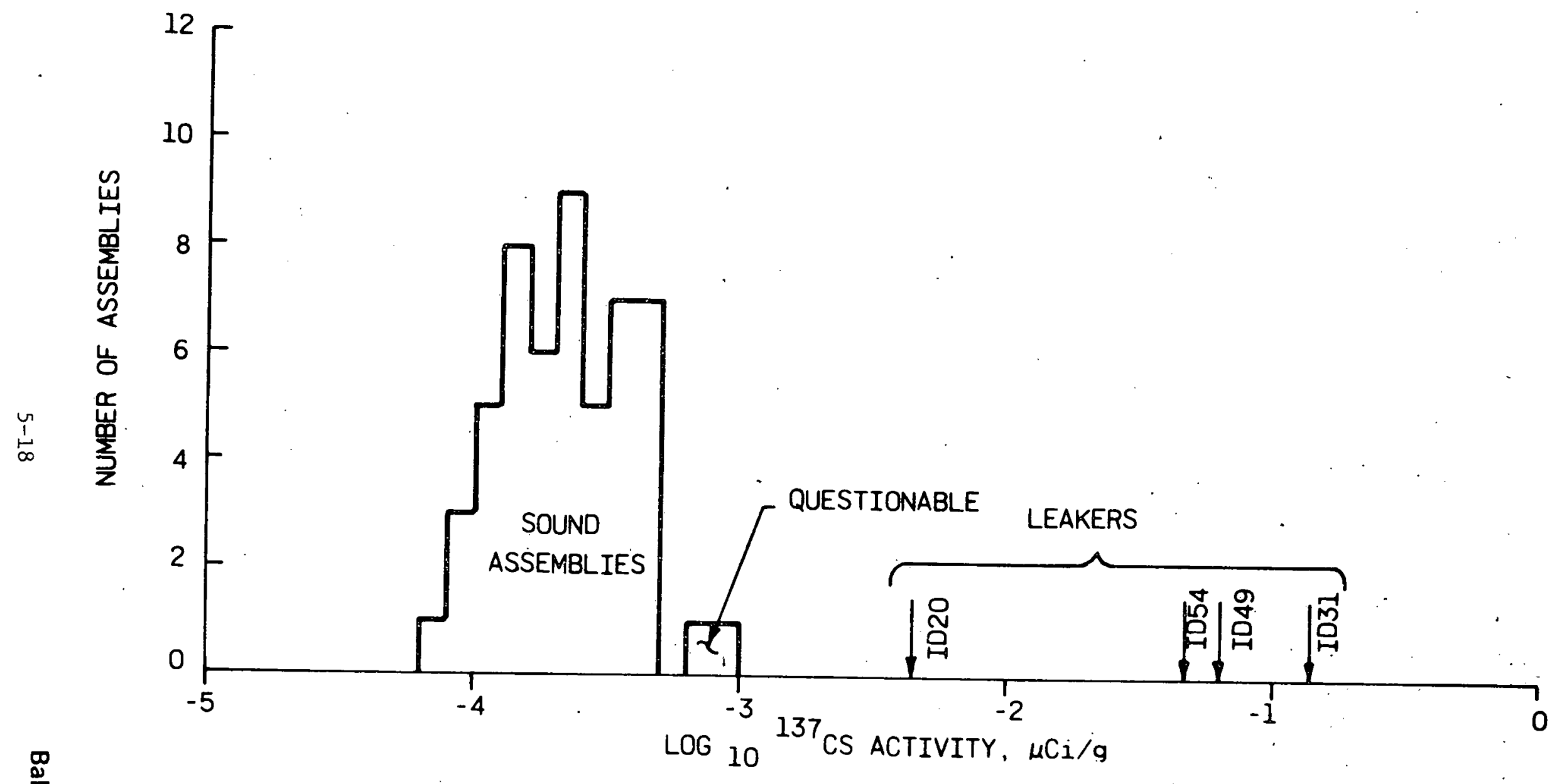


Figure 5-2. Photograph Displaying Narrow Circumferential Crud Bands, Assembly 1D13

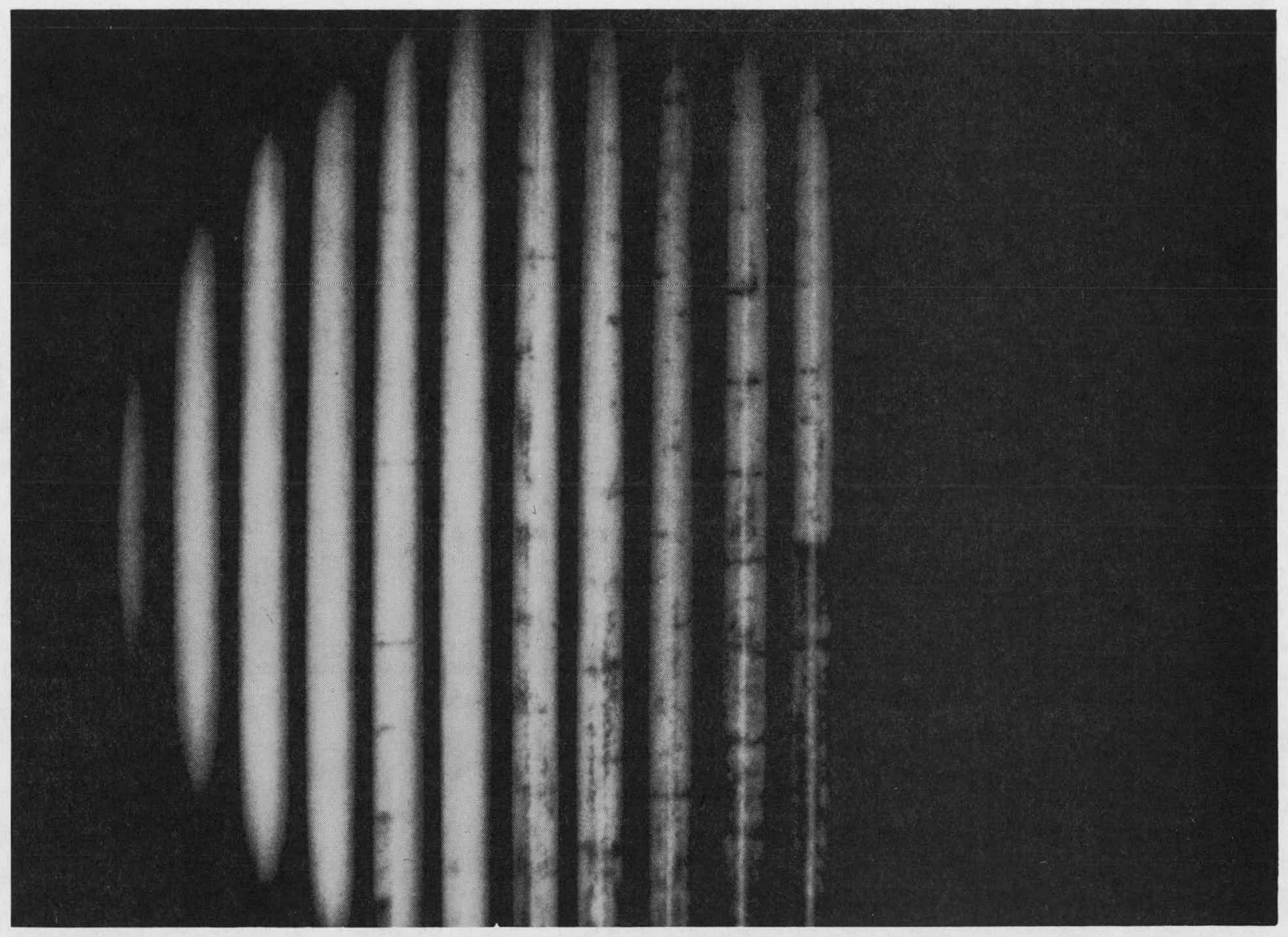


Figure 5-3. Photograph Displaying Indentation on Rod A13 of Assemb1y 1D21

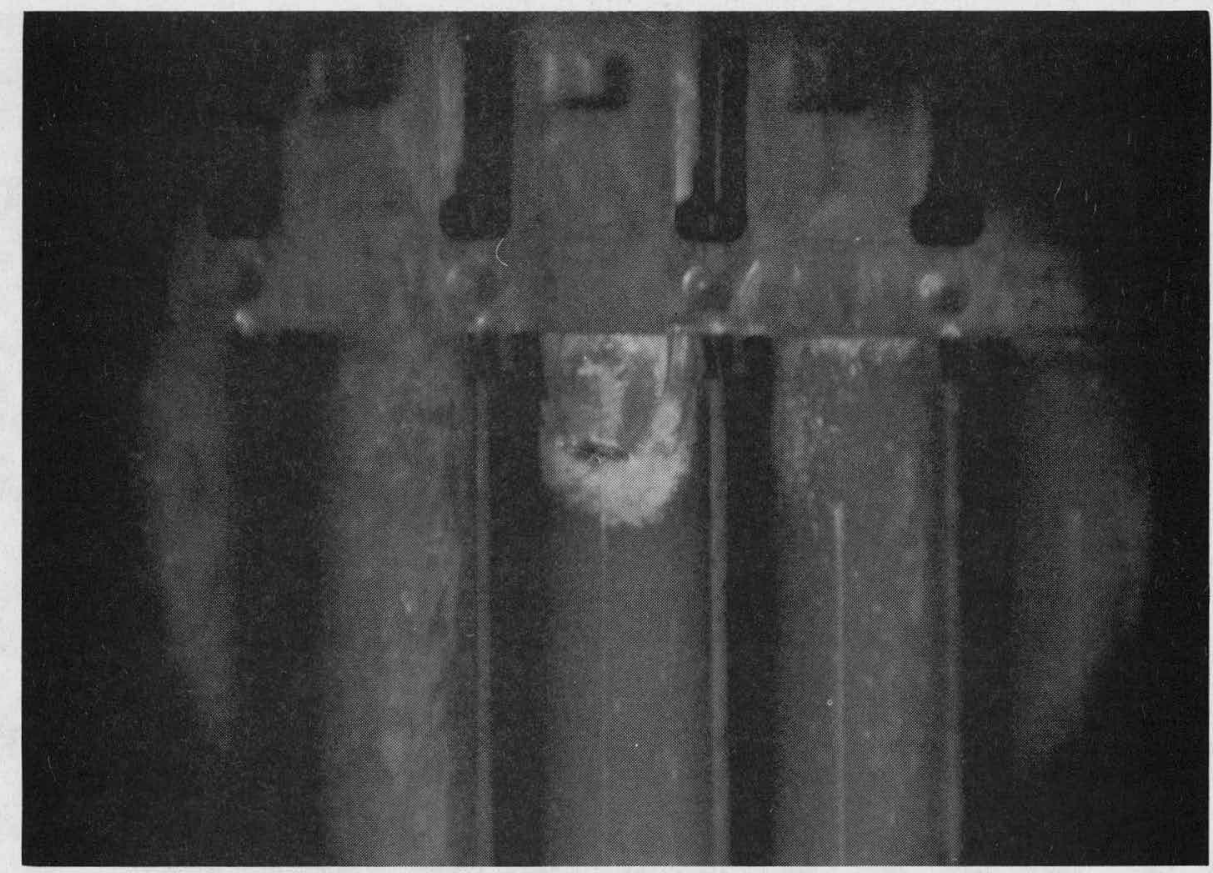

Figure 5-4. Photograph Displaying Dent on Grid Skirt of Assemb1y 1 D 42

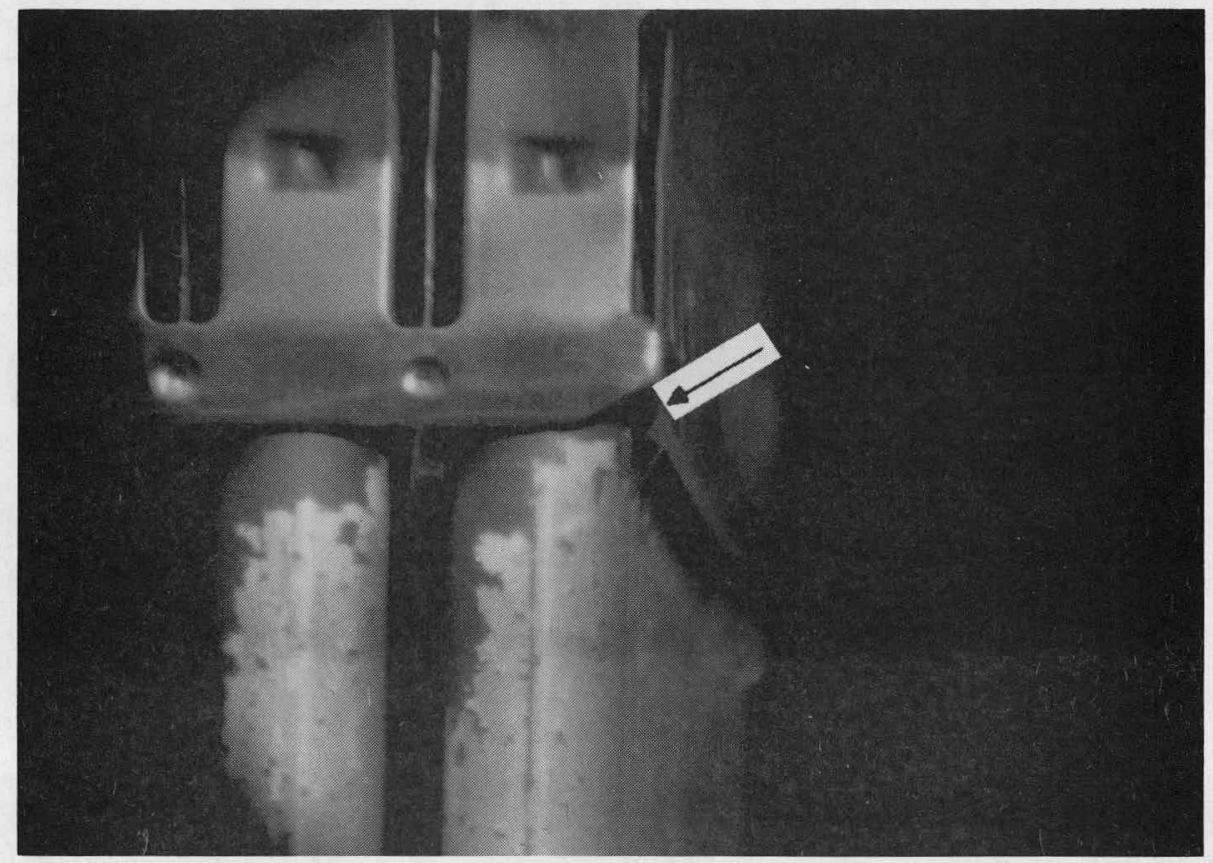


Figure 5-5. Fuel Assembly Growth as Function of Assembly Average Fluence

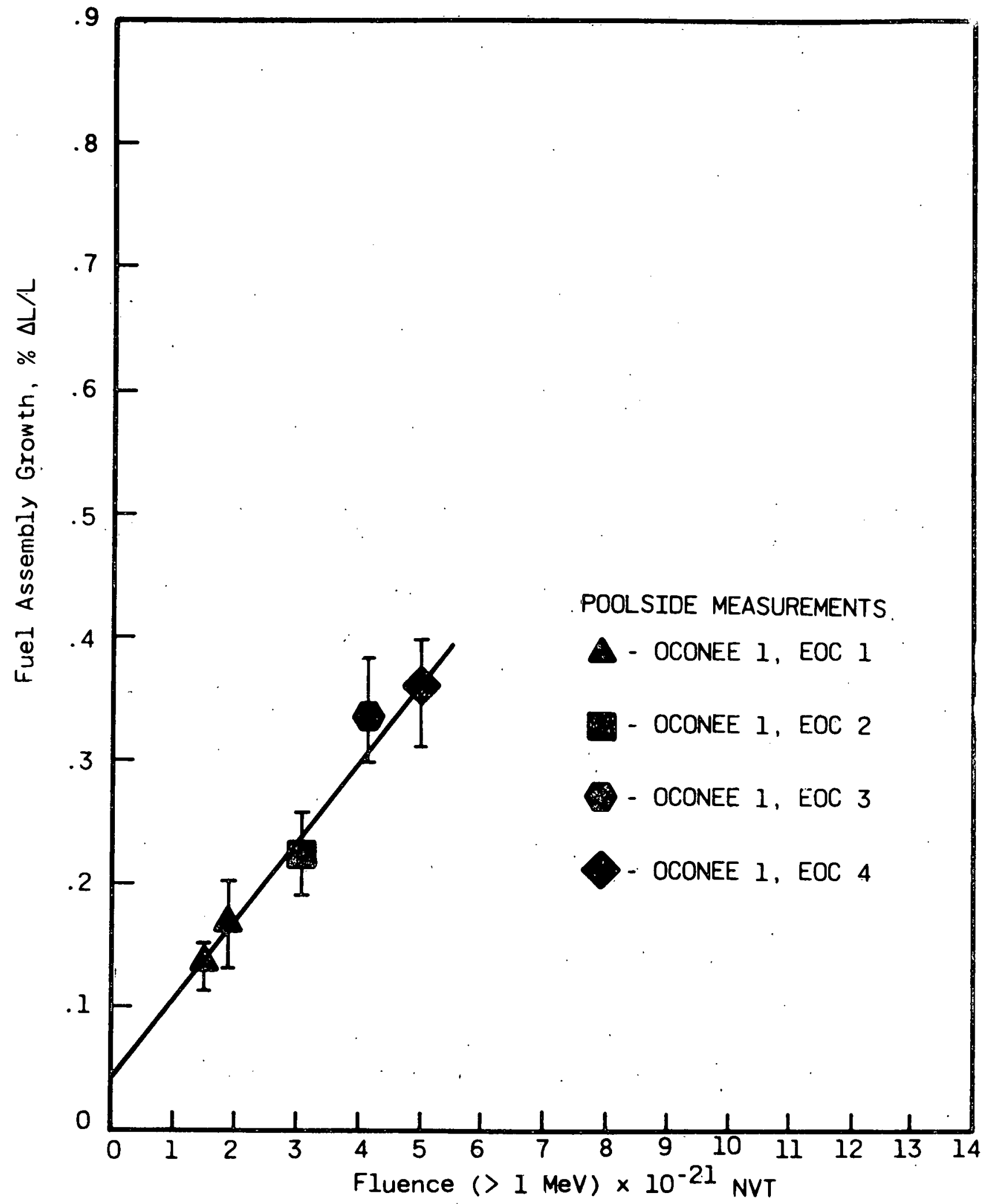




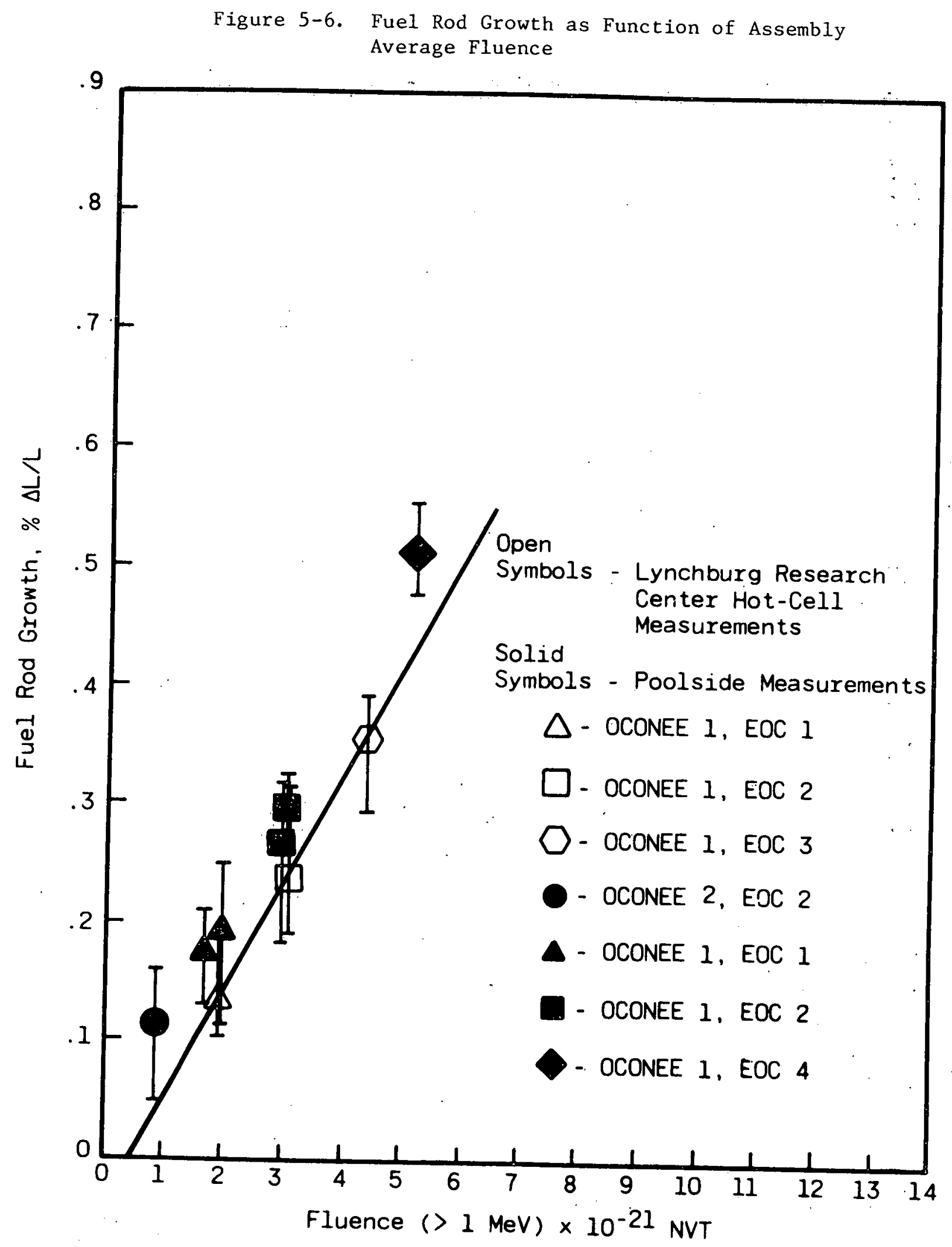


Figure 5-7. Assemb1y 1D26 Corner Fuel Rods Orthogonal Diameter Profilometry Traces

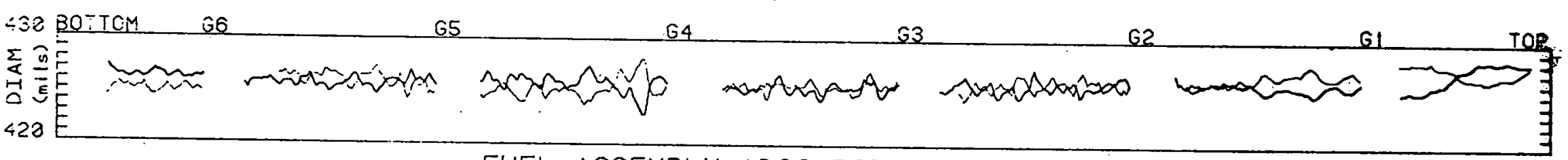

FUEL ASSEMBLY ID26 RODS AI \& D15

年

FUEL ASSEMBLY 1026 RODS DI \& C15

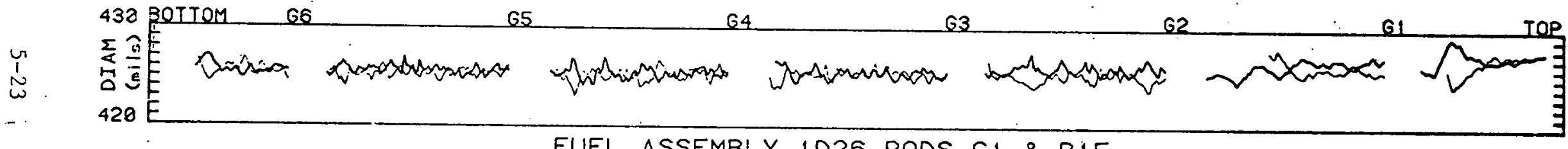

FUEL ASSEMBLY 1026 RODS CI \& B15

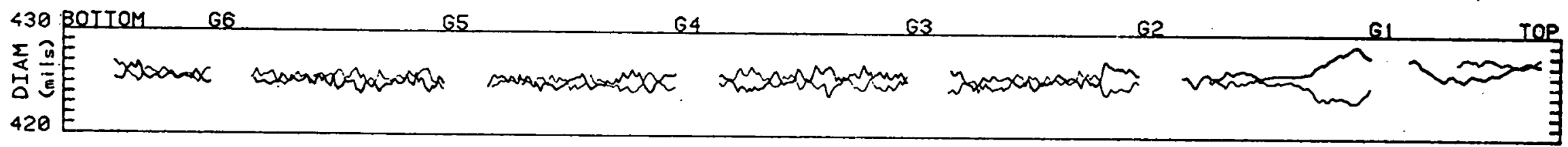

FUEL ASSEMBLY 1 D26 RODS BI \& A15

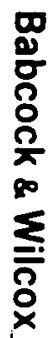




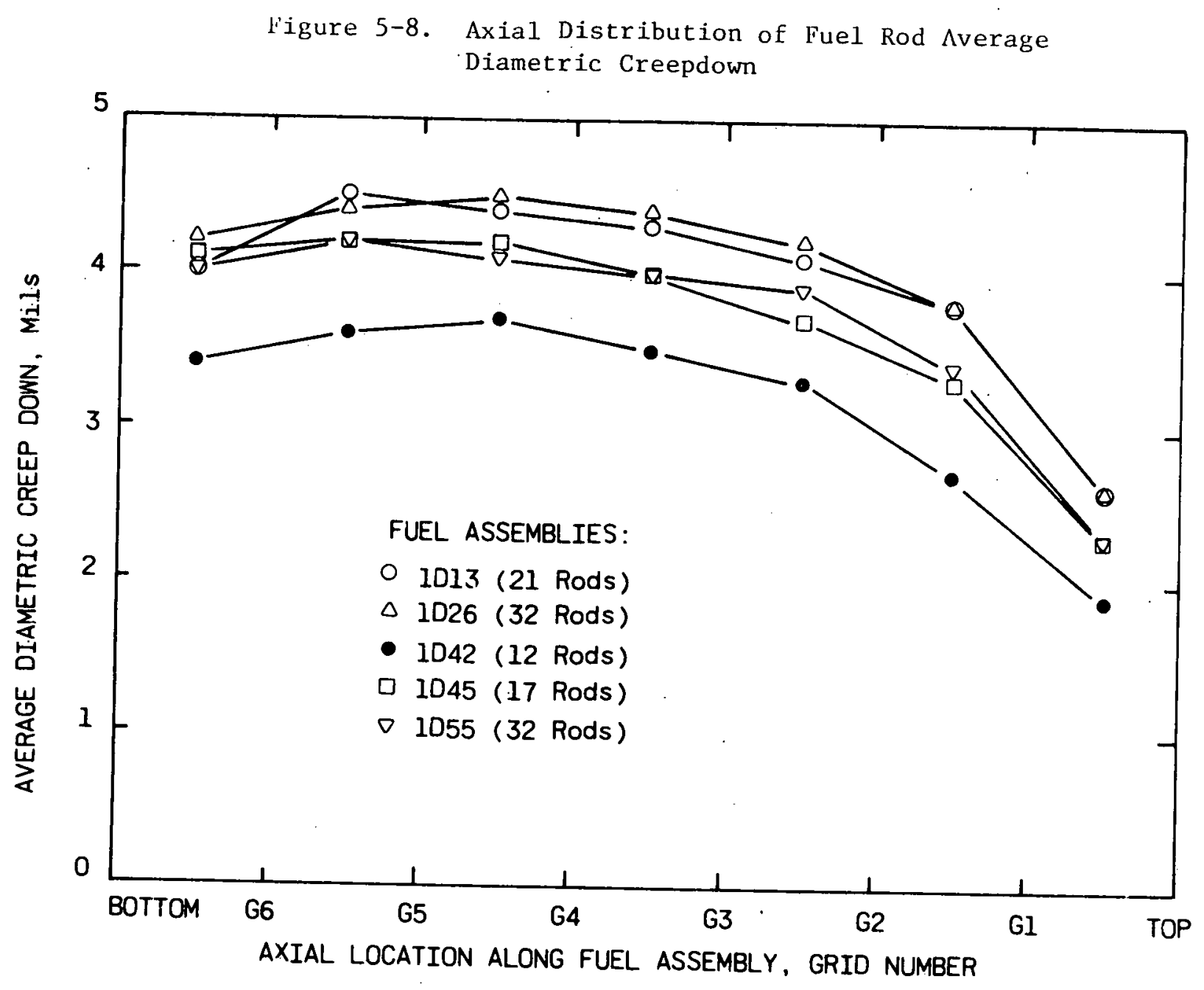


Figure 5-9. Typical Full-Size Diameter Trace Segments (Orthogonal Scans) - Fuel Assembly $1 D 55$
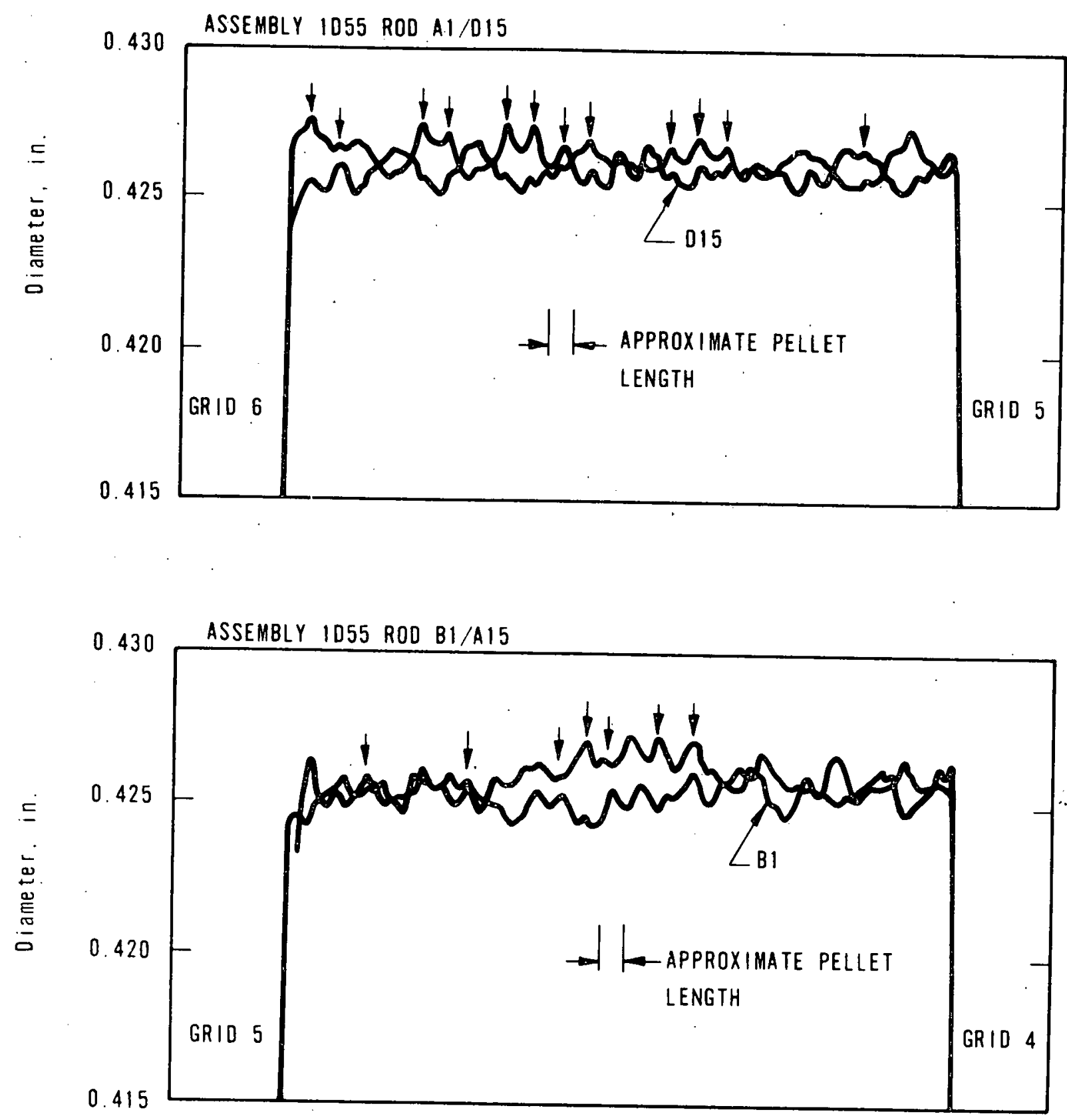


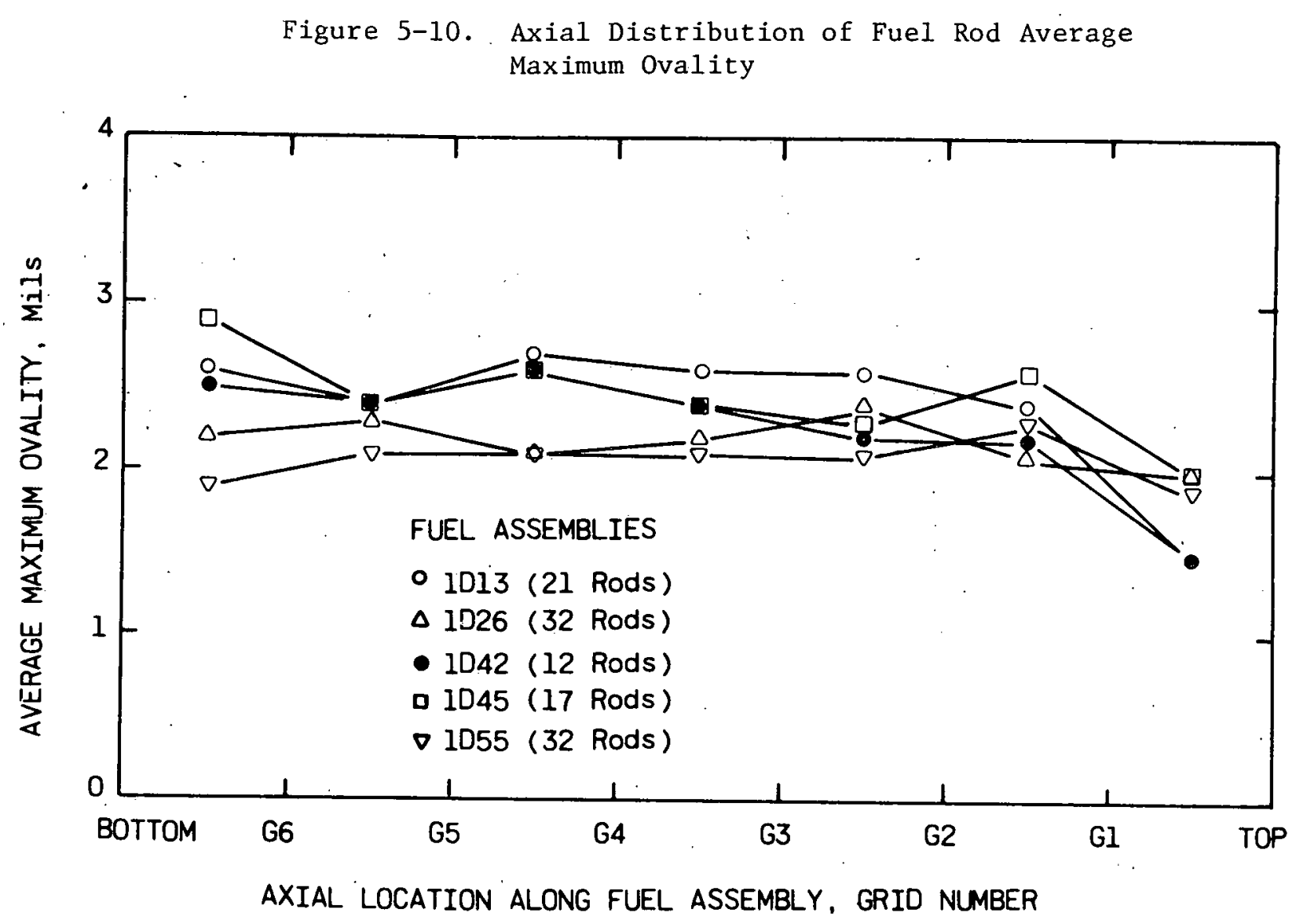


Figure 5-11. Worst-Span Water Channel Closure as Function of Assembly Average Burnup

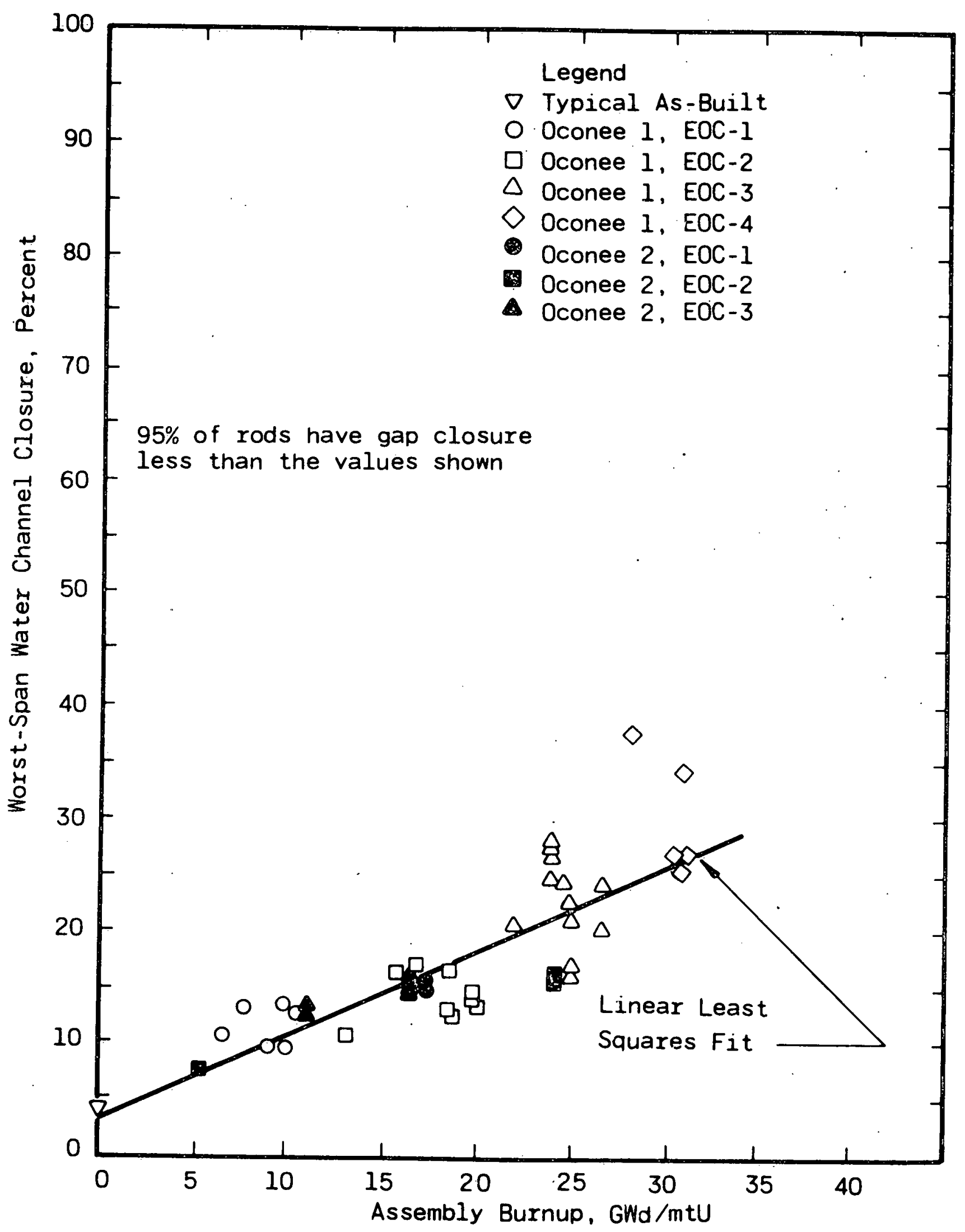


Figure 5-12. Axial Distribution of Water Channel Closure
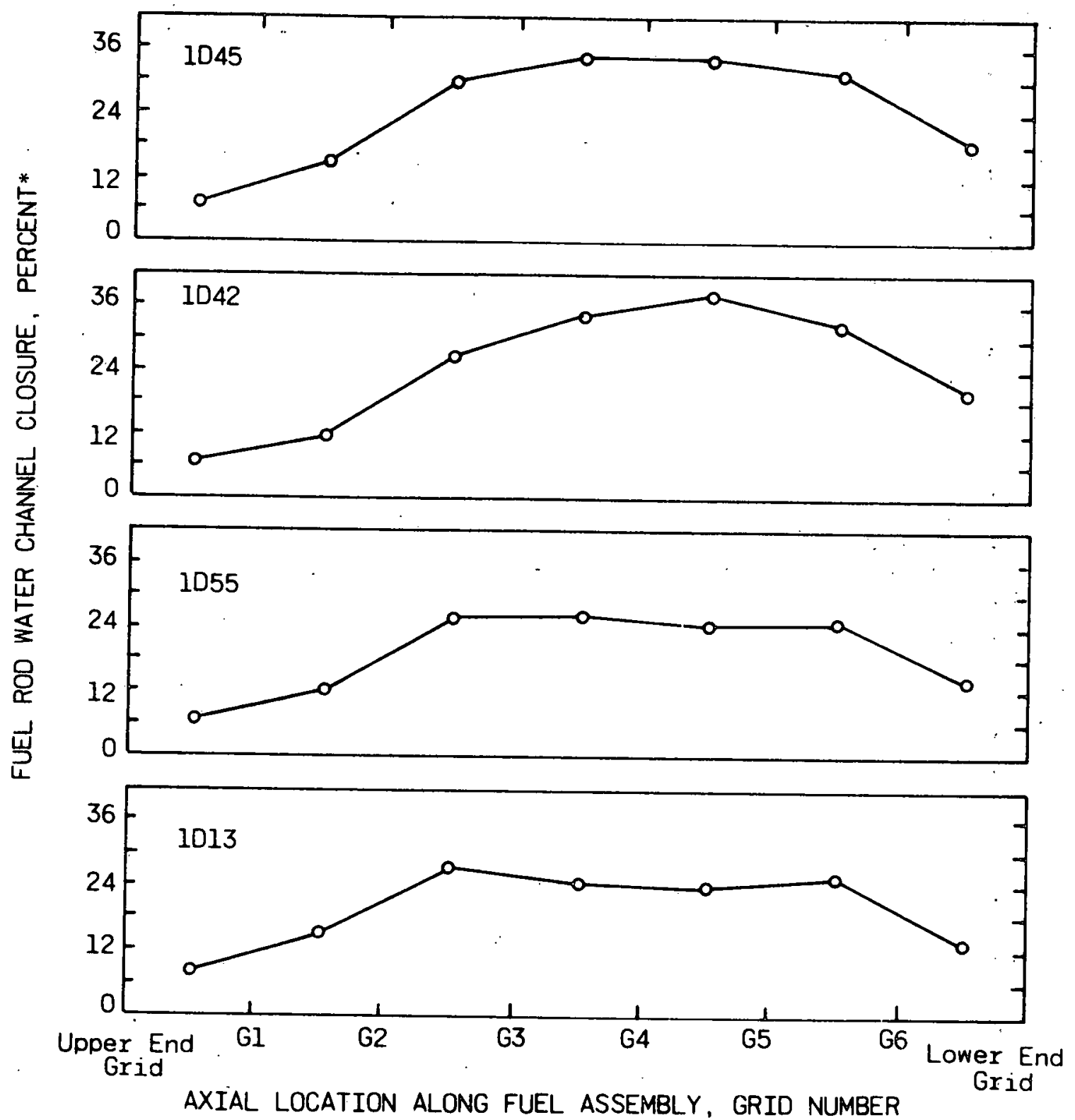

NOTE: The left most data point for each fuel assembly was measured 3" below midspan.

*95\% of the fuel rods have a gap closure less than the plotted value. 
Figure 5-13. Holddown Spring Net Operating Force

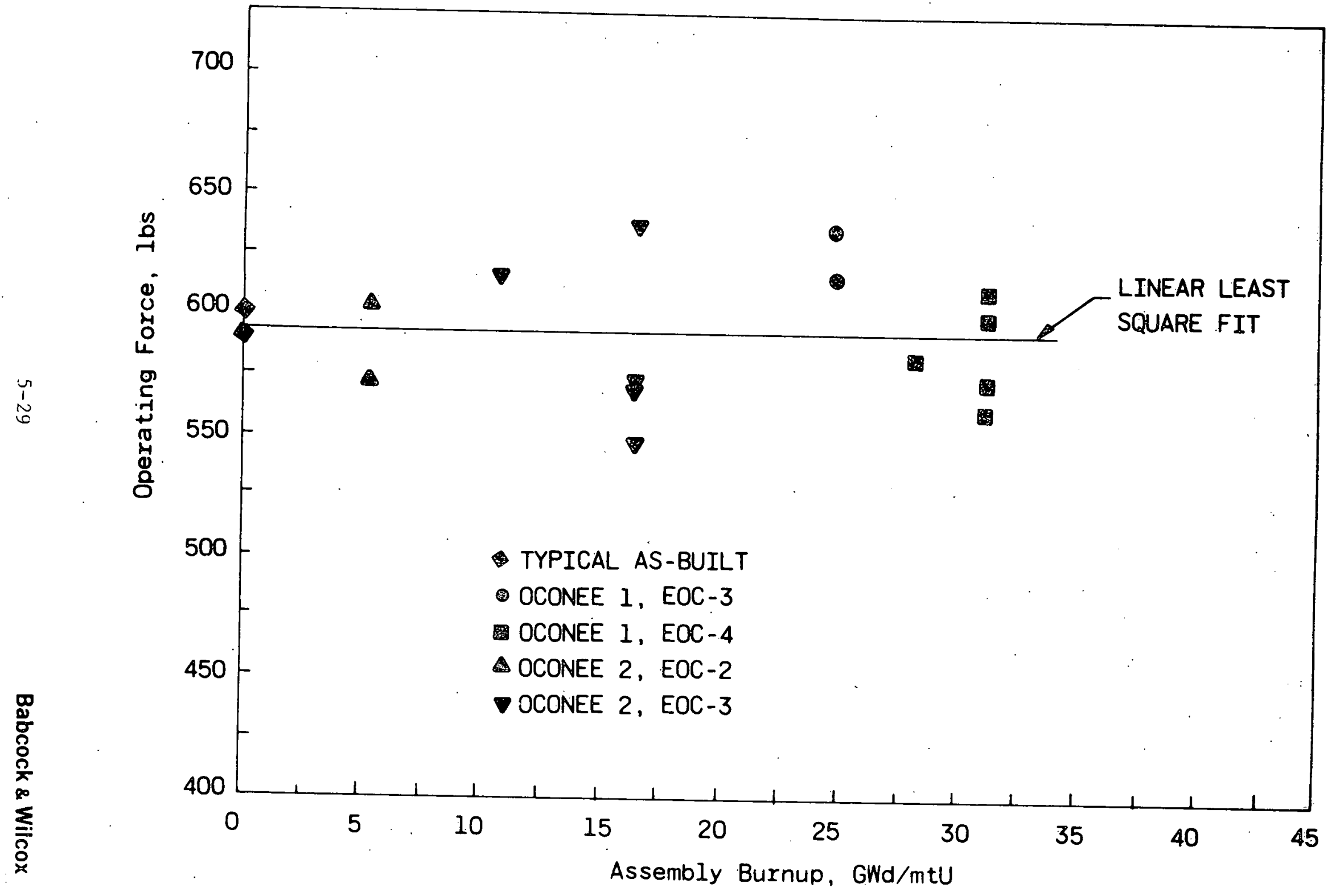


Figure 5-14. Portion of Gamma Scan Trace - Assembly 1D13, CD-Corner Fuel Rod

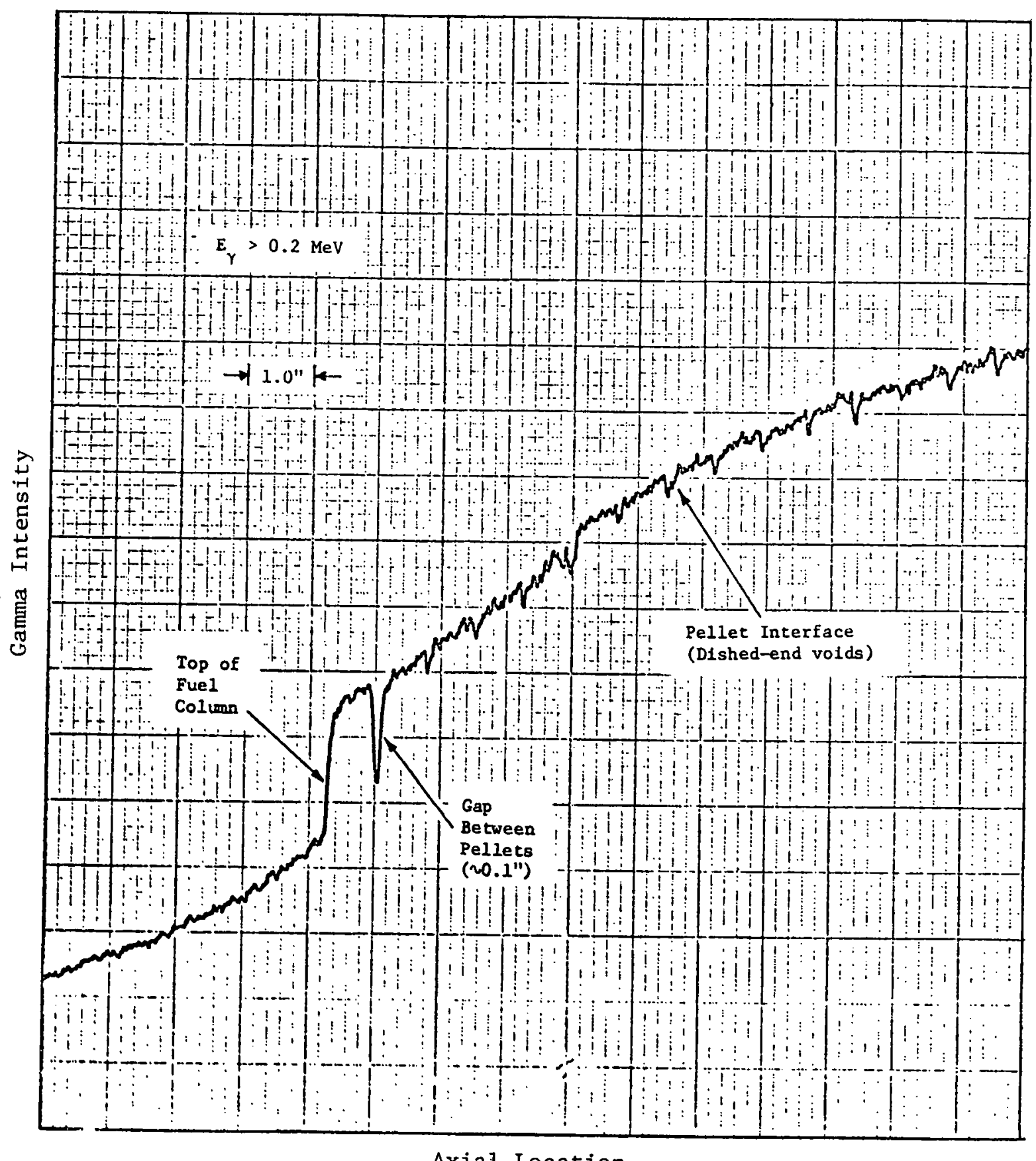

Axial Location 


\section{CONCLUSIONS}

Summarized below are the results of the Oconee 1 end-of-cycle 4 poolside examination.

1. Of the 57 three cycle (batch 4) fuel assemblies sipped, four were classified as leakers on the basis of the level of ${ }^{137} \mathrm{Cs}$ activity in their water samples. Three of these leakers operated in the same two symmetrically equivalent core locations as the extended burnup assemblies.

2. Visual examinations of the peripheral fuel rods of ten fuel assemblies revealed a common crud pattern consisting of thin, evenly-spaced bands on the cladding along the lower half of the assembly. These crud bands are associated with fuel pellet interfaces and are thought to be variations in crud coloration or composition possibly resulting from variations in coolant flow and/or heat flux.

3. Fuel assembly and fuel rod growth measurements of the extended burnup assemblies averaged 0.36 and $0.51 \% \Delta \mathrm{L} / \mathrm{L}$, respectively, consistent with previous poolside PIE results. Based on the fuel rod growth results obtained from previous (and more accurate) destructive examinations, differential growth between the fuel assembly and its fuel rods is not a limiting condition for extending operation of the current design $15 \times 15$ fuel assembly.

4. Fuel rod creepdown averaged 0.0032 in. for assembly 1D42, 0.0038 in. for the other four assemblies, and $0.0038 \mathrm{in}$ overall. Maximum creepdown occurred in the lower half of the assemblies where the maximum average creepdown observed between spacer grids was 0.0045 in.

5. Ripples in the fuel rod dlameter profilometry traces, which correlated with fuel pellet lengths in regions of low cladding ovality, indicate that pellet-clad contact had occurred in several corner rods in three of the five fuel assemblies examined. 
6. Fuel rod average maximum ovalities ( $4 \sigma$ range of the mean diameters) were statistically determined between spacer grids. The mean of the average maximum ovalities was $0.0023 \mathrm{in}$. The largest peak ovality, determined for the orthogonally-scanned corner rods, was approximately $0.005 \mathrm{in}$. No significant axial variation in ovality was observed.

7. Water channel closure was low in magnitude, comparing favorably with the results of previous poolside examinations conducted after three cycles of irradiation. Of the five assemblies examined, the greatest assembly average rod bow $(1 \sigma)$ was 0.0220 in., corresponding to a water channel closure of $26.2 \%$ ( $95 \%$ UTL). Although the scatter in the data increased beyond 23, $000 \mathrm{MWd} / \mathrm{mtU}$, worst-span closure continued to increase in an approximately linear manner with burnup, averaging $30.3 \%$ (95\% UTL) at the batch 4D average burnup of $30,600 \mathrm{MWd} / \mathrm{mtU}$.

8. Holddown spring preload force decreased an average of $35 \%$ from beginningof-1ife. However, fuel assembly growth adequately compensates for the decrease in spring preload force, so that the holddown spring net operating force remains relatively constant throughout the lifetime of the assembly.

9. Of the 20 fuel rods subjected to gamma scans $\left(E_{\gamma}>0.2 \mathrm{MeV}\right)$, seven of the rods contained a total of only eight axial gaps in their fuel columns. All eight gaps were 0.1 in. or less in length.

10. The average fuel column stack lengths exhibited no net change after three cycles of irradiation, which is in good agreement with predicted results. 


\section{REFERENCES}

1

Oconee Nuclear Station, Units 1, 2, and 3-Final Safety Analysis Reports, Docket Nos. 50-269, 50-270, and 50-287, Duke Power Company

C. W. Mays, and M. Furtney, FLAME3 - A Three-Dimensional Nodal Code for Calculating Core Reactivity and Power Distributions, BAW-10124A, Babcock \& Wilcox, Lynchburg, Virginia, August 1976.

3 Babcock \& Wilcox Version of PDQ07, BAW-10117A, Babcock \& Wilcox, Lynchburg, Virginia, January 1977.

4 Post-Irradiation Examination of Oconee 1 Fuel - Cycle 1 Nondestructive Test Phase, BAW-1519, Babcock \& Wilcox, Lynchburg, Virginia, June 1979.

5 Post-Irradiation Examination of Oconee 1 Fuel - Cycle 1 Destructive. Test Phase, BAW-1535, Babcock \& Wilcox, Lynchburg, Virginia, July 1979.

6 Post-Irradiation Examination of Oconee 1 Fuel - End-of-Cycle 2 Nondestructive Test Phase, BAW-1574, Babcock \& Wilcox, Lynchburg, Virginia, November 1979. 
APPENDIX

Fuel Rod Diameter Profilometry Definftion of Terms 
1. Average Diameter - the arithmetic mean of all diameter values from a given rod segment (between spacer grids). Rod average diameter is the unweighted mean of the segment means.

2. Average Creepdown - the BOL diameter (0.4299 in.) minus average diameter as defined above.

3. Average Maximum Ovality - the standard deviation of diameter values for a rod segment multiplied by four. Rod average maximum ovality is the unweighted mean of the segment values. This value was chosen because it includes $95 \%$ of the diameter values on either side of the mean. Note that it is only intended to provide an approximation of ovality peaks rather than to approximate the average ovality. When compared to hot cell data (obtained using $180^{\circ}$ rotating, step-scan profilometry), it compares favorably with average ovality if the ovality is fairly constant, but it is higher than average ovality when there are large fluctuations in the hot cell ovality data.

4. Peak Ovality - the maximum minus the minimum outside diameter measured in the same transverse plane. Approximate peak ovality values can be obtained from orthogonal, single-orientation, line scan traces of corner rods. The measured values are not necessarily the true peak ovality values because the orientation of the profilometry scans may not coincide directly with the major and minor axes of the respective oval. However, since the true peak ovalities cannot be smaller than the corresponding observed values, the measured values indicate the minimum peak ovality of the cladding. 


\section{DISTRIBUTION}

Mr. Thomas Abernathy, Chief (150) Document Management Branch U.S. Department of Energy Technical Information Center P. 0. Box 62

Oak RIdge, TN 37830

Babcock \& Wilcox

Andrews, JB

Brunson, WT

Chipman, EE

Coleman, TA (25)

Coppola, EJ (26)

Croft, MW

Davis, $\mathrm{HH}$

DeMars, RV

Gudorf, MR

Kane, ER

Library

Mayer, JT

Meyer, GA

Montgomery, MH

Papazaglou, TP

Pyecha, TD

Romano, JJ (6)

Sapyta, JJ

Shipman, GA

Smotrel, JR

Stein, KO

Travis, CC/TRG

Trost, RJ

Tulenko, JS

Wilson, HW

\section{Others}

Mr. S. Armijo

GENERAL ELECTRIC CO.

Nuclear Energy Division

175 Curtner Avenue

San Jose, CA 95125

Mr. Gordon Bond

GPU SERVICE CORP.

260 Cherry Hil Road

Parsippany, NJ 07054

Mr. F. W. Buckman

CONSUMERS POWER COMPANY

1945 Parnall Road

Jackson, MI 49201

Mr. J. P. Cagnetta

NORTHEAST UTILITIES SERVICE CO.

P. 0. Box 270

Hartford, CT 06101

Mr. Dennis R. Coleman

NUCLEAR ASSOCIATES INTERNATIONAL

6003 Executive Boulevard

Rockville, MD 20852

Mr. C. E. Crouthame1

EXXON NUCLEAR COMPANY, INC.

Richland, WA 99352

Mr. Orville Cypret

ARKANSAS POWER \& LIGHT

P. O. Box 551

Little Rock, AK 72203

Mr. G. F. Daebeler

PHILADELPHIA ELECTRIC CO.

2301 Market Street

P. O. Box 8699

Phtladelphia, PA 19101 


\section{Others (Cont'd)}

Mr. R. N. Duncan

COMBUSTION ENGINEERING, INC.

1000 Prospect H111 Road

Windsor, CT 06095

Mr. M. S. Freshley

BATTELLE-NORTHWEST LABORATORY

Richland, WA 99352

Mr. F. E. Gelhaus

ELECTRIC POWER RESEARCH INSTITUTE

P. O. Box 10412

Palo Alto, CA 94303

Mr. S. J. Groetch

GENERAL ELECTRIC COMPANY

Knolls Atomic Energy Laboratory

P. 0. Box 1072

Schenectady, NY 12301

Mr. R. M. Grube

YANKEE ATOMIC ELECTRIC COMPANY

20 Turnpike Road

Westboro, MA 01581

Mr. John Hallam

NUCLEAR SERVICES CORP.

1700 Dell Avenue

Campbe11, CA 95008

Mr. C. R. Hann

BATTELLE-NORTHWEST LABORATORY

Richland, WA 99352

Mr. W. R. Harris

RAND CORPORATION

1700 Main Street

Santa Monica, CA 90406

Mr. W. M. Kiefer

COMMONWEALTH EDISON COMPANY

P. O. Box 767

Chicago, IL 60690

Mr. J. Korthever

DUKE POWER COMPANY

P. O. BOX 2178

Charlotte, NC 28342
Mr. D. L. Lark1n

WASHINGTON PUBLIC POWER SUPPLY SYSTEM

P. 0. Box 968

Richland, WA 99352

Mr. M. L. Lee

CONSOLIDATED EDISON COMPANY OF NEW YORK

4 Irving Place

New York, NY 10003

Mr. W. Liplnsk1

ARGONNE NATIONAL LABORATORY

9700 South Cass Avenue

Argonne, IL 60439

Mr. Kashmir1 Mahna

PUBLIC SERVICE ELECTRIC \& GAS CO. 80 Park Place

Newark, NJ 07101

Mr. R. S. Miller

WESTINGHOUSE ELECTRIC CORP.

Nuclear Fuel Division

Box 355

P1ttsburgh, PA 15230

Mr. R. J. Mullin

TENNESSEE VALLEY AUTHORITY

1410 Commerce Unton Bank Bldg.

Chattanooga, TN 37402

Mr: D. O'Boyle

COMMONWEALTH EDISON CO.

P. 0. Box 767

Chicago, IL 60690

Mr. R. R. O'Laughlin

PUBLIC SERVICE OF INDIANA

1000 East Main Street

Plainfleld, IN 46168

Mr. R. Omber 8

HANFORD ENGRG DEVELOPMENT LABORATORY

P. O. Box 1970

Richland, WA 99352

Mr. B. A. Pasternak

BOOZ-ALLEN APPLIED RESEARCH

4330 East-West H1ghway

Bethesda, MD 20014 
Others (Cont'd)

Mr. J. T. A. Roberts

FLECTRIC POWER RESEARCH INSTITUTE

P. O. Box 10412

Palo Alto, CA 94303

Mr. T. Row

OAK RIDGE NATIONAL LABORATORY

P. 0. Box X

Oak RIdge, TN 37830

Mr. H. W. Schadler, Manager

Metallurgy Laboratory

GENERAL ELECTRIC CO. R\&D CENTER

P. O. Box 8

Schnectady, NY 12301

Mr. Howard Sobel

AMERICAN ELECTRIC POWER SERVICE

Nuclear Materials and Fuel

Management Section

2 Broadway

New York, NY 10004

Mr. G. Sofer

EXXON NUCLEAR COMPANY, INC.

Richland, WA 99352

Mr. I. Spiewak

OAK RIDGE NATIONAL LABORATORY

P. O. Box X

Oak Ridge, TN 37830

Mr. E. Straker

SCIENCE APPLICATIONS, INC.

8400 Westpark Drive

McLean, VA 22101

Mr. J. R. Tomonto

FLORIDA POWER \& LIGHT CO.

P. O. BOX 013100

Miami, FL 33101

Mr. W. J. Tunney

LONG ISLAND LIGHTING CO.

175 E. Old Country Road

Hicksville, NY 11801
U.S. Department of Energy

NASAP Control office

Room F-409 (Ma11 Stop B-107)

Germantown, Maryland 20767

Mr . D. B. Wehmeyer

DETROIT EDISON CO.

2000 Second Avenue

Detroit, MI 48226

Mr. W. A. Weinreich

WESTINGHOUSE ELECTRIC CORP.

Bettis Atomic Power Laboratory

P. 0. Box 79

West Mifflin, PA 15122

Mr. S. W. Wilczek, Jr.

NIAGARA MOHAWK POWER CORP.

300 Erie Boulevard West

Syracuse, NY 13202

Mr. K. Woods

EXXON NUCLEAR COMPANY, INC.

Richland, WA 99352 